\title{
Travel Patterns and Characteristics of Transit Users in New York State
}

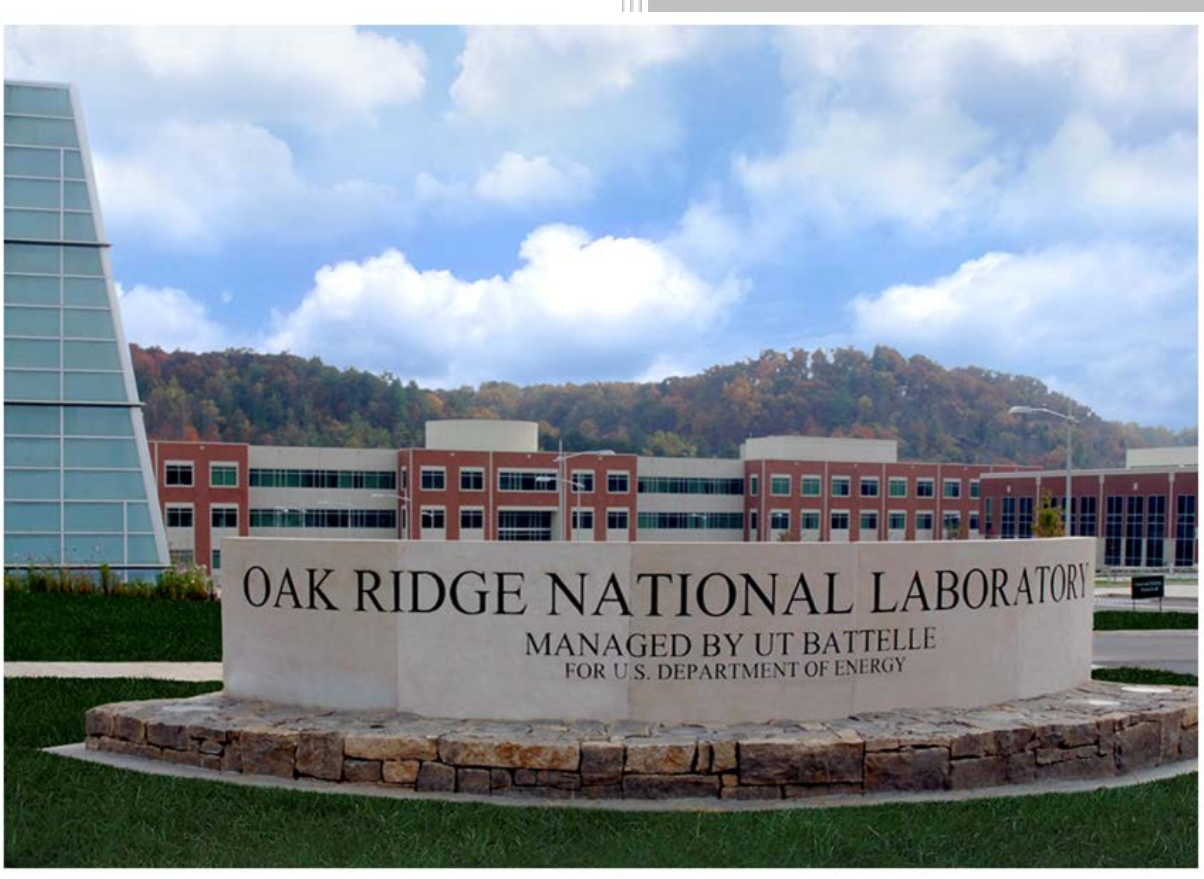

Approved for public release. Distribution is unlimited.

OAK RIDGE NATIONAL LABORATORY MANAGED BY UT-BATTELLE FOR THE US DEPARTMENT OF ENERGY
Ho-Ling Hwang Daniel Wilson Tim Reuscher Shih-Miao Chin Rob Taylor

December 2015 


\title{
DOCUMENT AVAILABILITY
}

Reports produced after January 1, 1996, are generally available free via US Department of Energy (DOE) SciTech Connect.

\section{Website http://www.osti.gov/scitech/}

Reports produced before January 1, 1996, may be purchased by members of the public from the following source:

\author{
National Technical Information Service \\ 5285 Port Royal Road \\ Springfield, VA 22161 \\ Telephone 703-605-6000 (1-800-553-6847) \\ TDD 703-487-4639 \\ Fax 703-605-6900 \\ E-mail info@ntis.gov \\ Website http://www.ntis.gov/help/ordermethods.aspx
}

Reports are available to DOE employees, DOE contractors, Energy Technology Data Exchange representatives, and International Nuclear Information System representatives from the following source:

Office of Scientific and Technical Information

PO Box 62

Oak Ridge, TN 37831

Telephone 865-576-8401

Fax 865-576-5728

E-mail reports@osti.gov

Website http://www.osti.gov/contact.html

This report was prepared as an account of work sponsored by an agency of the United States Government. Neither the United States Government nor any agency thereof, nor any of their employees, makes any warranty, express or implied, or assumes any legal liability or responsibility for the accuracy, completeness, or usefulness of any information, apparatus, product, or process disclosed, or represents that its use would not infringe privately owned rights. Reference herein to any specific commercial product, process, or service by trade name, trademark, manufacturer, or otherwise, does not necessarily constitute or imply its endorsement, recommendation, or favoring by the United States Government or any agency thereof. The views and opinions of authors expressed herein do not necessarily state or reflect those of the United States Government or any agency thereof. 
Engineering and Transportation Science Division | Center for Transportation Analysis

\title{
TRAVEL PATTERNS AND CHARACTERISTICS OF TRANSIT USERS IN NEW YORK STATE
}

\author{
Final Technical Memorandum for Task 14
}

December 2015

\author{
Ho-Ling Hwang, Ph.D. \\ Daniel Wilson \\ Tim Reuscher \\ Shih-Miao Chin, Ph.D. \\ Rob Taylor
}

\author{
Prepared for \\ New York State Department of Transportation
}

\author{
Prepared by \\ OAK RIDGE NATIONAL LABORATORY \\ Oak Ridge, TN 37831-6283 \\ managed by \\ UT-BATTELLE, LLC \\ for the \\ US DEPARTMENT OF ENERGY \\ under contract DE-AC05-00OR22725
}





\section{CONTENTS}

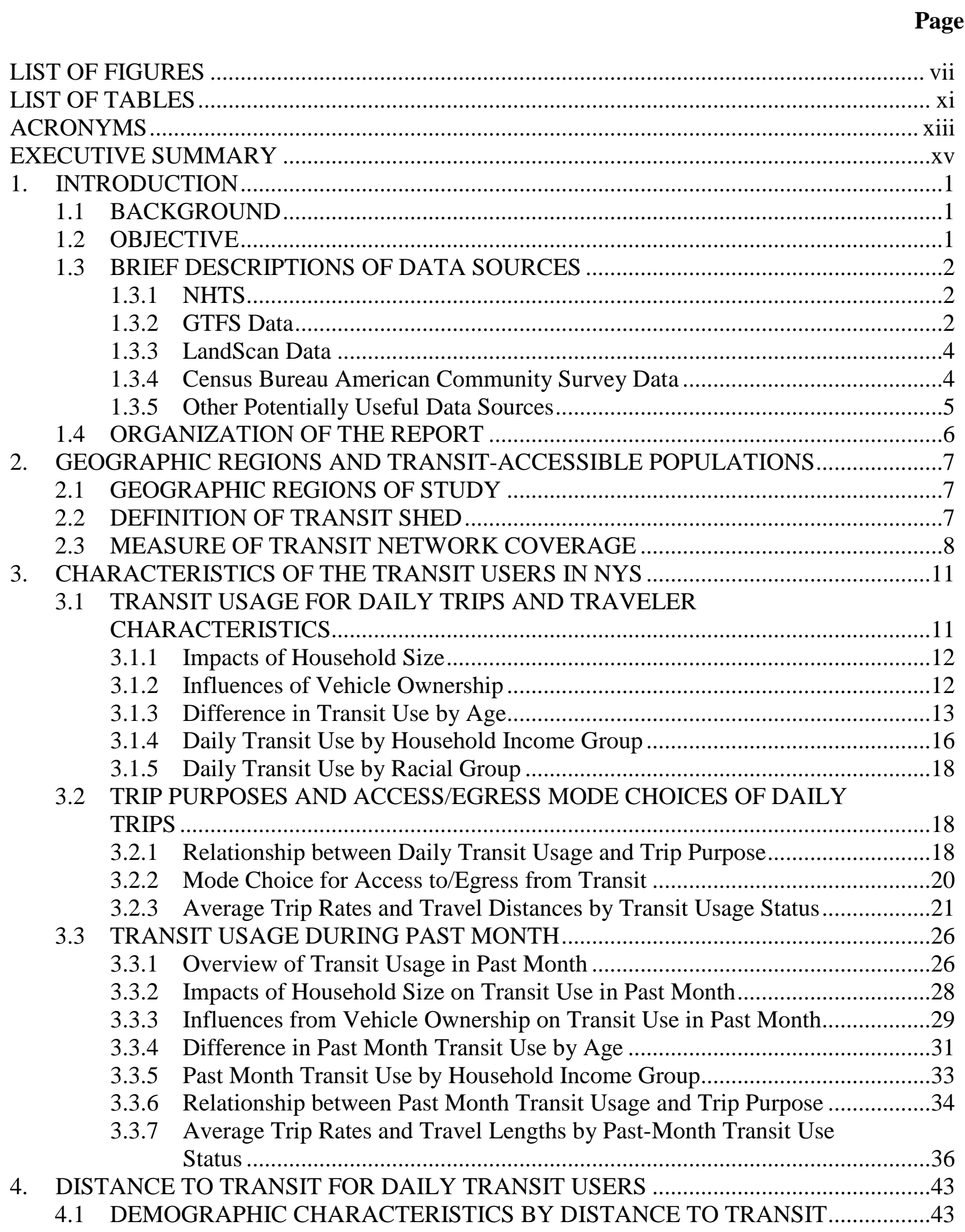


4.1.1 Association of Household Size with Distance to Transit .................................44

4.1.2 Distance to Transit and Household Vehicle Ownership ...................................45

4.1.3 Household Income and Distance to Transit ..................................................46

4.1.4 Influence of Distance to Transit on Elderly Travelers ....................................48

4.2 IMPACTS OF DISTANCE TO TRANSIT ON TRAVEL CHARACTERISTICS......48

4.2.1 Impacts on Mode Choice for Daily Trips .......................................................48

4.2.2 Influence of Distance to Transit on Travel Behaviors ...................................49

4.3 DAILY TRANSIT USAGE ON PERSONS LIVING IN 1-MILE TRANSIT

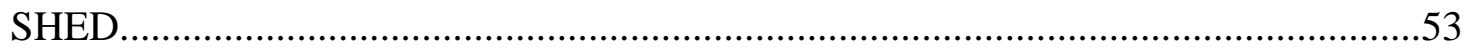

4.3.1 Relationships between Transit Usage and Household Characteristics..............54

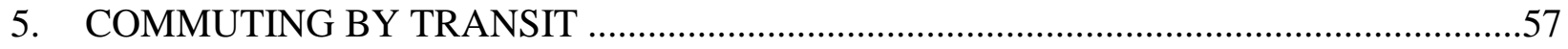

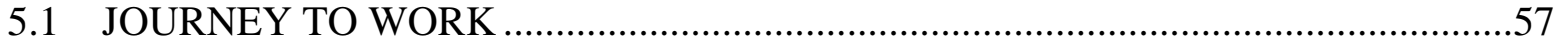

5.1.1 Trends in Transit Mode Share for Commuting ............................................57

5.1.2 Age Impact on Transit Commuting...............................................................58

5.1.3 Travel Time to Work by Transit....................................................................59

5.1.4 Relationship of Income to Transit Mode-Share for Commuting Trips .............60

5.2 TRANSIT AVAIABILITY AND BUSINESS LOCATIONS ...............................62

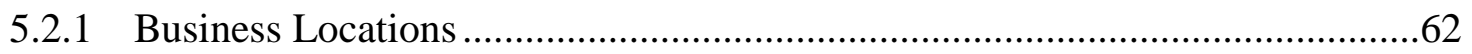

5.2.2 Transit Accessibility for Businesses...........................................................63

5.2.3 An Observation on Businesses with Less Than 10 Employees........................64

5.3 INFORMATION FROM THE SMART LOCATION DATABASE .........................65

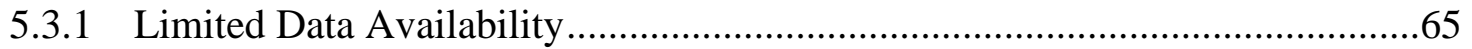

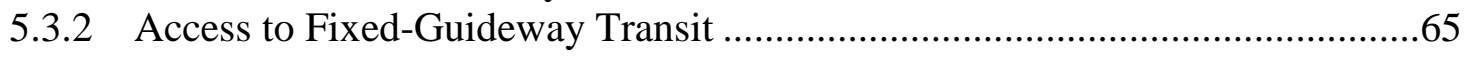

5.3.3 Jobs and Worker Accessibility by Transit...............................................66

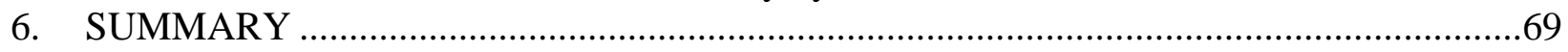

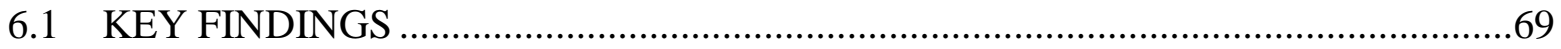

6.1.1 Demographic Characteristics of Transit Users...........................................69

6.1.2 Travel Patterns and Trip Characteristics of Transit Users .............................69

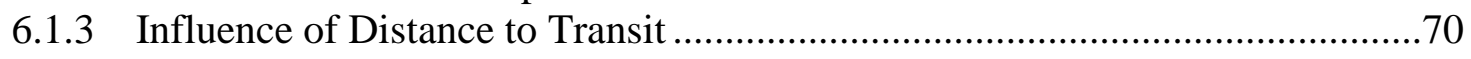

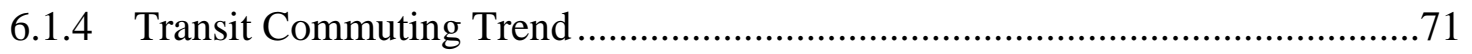

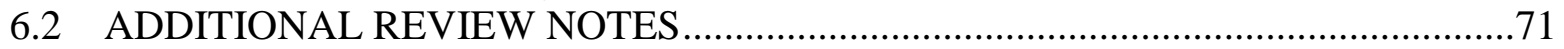

6.2.1 Distance to Transit From Trip Origins ........................................................71

6.2.2 Transit Time of Use as the Main Mode of Travel ..........................................72 


\section{LIST OF FIGURES}

\section{Figure}

Page

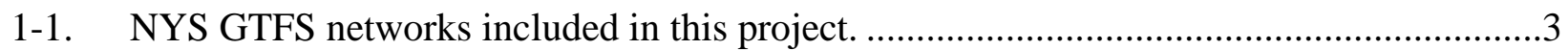

1-2. LandScan estimated population for NYS in 2011 (in a 30-meter $\mathrm{x}$ 30-meter grid). ............

2-1. Example of transit accessibility showing transit sheds (1-, 2.5-, and 5-mile

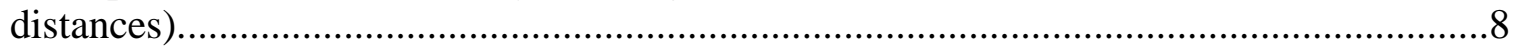

2-2. Location of NYS households in 2009 NHTS and GTFS transit sheds.............................10

3-1. Percent of households that used transit on travel day by household region, 2009

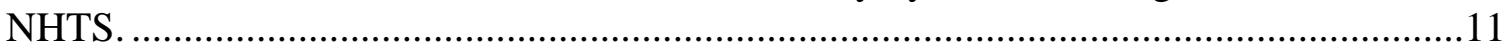

3-2. Percent of residents used transit on travel day by household region, 2009 NHTS.............11

3-3. Percent of population that used transit on travel day by household size (2009 NHTS)......

3-4. Percent of persons that used transit on travel day by household vehicle count (2009 NHTS).

3-5. Distribution of vehicle ownership by status of transit use by regions (2009 NHTS).

3-6. Share of residents that used transit by age group (2009 NHTS)......................................15

3-7. Distribution of NYS population by transit use status and region (2009 NHTS). ...............16

3-8. Shares of transit users in each household income group (2009 NHTS)............................17

3-9. Distribution of household income for transit users and all populations, by region (2009 NHTS).

3-10. Percent of persons used transit by racial group (2009 NHTS). ..........................................18

3-11. Distribution of person trips by trip purpose by transit usage in NYMTC (2009 NHTS).

3-12. Distribution of person trips by purpose by transit usage in Rest of NYS (2009 NHTS).

3-13. Average trip rate per person by transit use status and region, for daily person-trips (2009 NHTS).

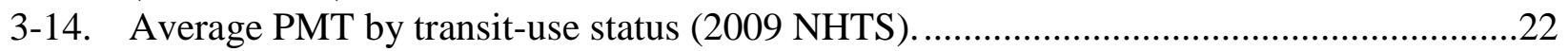

3-15. Average person-trip length (in miles) by transit use status and region (2009 NHTS).

3-16. Average vehicle-trip rates per driver by transit use status and region (2009 NHTS).

3-17. Average VMT per driver by transit use status by region (2009 NHTS).............................24

3-18. Average vehicle-trip length by transit use status and region (2009 NHTS)......................25

3-19. Average travel time per person-trip (in minutes) by transit use status (2009 NHTS).

3-20. Distribution of "past month" transit users by transit use and region. ................................28

3-21. Percent of persons that used transit in past month by household size (2009 NHTS).

3-22. Percent of persons used transit in past month by household vehicle ownership................30

3-23. Distribution of vehicle ownership by past month transit use status by region. ...................31

3-24. Share of persons that used transit in past month by age group (2009 NHTS)....................32

3-25. Share of transit users on travel day versus past month (2009 NHTS) ................................32 
3-26. Share of past-month transit users by household income group (2009 NHTS).

3-27. Distribution of household income for past-month transit users and general populations by region (2009 NHTS).

3-28. Distribution of NYMTC person trips by trip purpose and past-month transit use status (2009 NHTS).

3-29. Distribution for Rest of NYS resident person-trips by trip purpose and transit use in past month (2009 NHTS).

3-30. Average person-trip rate by past-month transit use status (2009 NHTS).......................37

3-31. Average PMT by past-month transit use status (2009 NHTS). ....................................37

3-32. Average vehicle-trip rate per driver by past-month transit use status (2009

NHTS). 7

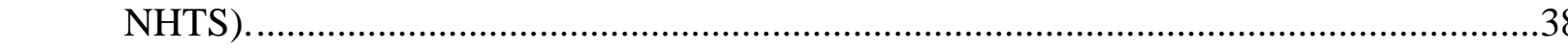

3-33. Average VMT per driver by past-month transit use status (2009 NHTS)........................39

3-34. Average travel time per person-trip (in minutes) by past-month transit use status. ..........40

3-35. Average person-trip length (in miles) by past-month transit use status...........................40

3-36. Average vehicle-trip length (in miles) by past-month transit use status (2009

NHTS)

4-1. Distribution of number of households in region by distance to transit (2009 NHTS).

4-2. Distribution of persons in NYMTC by household size and distance to transit. ...............44

4-3. Distribution of persons in Rest of NYS by household size and distance to transit. ..........44

4-4. Distribution of persons in NYMTC by vehicle ownership and distance to transit............45

4-5. Distribution of persons in Rest of NYS by vehicle ownership and distance to transit

4-6. Distribution of NYMTC population by household income and distance to transit. ..........47

4-7. Distribution of population by household income and distance to transit in Rest of NYS.....

4-8. Distribution of NYS population by distance to transit and age group status....................48

4-9. Average daily person-trip rates by distance to transit by region (2009 NHTS). ..............50

4-10. Average daily vehicle-trip rates by distance to transit by region (2009 NHTS). .............50

4-11. Average PMT per person by distance to transit (2009 NHTS).....................................51

4-12. Average VMT per driver by distance to transit (2009 NHTS)......................................51

4-13. Average travel time (minutes) by distance to transit (2009 NHTS) . ..............................52

4-14. Average person-trip length (miles) by distance to transit (2009 NHTS).........................53

4-15. Average vehicle-trip length (miles) by distance to transit (2009 NHTS).......................53

4-16. Shares and numbers of transit users based on households/persons living within 1-

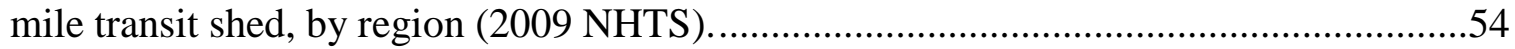

4-17. Distributions of population within 1-mile transit shed by household size, transit

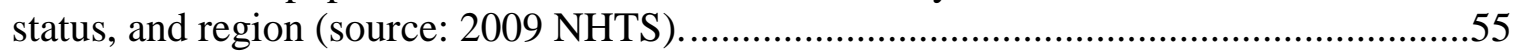

4-18. Distributions of population within 1-mile transit shed by vehicle ownership, transit status, and region (source: 2009 NHTS).

4-19. Distributions of households within 1-mile transit shed by household income,

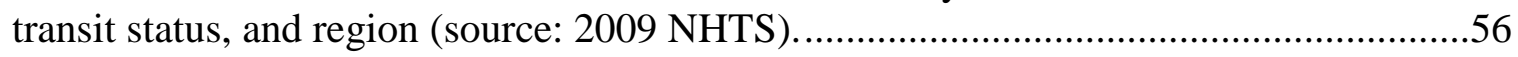

5-1. Transit and POV mode commuting shares for NYMTC workers (ACS data).................57

5-2. Transit and POV commuting mode shares for workers that was from the Rest of NYS (ACS data).

5-3. Transit commuting share by age group for workers in NYMTC (ACS data). . .59 
5-4. Transit commuting share by age group for workers in Rest of NYS (ACS data).

5-5. Average travel time (in minutes) by mode and geography of workers (ACS data). .........60

5-6. Transit mode shares for commuting by NYMTC workers and household income...........61

5-7. Transit shares for commuting for the Rest of NYS workers by household income..........61

5-8. Locations of businesses (with 10 or more employees) overlaid on transit sheds in NYS

5-9. Distribution of block groups by the proportion of block-group employment within 0.5 mile of fixed-guideway transit stops in NYMTC and GBNRTC regions (EPA SLD data).

5-10. Distribution of block groups in NYMTC by the number of jobs/workers within a 45-minute transit commute (EPA SLD data).

5-11. Distribution of block groups in GBNRTC by the number of jobs/workers within a 45-minute transit commute (EPA SLD data).

5-12. Distribution of block groups in GTC by the number of jobs/workers within a 45minute transit commute (EPA SLD data).

6-1. Distribution of transit use measured in person-trips by time of day and day of week. 


\section{LIST OF TABLES}

Table

$\underline{\text { Page }}$

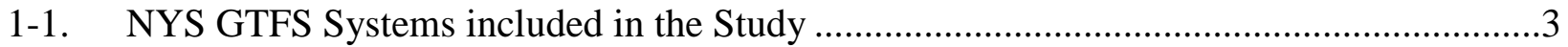

2-1. Population Coverage by NYS GTFS Transit Sheds .....................................................9

3-1. Share of Transit User Person-Trips Taken by Trip Purpose and Region (2009

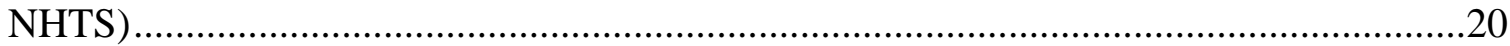

3-2. $\quad$ Access/Egress Mode Choices for Transit Trips - 2009 NHTS .....................................21

3-3. Comparison of Transit Use between Travel Day and Past Month (2009 NHTS) ............27

3-4. Number of Transit Users by Average Frequency of Use during Past Month ...................27

3-5. Definition of Categories for Transit Use in Past Month ...............................................28

3-6. Share of Person-Trips Taken by Past-Month Transit Users by Trip Purpose by

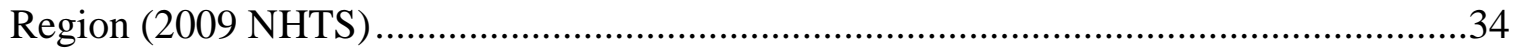

4-1. Mode Shares by Distance to Transit in NYS (2009 NHTS) ...........................................49

5-1. Coverage of NYS Businesses with Ten or More Employees by Distance to Transit........63

5-2. Coverage of NYMTC Businesses with 10 or More Employees by Distance to

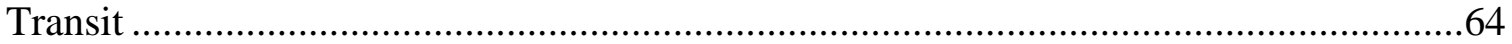

5-3. Coverage of Businesses (10 or More Employees) in Rest of NYS by Distance to

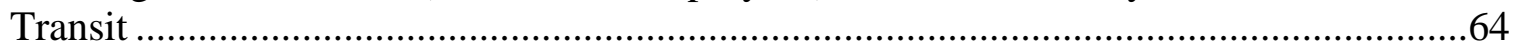

5-4. Percent of NYS Small Businesses by Select Economic Measures .................................65

6-1. Average Daily Trip Rates by Transit Use Status and Geographic Location ....................70

6-2. $\quad$ Share of Main Mode Used by Distance to Transit and by Region (Measured by

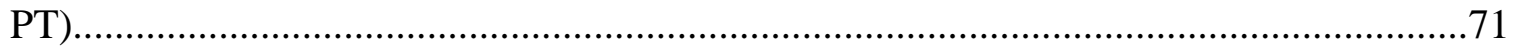

6-3. Shares of Transit Usage Measured in PT, PMT, VT, and VMT by Trip Origin Location 


\section{ACRONYMS}

$\begin{array}{ll}\text { ACS } & \text { American Community Survey } \\ \text { AOA } & \text { Administration on Aging } \\ \text { APTA } & \text { American Public Transportation Association } \\ \text { CBG } & \text { Census Block Group } \\ \text { CBP } & \text { County Business Patterns } \\ \text { FARS } & \text { Fatality Analysis Reporting System } \\ \text { FHWA } & \text { U.S. Federal Highway Administration } \\ \text { GBNRTC } & \text { Greater Buffalo-Niagara Regional Transportation Council } \\ \text { GTC } & \text { Genessee Tranportation Council } \\ \text { GTFC } & \text { General Transit Feed Specications } \\ \text { JTW } & \text { Journey to Work } \\ \text { NHTS } & \text { National Household Travel Survey } \\ \text { NHTSA } & \text { National Highway Traffic Safety Administration } \\ \text { NPTS } & \text { Nationwide Personal Transportation Survey } \\ \text { NTD } & \text { National Transit Database } \\ \text { NYC } & \text { New York City } \\ \text { NYMTC } & \text { New York Metropolitan Transportation Council (New York City) } \\ \text { NYS } & \text { New York State } \\ \text { NYSDOT } & \text { New York State Department of Transportation } \\ \text { PMT } & \text { Person Miles of Travel } \\ \text { PT } & \text { Person Trips } \\ \text { POV } & \text { Privately Owned Vehicle } \\ \text { SLD } & \text { Smart Location Database } \\ \text { USDOT } & \text { U.S. Department of Transportation } \\ \text { VMT } & \text { Vehicle Miles Traveled } \\ \text { VT } & \text { Vehicle Trips }\end{array}$




\section{EXECUTIVE SUMMARY}

\section{OVERVIEW}

This research is a detailed examination of the travel behaviors and patterns of transit users within New York State (NYS), primarily based on travel data provided by the National Household Travel Survey (NHTS) in 2009 and the associated Add-on sample households purchased by the New York State Department of Transportation (NYSDOT). Other data sources analyzed in this study include:

> NYS General Transit Feed Specification (GTFS) to assist in analyzing spatial relationships for access to transit and the creation of Transit Shed geographic areas of 1, 2.5, and 5 miles from transit stop locations,

$>$ LandScan population database to understand transit coverage, and

$>$ Census Bureau's American Community Survey (ACS) data to examine general transit patterns and trends in NYS over time.

The majority of analyses performed in this research aimed at identifying transit trip locations, understanding differences in transit usage by traveler demographics, as well as producing trip/mode-specific summary statistics including travel distance, trip duration, time of trip, and travel purpose of transit trips made by NYS residents, while also analyzing regional differences and unique travel characteristics and patterns. The analysis was divided into two aggregated geographic regions: New York Metropolitan Transportation Council (NYMTC) and NYS minus NYMTC (Rest of NYS). The inclusion of NYMTC in all analysis would likely produce misleading conclusions for other regions in NYS.

\section{TRANSIT COVERAGE}

The NYS transit network has significant coverage in terms of transit stop locations across the state's population. Out of the 19.3 million NYS population in 2011, about 15.3 million (or 79\%) resided within the 1-mile transit shed. This NYS population "transit coverage" increased to 16.9 million (or 88\%) when a 2.5-mile transit shed was considered; and raised to 17.7 million (or 92\%) when the 5-mile transit shed was applied.

\section{KEY FINDINGS}

- Based on 2009 NHTS data, about 40\% of NYMTC households used transit as their means of transportation on any typical day; while only $4 \%$ of households located elsewhere in NYS did the same.

- Regardless of geographic regions, $45 \%$ of the transit users came from households with income under $\$ 40,000$, while $20 \%$ of transit users were from the top income group of $\$ 100,000$ plus households.

- Travel made by NYMTC transit users were nearly twice as likely to be for work trips as compared to their counterpart non-transit users. 
- Transit users in NYS generally made more trips but with shorter distances; they also drove less, which resulted in fewer miles. Furthermore, NYS transit users spent more time on each trip than their counterpart non-transit users.

- Because of the intensity of transit network services within NYMTC, 88\% of the households reside within the 1-mile transit shed. Outside the NYMTC, however, only 54\% of the region's households are located within the same distance.

- Impact to vehicle ownership was clearly evidenced. Nearly all people from zero-vehicle households in NYMTC lived within a 1-mile radius of transit stops. Elsewhere in NYS, 74\% of residents from zero-vehicle households resided within the 1-mile transit shed.

- Close proximity to transit has a significant impact on increasing transit uses. Transit mode share, as a main mode, was higher for NYS residents that lived within the 1-mile transit shed than others.

- $\quad$ Based on ACS data, over the period from 2005 to 2013, the total number of NYMTC workers increased more than $9 \%$, while transit commuting grew at a higher rate of more than $15 \%$ during the same period.

\section{REMARKS}

Note that transit use in areas outside the NYMTC region generally is not common, resulting in a smaller sample size of transit users in the Rest of NYS region. Caution should be exercised for statistics produced based on small sample sizes that tend to be less precise (i.e., with a larger margin of error). Furthermore, standardized transit network data were not available prior to 2005; comparable analyses using 2001 NHTS therefore was not feasible. As a result, this study focused on examining travel behaviors of transit users using 2009 NHTS data only. 


\section{INTRODUCTION}

\subsection{BACKGROUND}

Policy and decision makers in federal, state, and local governments rely on transportation statistics and passenger/goods movement data to formulate strategic transportation polices, develop investment plans, and improve the safety and efficiency of the transportation systems. Particularly, data on personal travel patterns and trends are needed to examine the efficiency, capacity, reliability, flexibility, and accessibility of the transportation systems to meet current demands as well as to accommodate future demands. Furthermore, these data are critical in supporting the assessment and evaluation of alternatives (e.g., congestion-alleviating technologies) for transportation investment programs, and in estimating energy use or air quality impacts of transportation policies.

Because of the need for this type of data, the U.S. Department of Transportation (USDOT) has collected detailed data on daily personal travel since the late 1960's, originally under the Nationwide Personal Transportation Survey (NPTS). The NPTS was conducted in 1969, 1977, 1983, 1990, and 1995.Then the survey was renamed to the National Household Travel Survey (NHTS) for the 2001 survey. The latest NHTS was conducted in 2009 and preparation for the 2015 NHTS is being conducted at this time.

For many years, the New York State Department of Transportation (NYSDOT) has participated in the NHTS as an Add-on state by procuring additional sample households. This permits NYSDOT to have sufficient sample data to address transportation planning issues pertinent to geographic areas that are significantly smaller than what the national NHTS data allows. Under the agreement to provide technical support and research assistance to the NYSDOT, the Oak Ridge National Laboratory (ORNL) research team was tasked to utilize data collected from the 2009 NHTS and conduct a detailed examination of the travel behaviors and patterns of several special subpopulations in the state. The special subpopulation groups selected include: (1) the elderly (defined as those who were 65 years old or older), (2) transit users, (3) disabled persons (defined as those who reported a condition that interferes with travel), (4) low-income households, and (5) foreign-born resident groups. This report documents the travel behaviors and patterns of the subpopulation of transit users that lived in New York State (NYS).

\subsection{OBJECTIVE}

The 2009 NHTS data was used as the primary data source to analyze subjects and address questions such as, but not limited to, the following:

- Are there differences in traveler demographics between those who used/did not use transit?

- Are there any regional differences, in terms of traveler living in New York City Metro area, other parts of NYS, or outside NYS?

- Do any unique travel characteristics or patterns exist for this subpopulation group? 


\subsection{BRIEF DESCRIPTIONS OF DATA SOURCES}

\subsubsection{NHTS}

Overall, statistics presented in this report were produced using data from the 2009 NHTS. The NHTS is a Federal Highway Administration (FHWA) sponsored national travel survey of U.S. households. It surveyed over 150,000 households in 2009. ${ }^{1}$ The NHTS ${ }^{2}$ is the authoritative source of national data for the travel behavior of the American public. It includes questions about trip frequency, distance, travel time, and modes of transportation, including public transit.

Due to data limitations in earlier NHTS/NPTS years, analyses for the subpopulation group of "transit users" were mainly conducted based on the 2009 NHTS data. Note that the NHTS collected information from populations that were age 5 years old and older at the survey time only. In addition, the NHTS definition of "transit modes" includes local public bus, commuter bus, commuter train, subway/elevated train, and streetcar/trolley.

The majority of analyses performed under this research aimed at identifying transit trip locations, traveler demographics, as well as producing trip/mode-specific summary statistics including travel distance, trip duration, time of trip, and travel purpose of transit trips made by NYS residents. Limited effort was made to investigate whether prior year NHTS/NPTS data have sufficient information to support a meaningful trend analysis. Standardized transit network data were not available prior to 2005 therefore, comparable analyses using 2001 NHTS was not feasible. Thus, this study focused on examining travel behaviors of transit users using 2009 NHTS data only.

\subsubsection{GTFS Data}

The ORNL research team collected available NYS General Transit Feed Specification (GTFS) ${ }^{3}$ data and converted it from its native format into GIS format. This included information on both transit stops and transit routes. The GTFS datasets generally include information on agency, stop location, route locations, trips, stop times, and calendar information. Additional transit systems were added after an initial project scoping between the research team and the NYSDOT transit staff. The final set of GTFS data for NYS locations compiled by the ORNL team includes the systems listed in Table 1-1. A map of these transit networks is provided in Figure 1-1. Not surprisingly, transit networks are concentrated at population centers (i.e., major metropolitan areas). The highest concentration and the largest coverage of transit systems are around the New York City (NYC) region.

\footnotetext{
${ }^{1}$ U.S. territories are not included in the NHTS sampling frame.

${ }^{2}$ NHTS website at: http://nhts.ornl.gov/introduction.shtml.

${ }^{3}$ GTFS Data Exchange, http://www.gtfs-data-exchange.com/.
} 
Table 1-1. NYS GTFS Systems included in the Study

\begin{tabular}{l||l}
\hline \multicolumn{1}{l||}{ Region } & Region \\
\hline New York City & Long Island \\
o Metro-North (rail) & o Nassau Inter-County Express (bus) \\
o MTA (bus/rail) & O Long Island (bus/rail) \\
o NYCT (bus) & Central NY (CENTRO) \\
o Syracuse (bus) \\
Albany (bus) & o Oswego (bus) \\
Rochester (bus) & o Auburn (bus) \\
\hline Westchester (bus) & o Rome (bus) \\
\hline Buffalo (bus) & o Utica (bus) \\
\hline Rockland (bus) & Broome County (bus) \\
\hline Coach USA (bus) & Middletown (bus) \\
\hline CTRAN (bus) & Newburgh (bus) \\
\hline Glens Falls (bus) & TCAT (bus) \\
\hline Warwick Transit (bus) & UCAT (bus) \\
\hline Watertown Citibus (bus) & \\
\hline
\end{tabular}

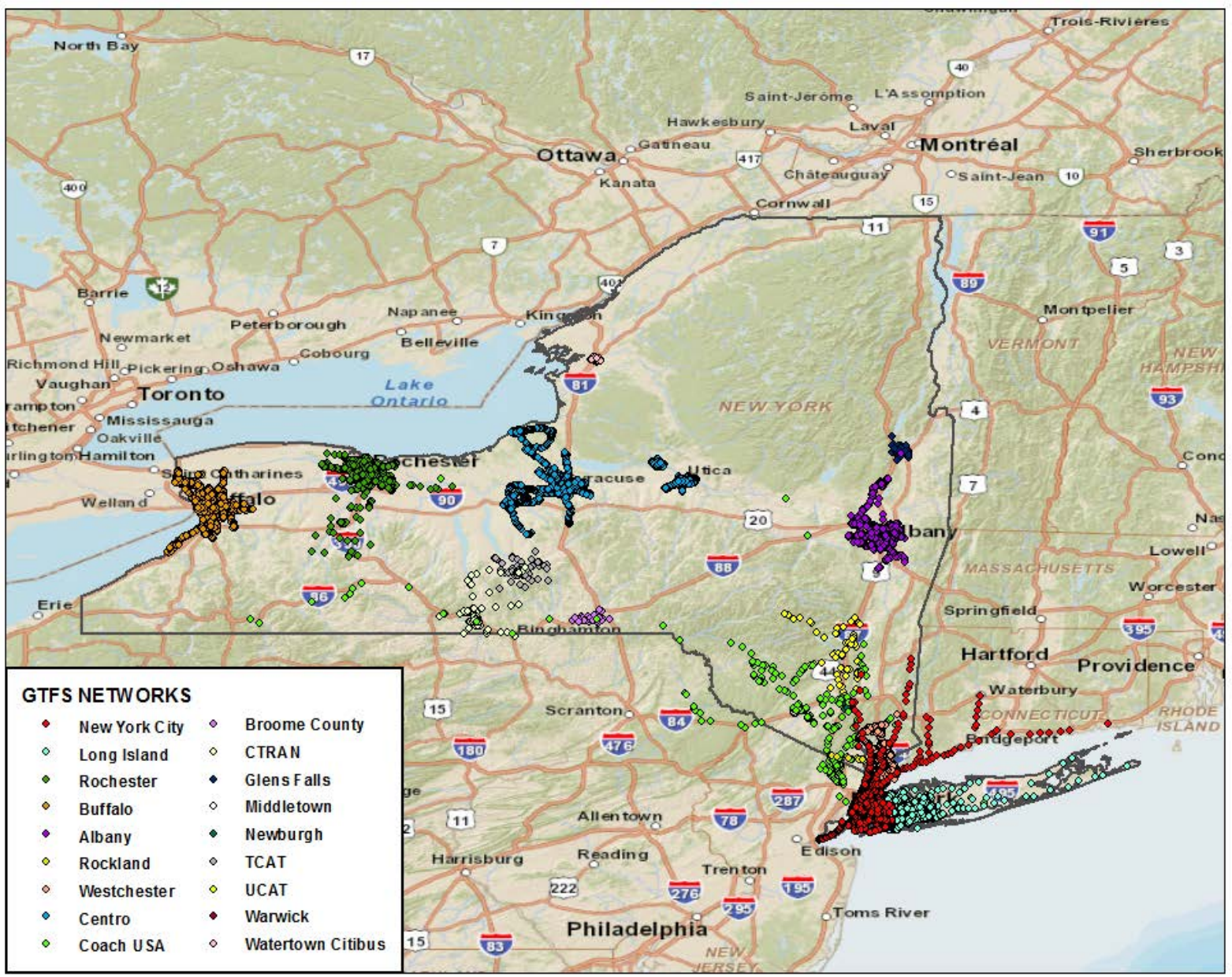

Figure 1-1. NYS GTFS networks included in this project. 


\subsubsection{LandScan Data}

LandScan data (http://web.ornl.gov/sci/landscan/) is the finest-resolution population distribution data available (about $1 \mathrm{~km}$ or 30-meter $\mathrm{x} 30$-meter resolution). It contains data on daytime and nighttime populations in all U.S. regions as well as globally. As an example, Figure 1-2 displays the 2011 LandScan nighttime population for NYS in a 30-meter-by-30-meter grid. Clearly visible is the concentration of population in the NYC region, as well as in other major metro areas across NYS.

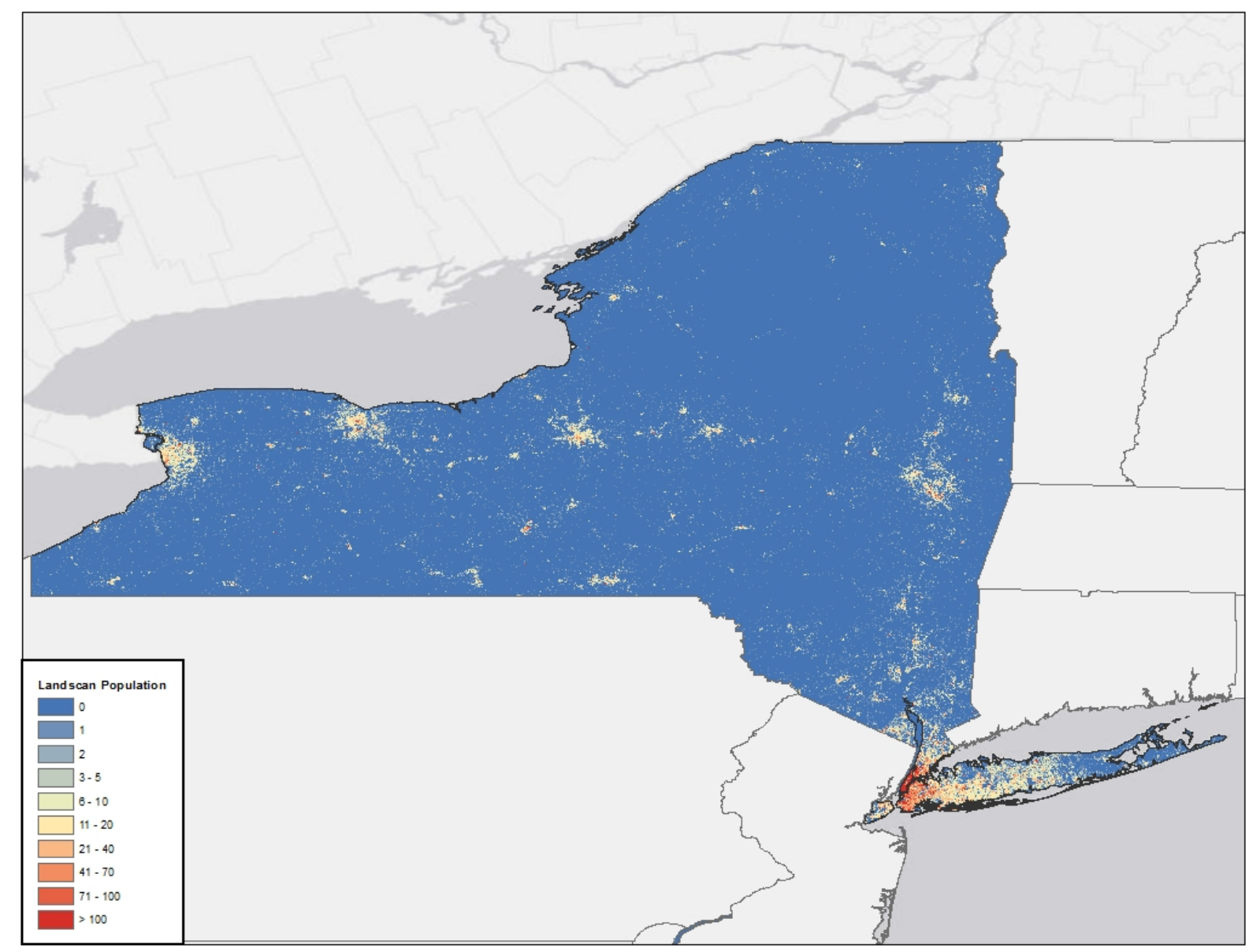

Figure 1-2. LandScan estimated population for NYS in 2011 (in a 30-meter x 30-meter grid).

\subsubsection{Census Bureau American Community Survey Data}

In addition to analysis of NHTS data, transit usage derived from the Census Bureau's American Community Survey (ACS) ${ }^{4}$ data were also investigated in this study. Data from the ACS allows one to examine general patterns and trends in transit use over time, although no trip-specific information is available in ACS except for commuting trips.

\footnotetext{
${ }^{4}$ American Community Survey website http://www.census.gov/programs-surveys/acs/.
} 
The ACS is a survey conducted by the U.S. Census Bureau of about 3 million households each year (a sample of 250 thousand households per month), subject to the constraint that households should not be surveyed more than one time in any given five-year period. Thus, the ACS is very intensive, with 3 million sampled households versus 150 thousand in the NHTS, and it is repeated annually.

Furthermore, the ACS is, geographically, more uniform than the NHTS. Each year's ACS sample includes, on average, almost 50 households per Census Tract and almost 15 households per Census Block Group (CBG). Data on demographic, social, and economic characteristics for all ages of populations living in the U.S. is collected in the ACS. Census publishes 1-year, 3year, and 5-year ACS estimates; with the 5-year dataset being the largest and the most reliable one; even though the 5-year data is the least current dataset.

In addition, the ACS collects data on commuting, i.e., the Journey to Work (JTW), which includes information on mode of transportation and travel time to work. Public transit is one of the modes published by the ACS for commuting trips (i.e., JTW data). Specifically, the 5-year ACS data permits researchers to analyze geographic patterns and trends for transit commuting.

\subsubsection{Other Potentially Useful Data Sources}

Additional information and data sources were also utilized along with the 2009 NHTS data to examine travel behavior and patterns associated with NYS transit users. A few other data sources also contained information associated with transit users that might be beneficial to this study topic. Some limited reviews were conducted to identify data items that might provide supplemental information to support findings from this study.

The Smart Location Database (SLD) ${ }^{5}$ is a data product of the Office of Sustainable Communities in the U.S. Environmental Protection Agency (EPA), which contains a set of variables that are related to transit. The SLD is a nationwide geographic data source with most of its attributes available at the 2010 CBG level. Information from SLD is commonly used as measures of landuse mix and transit accessibility within a region. Examples of transit-associated variables in the SLD include:

- Proportion of CBG employment within 1/2 mile of fixed guide way transit stop,

- Transit service frequency,

- Peak pm transit departure within 0.25 miles of CBG,

- Jobs within 45-minute transit commuting,

- Working-age population within 45-minute transit commuting,

- Job accessibility by transit as a proportion of total regional job accessibility by transit, and

- Accessibility to working-age population by transit (measured as a proportion of total regional accessibility).

\footnotetext{
${ }^{5}$ Smart Growth, Smart Location Mapping, U.S. EPA: http://www2.epa.gov/smart-growth/smart-locationmapping\#SLD.
} 
Other public data such as National Transit Database (NTD) from the Federal Transit Administration, Transit Oriented Development (TOD) database (for selected areas only), and information from the American Public Transportation Association (APTA) was briefly reviewed for supplemental information specific to this study.

\subsection{ORGANIZATION OF THE REPORT}

This report presents results generated from data analyses performed for transit-associated travel made by NYS residents. Specifically, analyzing the 2009 NHTS data to examine demographic characteristics of NYS transit users, trip frequency, travel distance (i.e., trip length), travel time, and trip purpose. Geographic regions of study and definition of several transit sheds were discussed in Section 2 of this report. The significance of transit systems in NYS was also addressed in this section. Section 3 of this report includes detail summaries generated from the analyses conducted using 2009 NHTS data, which was the emphasis of this research study. Effect of "distance to transit" on travel behaviors of NYS transit users was then presented in Section 4. Transit commuting trends was further examined using Census data and reported in Section 5, followed by a summary of study findings in Section 6 . 


\section{GEOGRAPHIC REGIONS AND TRANSIT-ACCESSIBLE POPULATIONS}

\subsection{GEOGRAPHIC REGIONS OF STUDY}

As described in Section 1.3.2, ORNL collected a comprehensive set of GTFS data that serve NYS regions and integrated these transit network systems into a GIS format. Attributes of the GTFS data include information on agency, stop location, route, trips, stop times, calendar (i.e., dates for service), frequencies, transfers, etc. This GTFS information was valuable in examination of transit accessibility at specific locations or certain targeted routes, for instance. Such degree of detail, however, are not supported by 2009 NHTS data due to its sample size limitations. In this study, analyses and statistics on travel behaviors of NYS transit users are generally summarized at aggregated geographic regions of:

- New York Metropolitan Transportation Council (NYMTC),

- New York State minus NYMTC (i.e., Rest of NYS), and

- New York State as a whole

The separation of NYMTC from the Rest of NYS is necessary due to the uniqueness of its regional demographic and travel characteristics. Although NYMTC occupies only $4 \%$ of the land area in NYS, it is where approximately $60 \%$ of the entire NYS population lives. Thus, inclusion of NYMTC in analyses would likely produce misleading conclusions for the regions outside NYMTC.

\subsection{DEFINITION OF TRANSIT SHED}

Although living nearby a transit station does not guarantee one's ridership on transit, the proximity likely has impacts on transit accessibility in general. To measure the significance of transit systems within NYS, all available NYS GTFS data were spatially analyzed against the 2011 LandScan population data to determine the proportion of NYS population residing within a selected distance from available transit stations (namely, a transit shed).

Three distances were included in defining the transit sheds. Specifically, 1-mile, 2.5-mile, and 5mile buffers around each transit station were used to form each of the transit sheds. Figure 2-1 shows these transit-sheds in NYS. Because some of the NYS GTFS networks extend beyond NYS boundary, i.e., serving regions within Connecticut, New Jersey, and Pennsylvania, the map (Figure 2-1) shows certain coverages outside NYS. However, this study considered the population (whether transit users or not) that lived in NYS only - a limitation due to the definition of the NHTS samples.

Note that using the common walking distance factor of " 5 minutes per quarter mile" means that it takes 20 minutes by foot to travel 1 mile. Based on that, walking for 2.5 miles ( 1 hour) or 5 miles (2 hours) to access transit is rather unlikely or unrealistic. To travel these longer distances, a transit user would likely require access/egress modes other than walking to reach, or leave, transit stations (e.g., park and ride or auto drop-off/pick-up). 


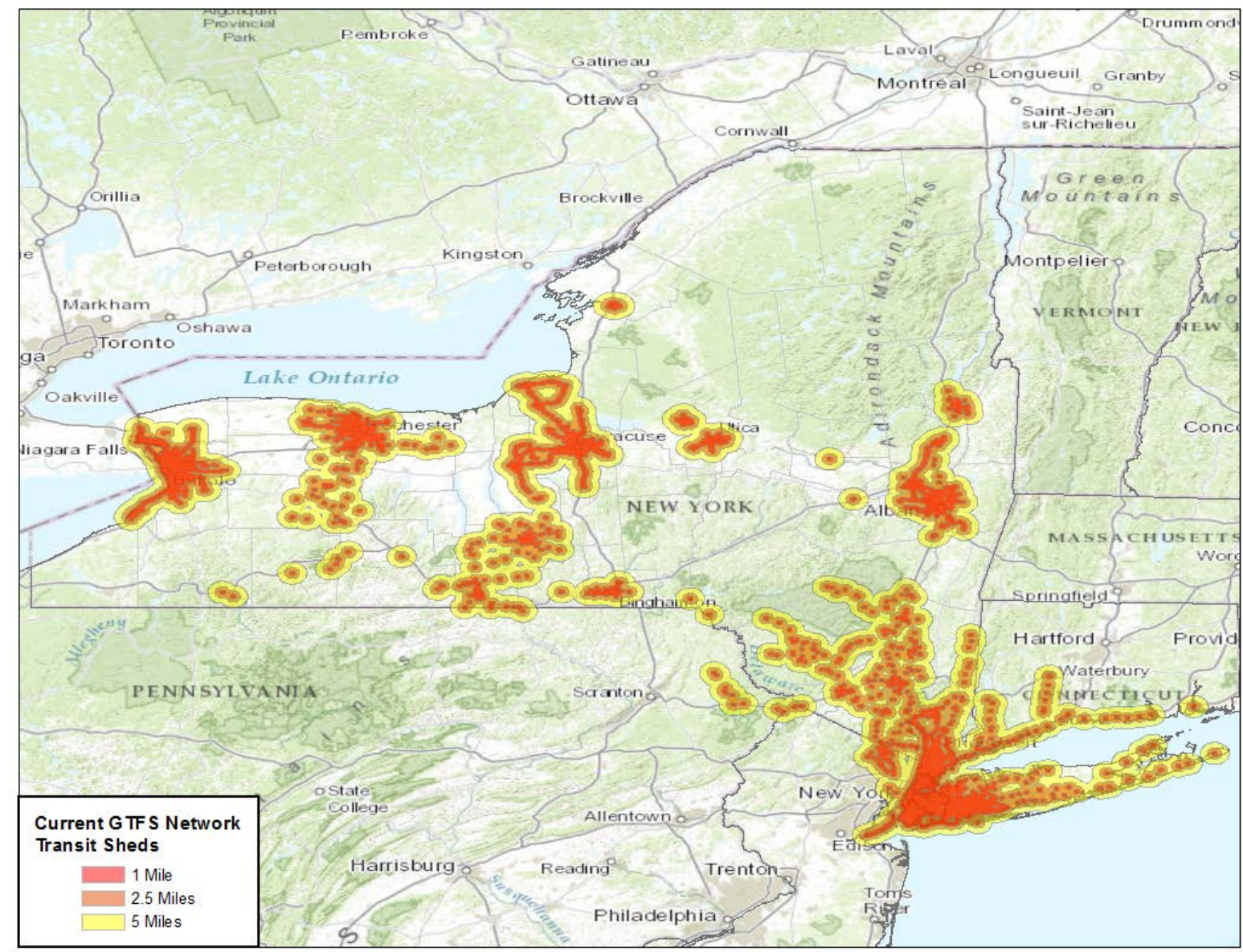

Figure 2-1. Example of transit accessibility showing transit sheds (1-, 2.5-, and 5-mile distances).

\subsection{MEASURE OF TRANSIT NETWORK COVERAGE}

For this study, LandScan data was applied to illustrate the significance of potential transit services in NYS, in terms of estimating the proportion of NYS population with access to transit stations. The "transit accessibility" within this context was defined by measuring the population within each given distance radius to transit stations (i.e., transit sheds defined above). The difference in data-year, i.e., 2009 NHTS data and 2011 LandScan data, did not cause any major concern for this purpose.

LandScan data was integrated with the three transit sheds defined and applied using spatial analysis tools to identify total NYS populations within each of the transit sheds. The results showed that, out of the total 19.3 million NYS population in 2011, about 15.3 million (or 79\%) resided within the 1-mile transit shed (i.e., within a 1-mile radius of the nearest GTFS transit stops). As the summary statistics presented in Table 2-1show, this NYS population "transit coverage" increased to 16.9 million (or 88\%) in the 2.5-mile transit shed; and it increased to 17.7 million (or 92\%) within the 5-mile transit shed (Table 2-1). This clearly shows that the NYS transit network has significant coverage, in terms of station locations, across the state's population. 
Table 2-1. Population Coverage by NYS GTFS Transit Sheds

\begin{tabular}{ccc}
\hline $\begin{array}{c}\text { Transit Shed } \\
\text { Distance }\end{array}$ & $\begin{array}{c}\text { Population within region } \\
\text { (million) }\end{array}$ & $\begin{array}{c}\text { Percent of total } \\
\text { NYS population }\end{array}$ \\
\hline 1 mile & 15.3 & $79 \%$ \\
\hline 2.5 miles & 16.9 & $88 \%$ \\
\hline 5 miles & 17.7 & $92 \%$ \\
\hline Overall NYS & 19.3 & $100 \%$ \\
\hline
\end{tabular}

Of course, this is only a rough approximation for measuring transit accessibility. Having t transit station accessibility does not necessarily mean there is frequent service provided from that station (e.g., transit stops at the given location only arrives twice a day); nor does that reflect that a variety of services are provided at that specific station (e.g., transit stops at the given location only goes to one side of the town). Although these are important subjects to consider for transit usage, it is out of scope for this current study.

This study aimed at using 2009 NHTS data to examine characteristics and travel patterns of transit users, and identify any differences between those who used transit and those who did not. The process and discussion provided above was mainly to establish a general appreciation for the significance of transit systems within NYS. That said, a limited number of analyses were conducted with 2009 NHTS households constrained to those who reside within boundaries of the selected transit sheds--particularly those living within the 1-mile transit shed. Figure 2-2 overlays NYS household locations from the 2009 NHTS data (shown in blue dots) to the transit sheds seen in Figure 2-1. Clearly visible are the household concentrations in major urban areas, mostly coinciding with where transit service is available. 


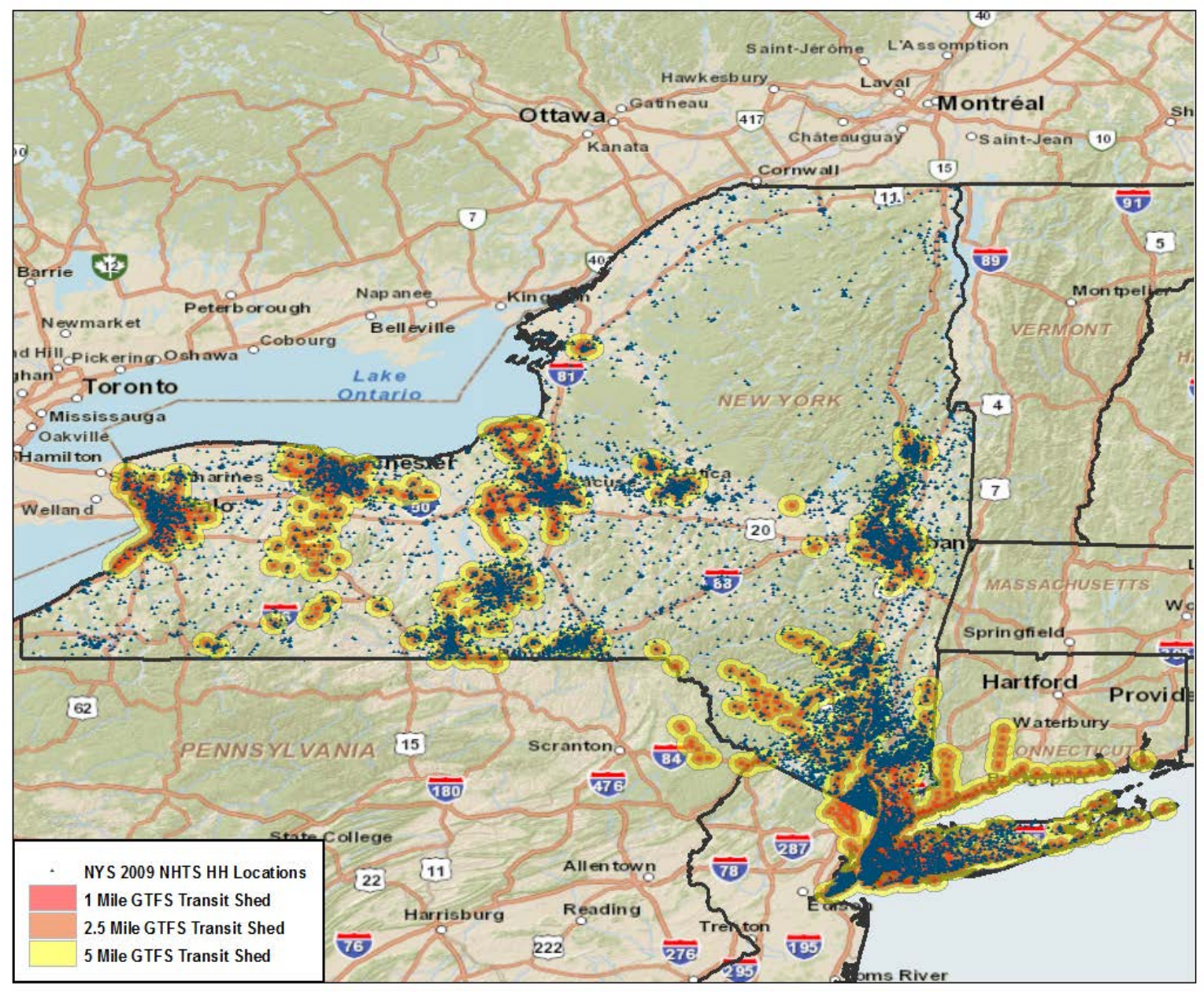

Figure 2-2. Location of NYS households in 2009 NHTS and GTFS transit sheds. 


\section{CHARACTERISTICS OF THE TRANSIT USERS IN NYS}

\subsection{TRANSIT USAGE FOR DAILY TRIPS AND TRAVELER CHARACTERISTICS}

Using data from 2009 NHTS, nearly 40\% of the approximately 4.4 million NYMTC households used public transit as their means of transportation on any typical day; while only about $4 \%$ of households that lived elsewhere in NYS did the same (see Figure 3-1). As a whole, about 26\% of the total NYS households used transit as their main mode of transportation on a typical day during 2009. Similarly, as shown in Figure 3-2 at the individual person level, about $27 \%$ of NYMTC residents used transit while only about $2 \%$ of those NYS residents who lived outside NYMTC used transit in the same year.

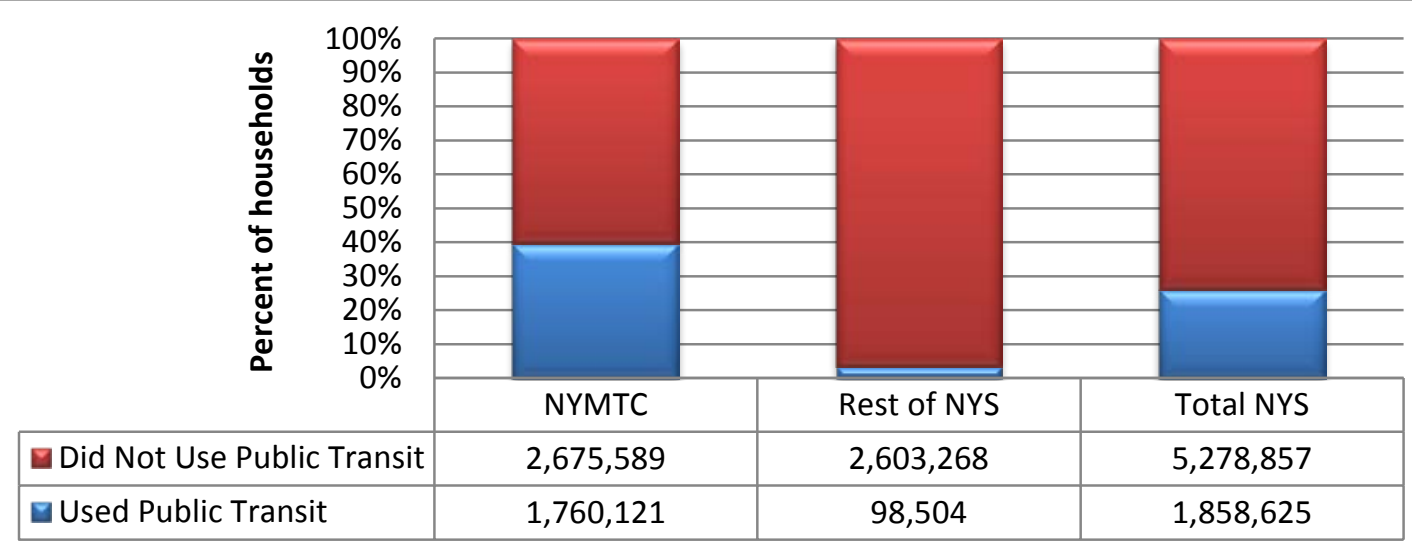

Number of households in region

Figure 3-1. Percent of households that used transit on travel day by household region, 2009 NHTS.

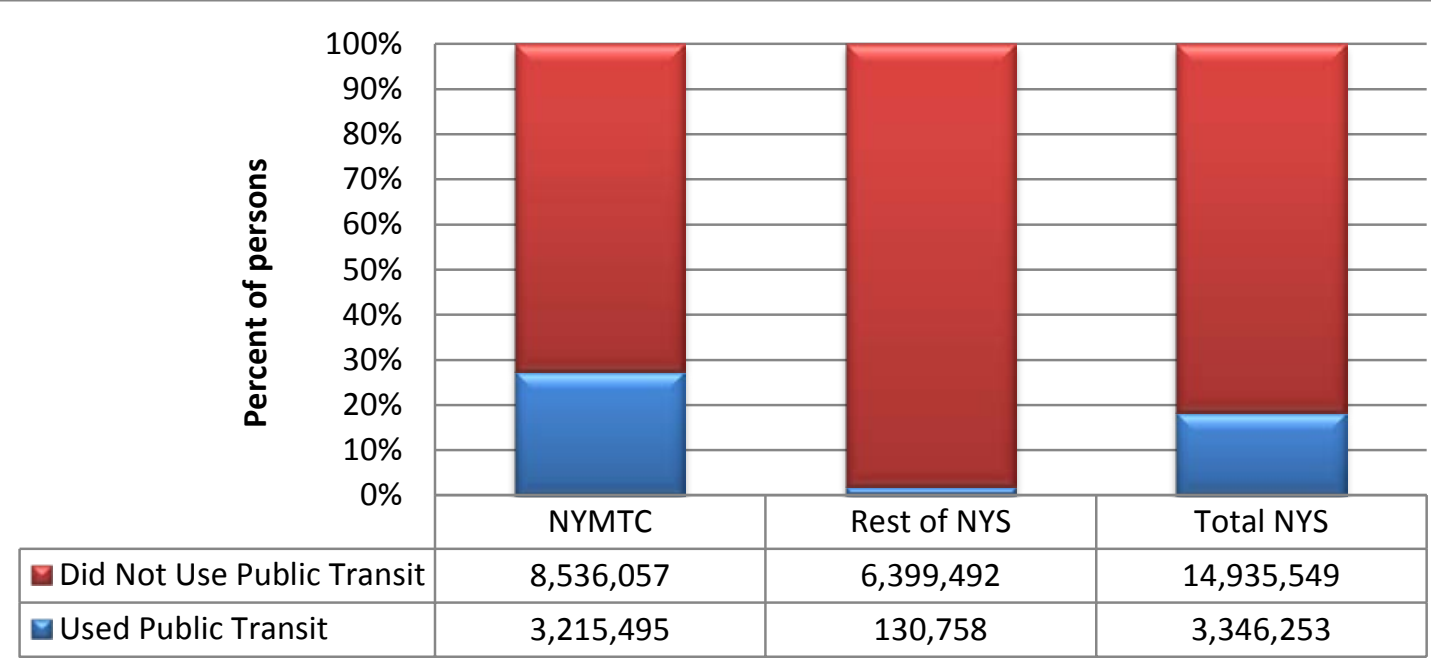

Number of persons in region

Figure 3-2. Percent of residents used transit on travel day by household region, 2009 NHTS. 


\subsubsection{Impacts of Household Size}

When considering travelers' household size, a significantly higher percent of those living alone (i.e., household size of 1) used transit as their main mode of transportation on a typical day, when compared to multiple-person households. As shown in Figure 3-3, about 37\% of the population from single-person households of NYMTC used transit on their travel day in 2009, while only around $26 \%$ of the population from multiple-person households in the same region did so during the same year. As expected, residents from the Rest of NYS have a much lower percent of transit usage regardless of their household size. Nevertheless, people from NYS single-person households living in regions outside the NYMTC were more than twice as likely to use transit for daily activities as their multiple-person household neighbors.

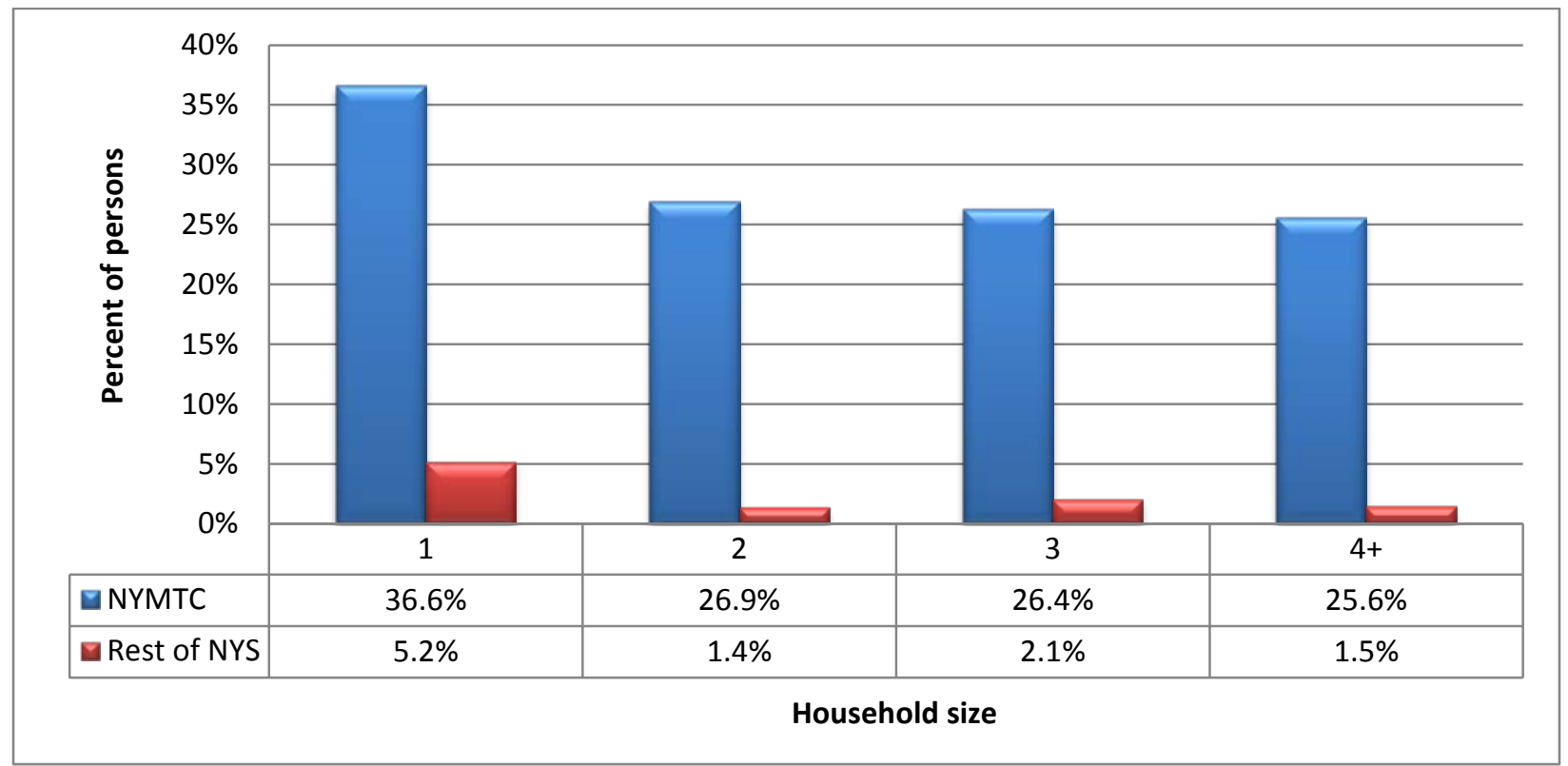

Figure 3-3. Percent of population that used transit on travel day by household size (2009 NHTS).

\subsubsection{Influences of Vehicle Ownership}

It is clearly visible from Figure 3-4 that the share of transit-use (measured by percent of persons who used transit within the given vehicle-ownership group) decreased as the number of vehicles owned in the household increased. This is true regardless where the person lived in NYS. Note that, as a unique characteristic of living in NYMTC, not owning any vehicles in a household was made mostly by choice, instead of financial reasons ${ }^{6}$. To get around, members of these NYMTC zero-vehicle households travel extensively by non-motorized means (walking and biking) or by utilizing public transportation systems (transit). Because of this, it is not a surprise to see that over $45 \%$ of NYMTC population from zero-vehicle households used transit; while only about $15 \%$ of those who lived in zero-vehicle households from elsewhere in NYS utilized transit as a main mode during 2009 (Figure 3-4). Furthermore, recall that the GTFS network systems shown in Figure 1-1 transit coverage in NYMTC region are quite dense signifying much stronger transit

\footnotetext{
${ }^{6}$ See Chapter 3 of the New York State 2009 NHTS Comparison Report, authored by Frank Southworth, T. Reuscher, and H. Hwang, Oak Ridge National Laboratory, ORNL/TM-2012/204, June 2012.
} 
accessibility in the area than any other regions in the NYS. This regional difference is visible in travel by persons from the one-vehicle households. Travelers from these NYMTC households also have a significantly higher share of transit use (29\%), compared to less than $2 \%$ of their counterparts living elsewhere in NYS.

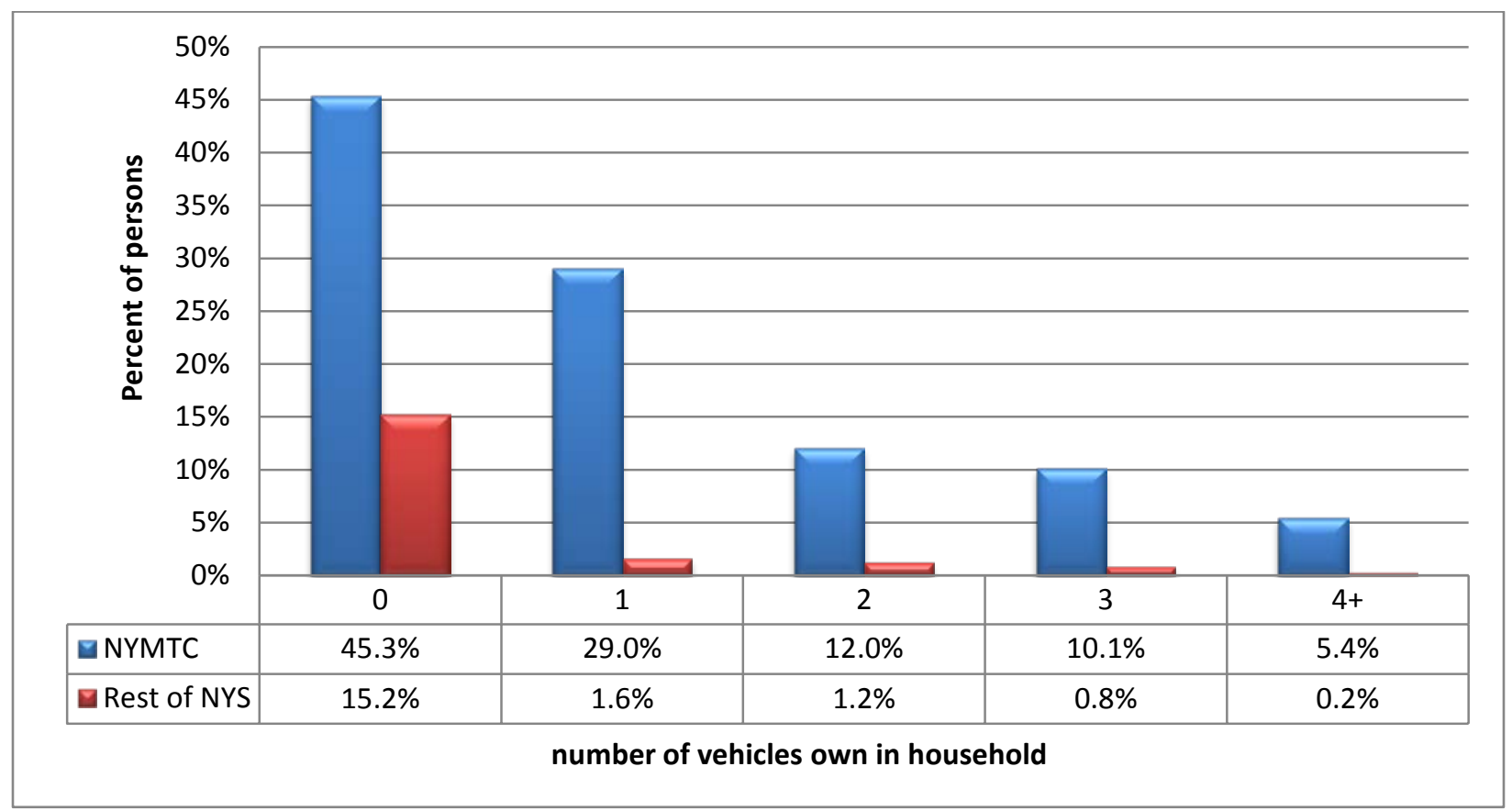

Figure 3-4. Percent of persons that used transit on travel day by household vehicle count (2009 NHTS).

When examining the composition of transit users as a group, by its distribution of vehicle ownership, it was interesting to discover that a similar large portion of transit users came from zero-vehicle households, regardless of geographic region difference. As presented in Figure 3-5, over 53\% of the transit users in NYMTC and more than $46 \%$ of transit users from the Rest of NYS did not own any vehicles in their households during 2009 NHTS year. On the other hand, less than $25 \%$ of non-users (i.e., persons who did not use transit on the 2009 NHTS-assigned travel date) who lived in NYMTC were from zero-vehicle households, while only about 5\% of non-users from the Rest of NYS came from zero-vehicle households in that region.

\subsubsection{Difference in Transit Use by Age}

The NYMTC residents took a significantly larger portion of their daily trips by transit in 2009 than those who lived outside the region, regardless of their ages. Higher percentages of transit usage among younger people (15 to 54 years old) are evident in Figure 3-6. Over 30\% of individuals within each age group between 15 and 54 years old had taken transit as a main mode on their trips. By comparison, only a small percent (under 4\%) of these same age group NYS residents that lived outside NYMTC used transit for their daily travel. 


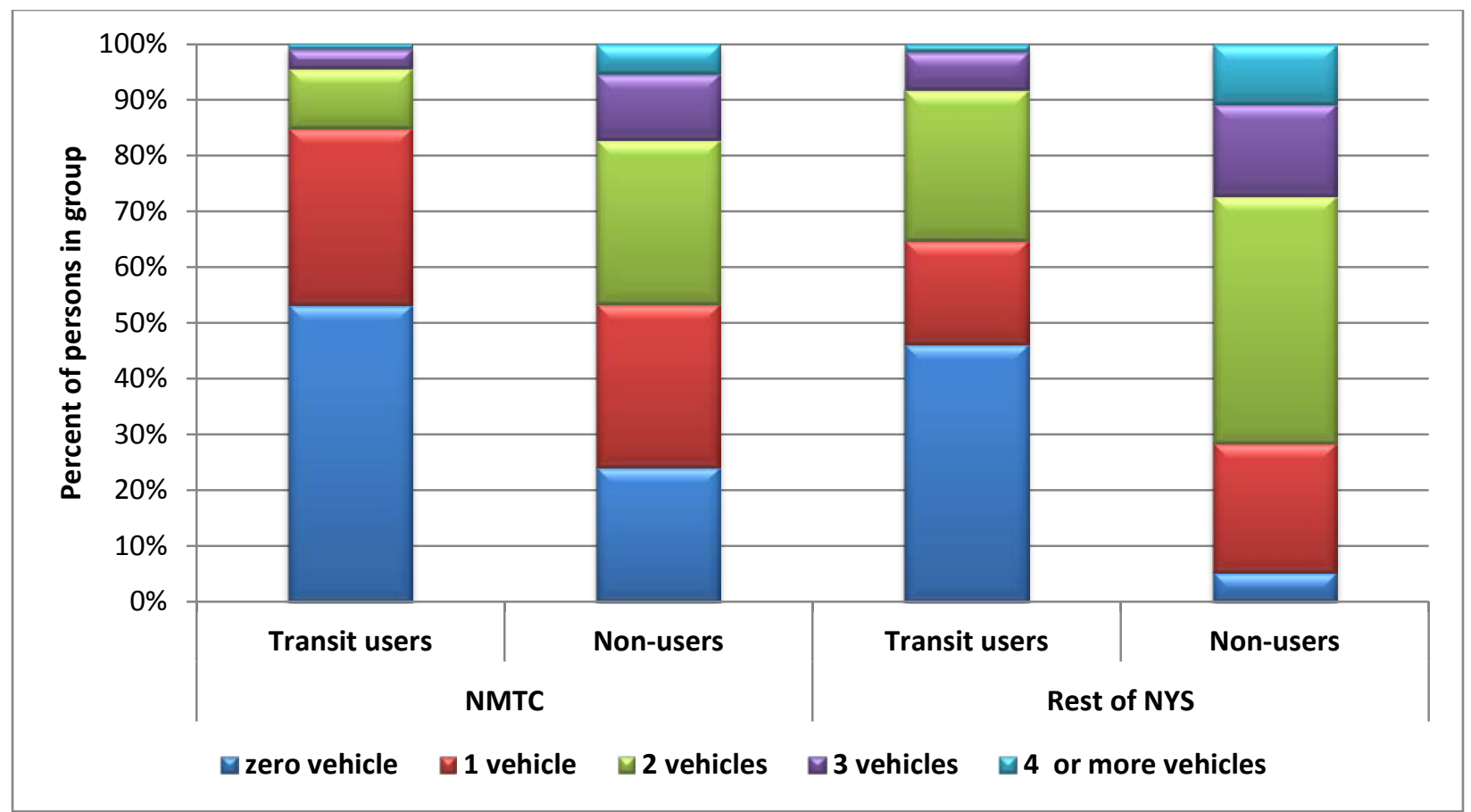

Figure 3-5. Distribution of vehicle ownership by status of transit use by regions (2009 NHTS).

The share of transit riders among NYMTC elderly residents (age 65 years and older) were significantly higher than their counterparts who lived elsewhere in NYS. This is consistent with the findings of a similar study on elderly travelers in $\mathrm{NYS}^{7}$. Because the population of NYMTC accounts for nearly $60 \%$ of the total NYS population, transit-use distribution by age for NYS as a whole (illustrated with green bars in Figure 3-6) resembles a very similar pattern as seen in NYMTC (in blue).

Furthermore, Figure 3-6 shows a declining trend in transit use as NYMTC residents aged. This downward trend started from age group 35 to 44 years old, and dropped relatively steady as the NYMTC traveler's age increased. Many younger elderly persons, i.e., those between 65 and 74 years old specifically, continued to utilize transit for their daily travel needs. About $24 \%$ of those who were 65 to 69 years old and nearly 19\% of those between 70 and 74 years old still rode transit to conduct their daily activities. Outside NYMTC, only limited transit usage was observed in all age groups.

\footnotetext{
${ }^{7}$ Hwang, H. L., D. Wilson, T. Reuscher, J. Yang, R. Taylor and S. M. Chin, Travel Patterns and Characteristics of the Elderly Subpopulation in New York State, ORNL/TM-2015/83, Oak Ridge National Laboratory, February 2015.
} 


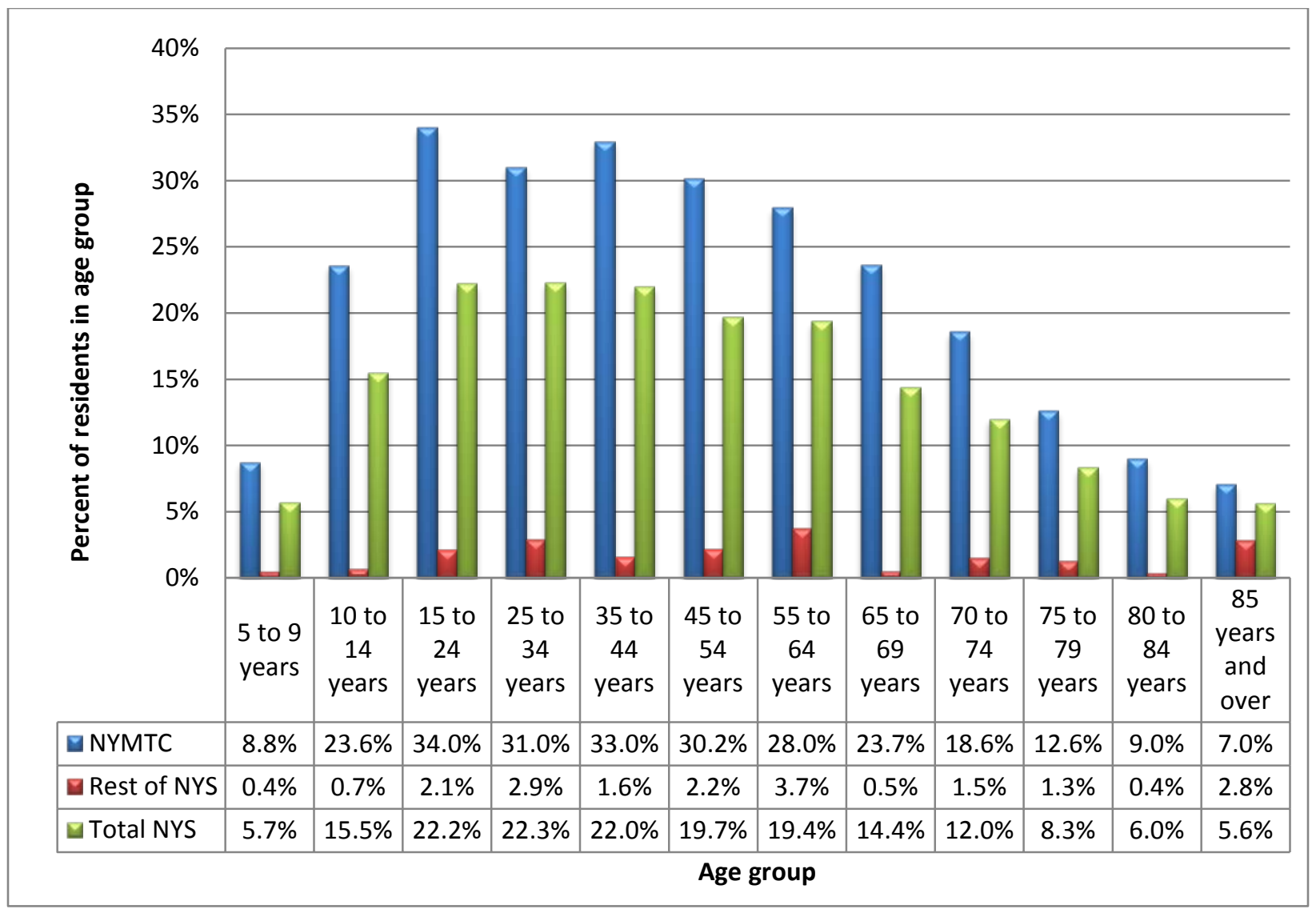

Figure 3-6. Share of residents that used transit by age group (2009 NHTS).

As a whole, only about 15\% of elderly (aged 65 and over) NYMTC residents used transit, versus around 30\% for their younger counterparts who lived in the same region. Note, the vertical-scale representing the percentages in Figure 3-7 was adjusted so that details of the small transit-user shares in the rest of NYS region could be observed. Not surprisingly, transit usage in the Rest of NYS was not common. With that, however, its elderly residents still only have about half of the likelihood of taking transit trips as compared to their younger neighbors. 


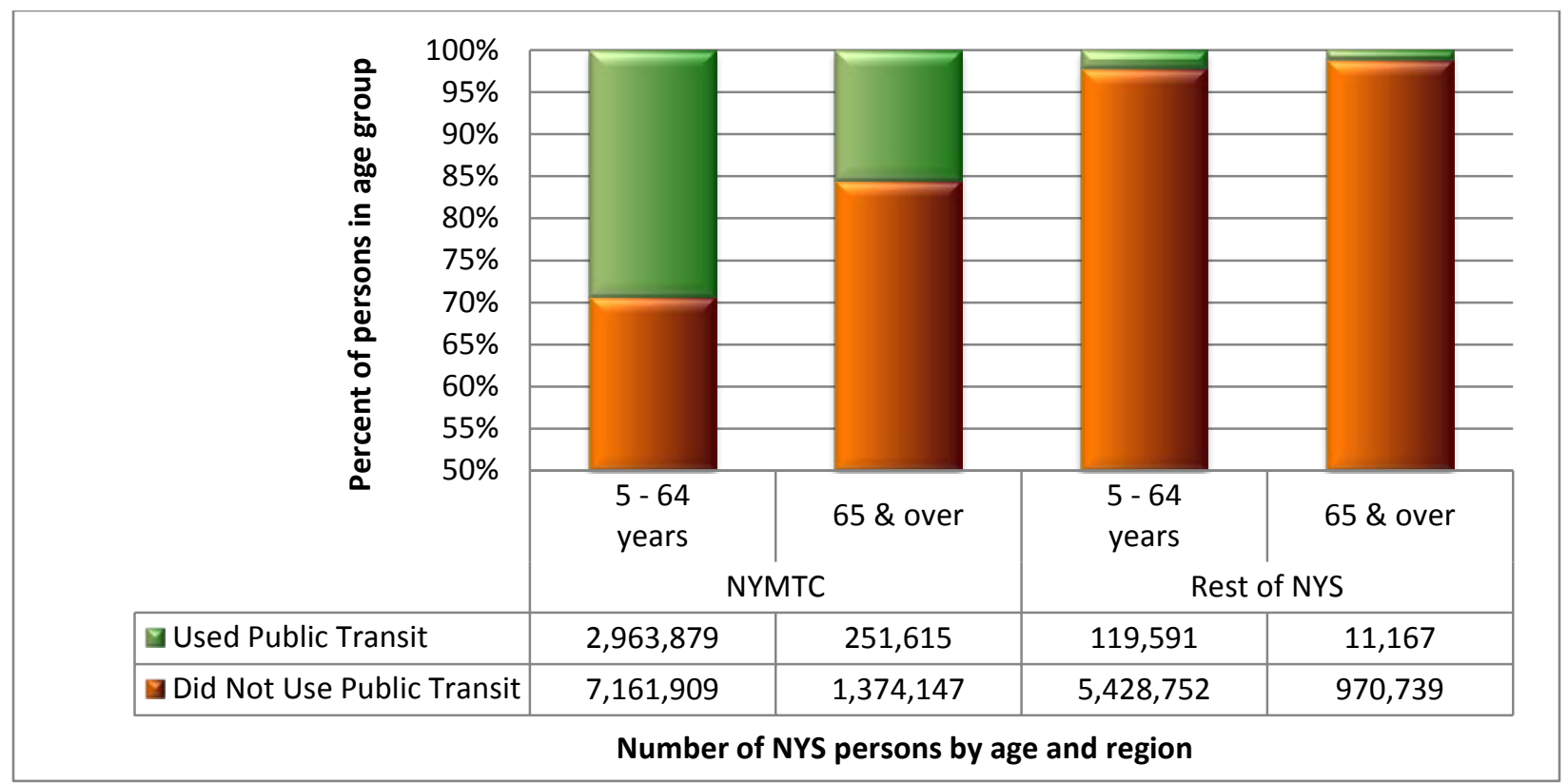

Figure 3-7. Distribution of NYS population by transit use status and region (2009 NHTS).

\subsubsection{Daily Transit Use by Household Income Group}

When taking into consideration transit users' household income level, Figure 3-8 shows that travelers from lower income households are more likely to use transit for their daily activities; as compared to their higher income counterparts from the same region. Specifically, residents from under \$40,000 annual income households in NYMTC were more likely to use transit ( 35\%) than those from $\$ 40,000$ to $\$ 100,000$ income groups ( 27\%). Nearly 20\% of NYMTC residents from the highest income group "\$100,000 or more” also used transit during 2009. Elsewhere in NYS, about $5 \%$ of residents from the lowest income group used transit, and less than $2 \%$ of other income-level people who lived in the Rest of NYS used transit as the main mode of transportation for their daily trips. As pointed out previously, NYMTC has a significantly higher share of transit use than all other areas of NYS, no matter which income level the traveler belongs.

When observing the distributions of NYS transit users by their income category, it shows a very similar pattern notwithstanding to the regions of residence. As displayed in Figure 3-9, income distributions for transit users from NYMTC and those from the Rest of NYS were nearly identical. Specifically, of all transit users in either NYMTC or the Rest of NYS, about 45\% came from the two lowest income groups (i.e., income under \$40,000) while slightly below 20\% of transit users were from the top income group of "\$100,000 or more." As a reference, distributions by income group from the general populations of NYMTC and from other NYS regions were also included in Figure 3-9. These are shown in points, a triangle shape for NYMTC and a circle for the Rest of NYS. The distributions from transit users were generally consistent with the general populations in both regions. 


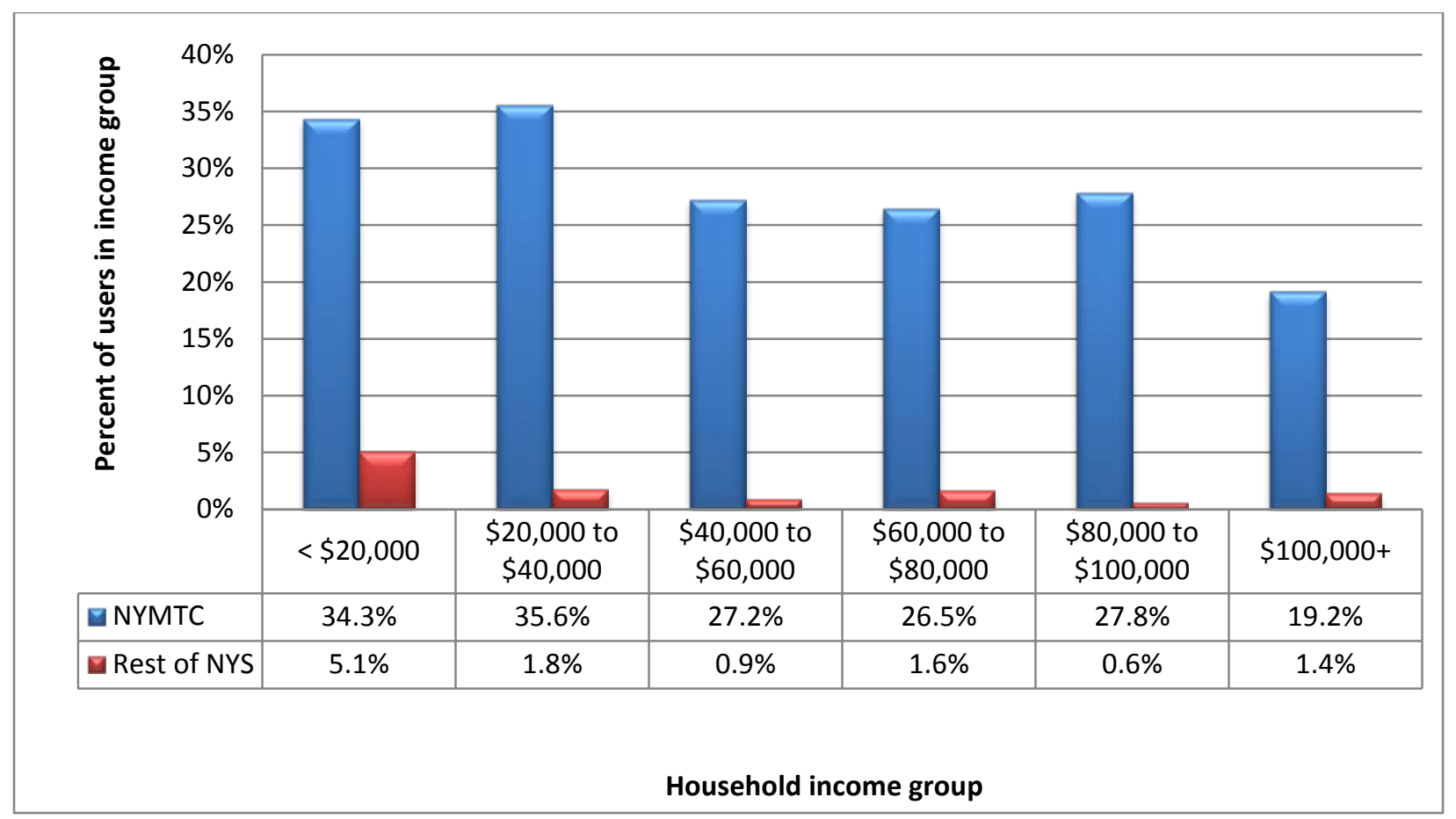

Figure 3-8. Shares of transit users in each household income group (2009 NHTS).

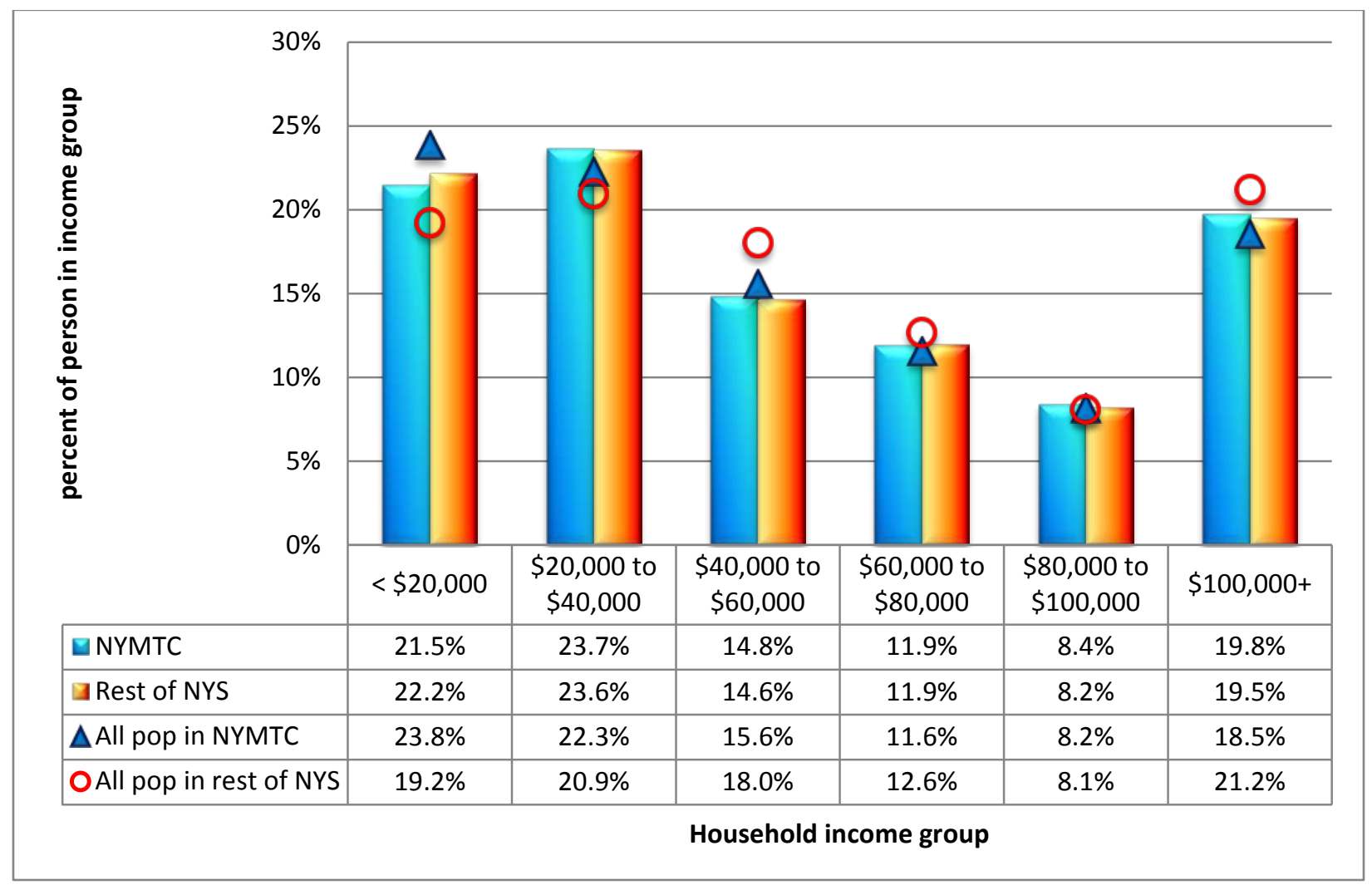

Figure 3-9. Distribution of household income for transit users and all populations, by region (2009 NHTS). 
However, it is visible that shares of higher income groups among the "general population" were slightly higher than their corresponding shares of transit users in the Rest of NYS (i.e., red circles over the top of corresponding bars). Specifically, using information presented in the data table of Figure 3-9 a total of about 60\% of NYS general population that lived outside NYMTC came from households with “\$40,000 or higher” annual income. However, this same income category covered about 54\% of transit users (i.e., 6\% lower than its population share). This implied a lower transit usage among higher income households (i.e., annual income of \$40,000 and more) who lived in the Rest of NYS.

\subsubsection{Daily Transit Use by Racial Group}

Transit use was less common among white residents of NYMTC than other racial groups from the same region. As presented in Figure 3-10, less than 20\% of NYMTC white residents used transit for their daily travel in 2009, while about twice as many of their non-white neighbors used transit. White residents living in the Rest of NYS were also significantly less likely to use transit than other racial groups; only about $2 \%$ of them used transit to perform their daily activities in 2009. Among those who lived elsewhere in NYS during 2009, about $9 \%$ of Hispanic/Mexican residents used transit on their daily trips, while 5\% of African Americans and less than 3\% of Asian/natives/multiracial people used transit for their trips during the same year.

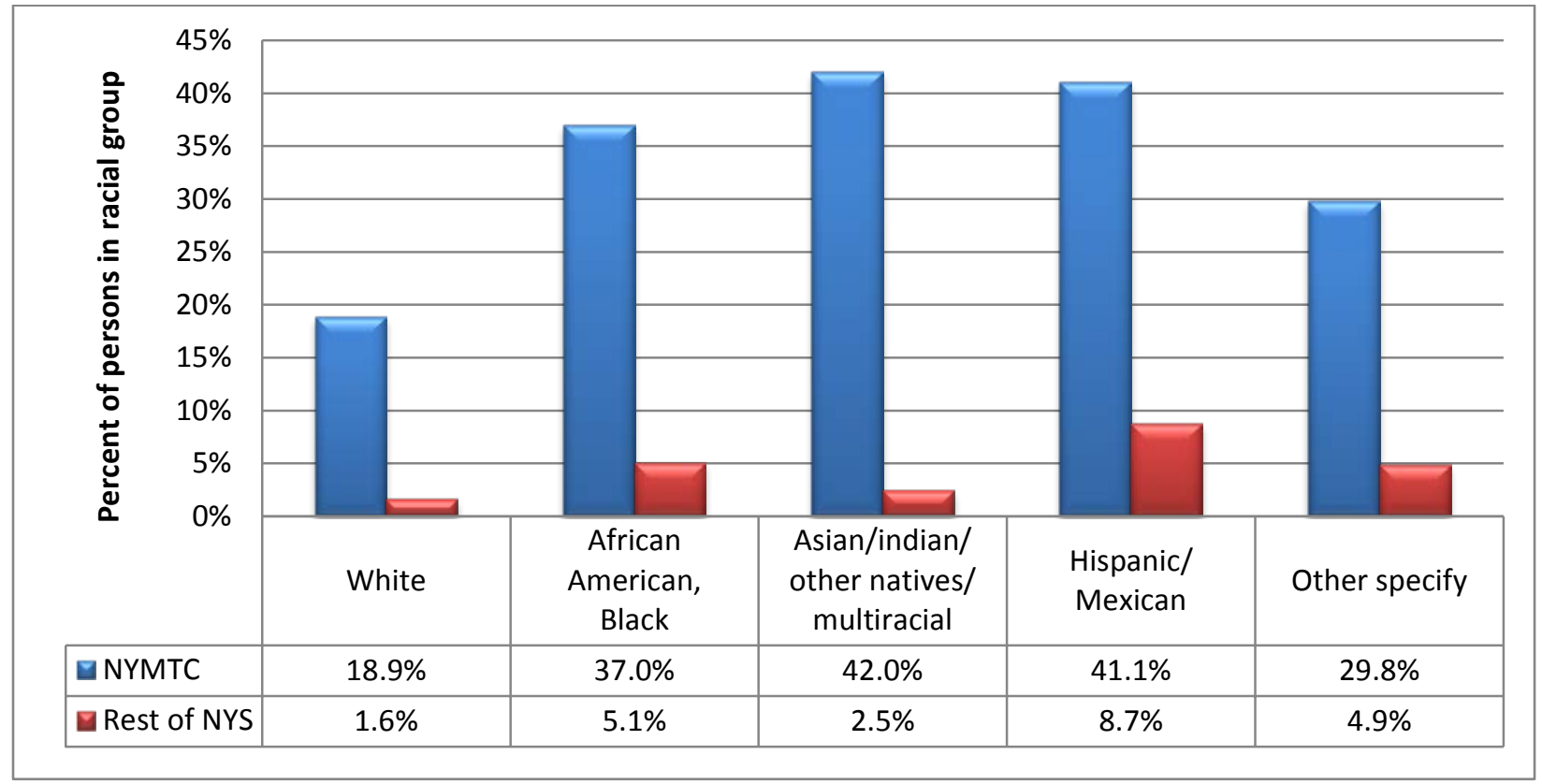

Figure 3-10. Percent of persons used transit by racial group (2009 NHTS).

\subsection{TRIP PURPOSES AND ACCESS/EGRESS MODE CHOICES OF DAILY TRIPS}

\subsubsection{Relationship between Daily Transit Usage and Trip Purpose}

The 2009 NHTS data was further examined to investigate whether trip purpose had any effect on transit usage on daily travel made by NYS residents. Distributions of person trips by trip purpose and by transit usage status are presented in Figure 3-11 and Figure 3-12 for NYMTC 
and the Rest of NYS, respectively including their corresponding total numbers of person-trips by trip purpose.

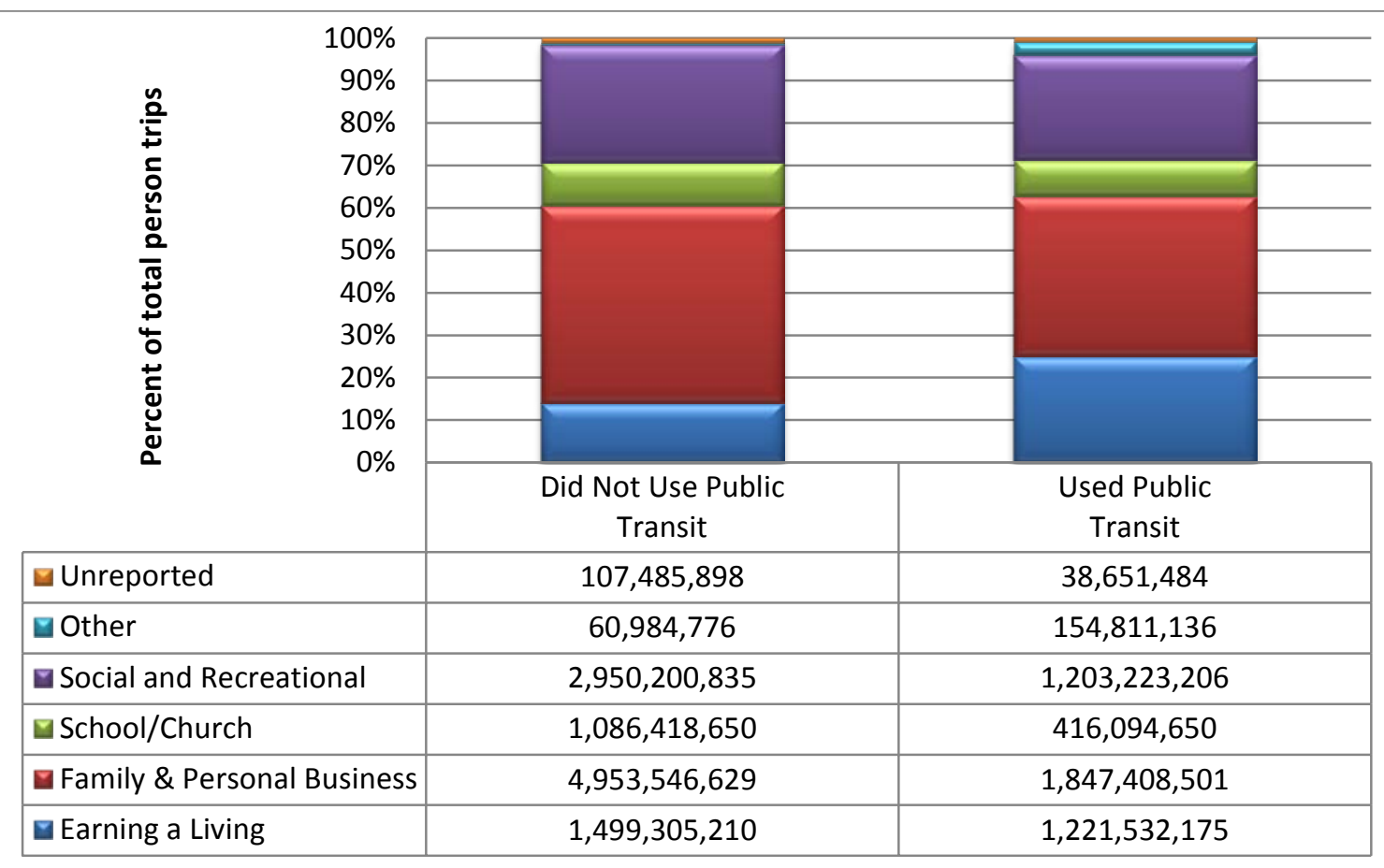

Figure 3-11. Distribution of person trips by trip purpose by transit usage in NYMTC (2009 NHTS).

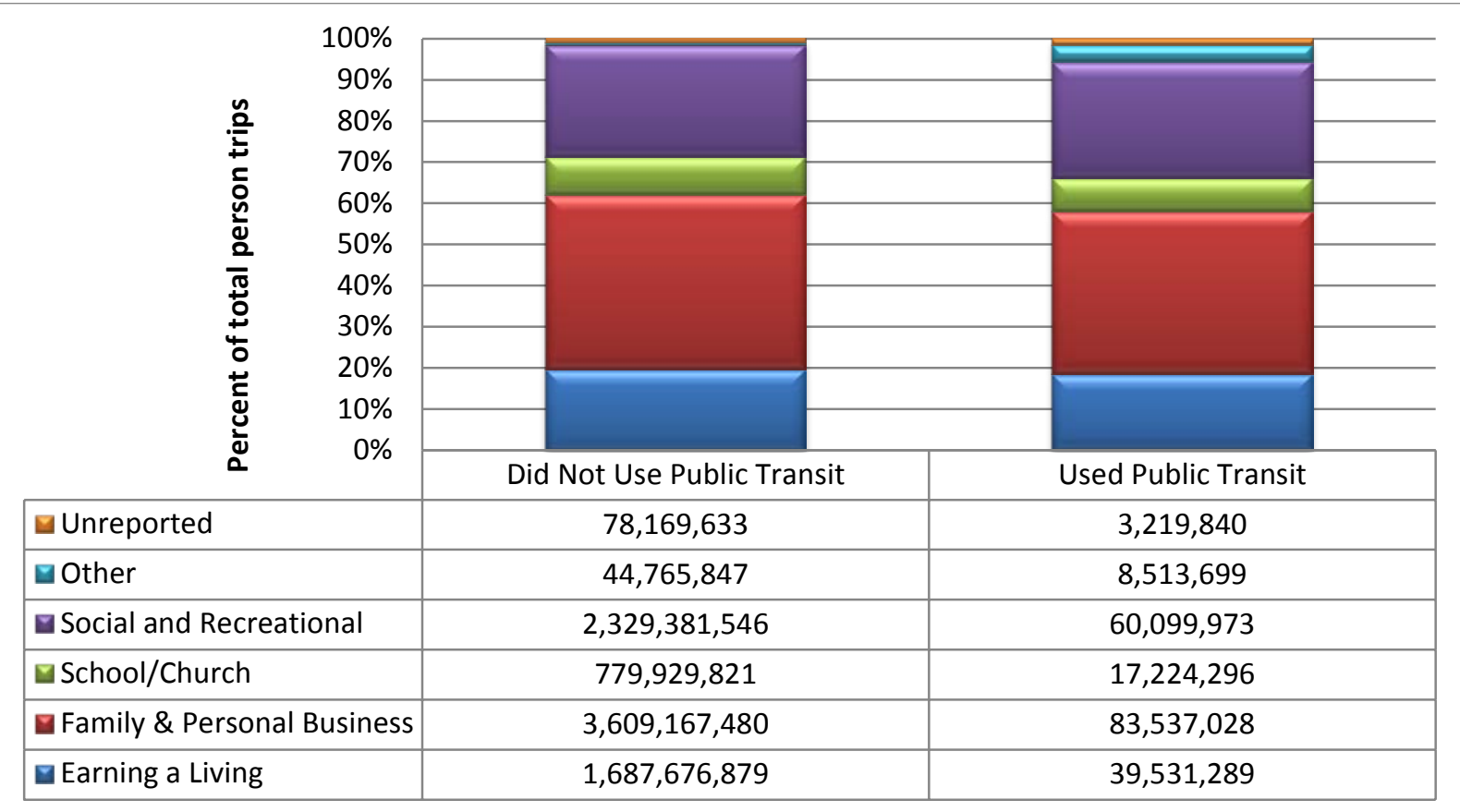

Figure 3-12. Distribution of person trips by purpose by transit usage in Rest of NYS (2009 NHTS). 
Among NYMTC residents, as observed in Figure 3-11, travel made by transit users was nearly twice as likely to be for commuting (i.e., work trips) as compared to their counterpart non-transit users, about 25\% versus 14\% respectively. Clearly, the absence of commuting trip share for non-transit users was mostly made up by the increasing shares of family and personal business trips. The share of person trips for family and personal business made by non-users was about $47 \%$, compared to $38 \%$ for the same trip purpose among transit users in NYMTC. Unlike residents of NYMTC, distribution patterns of person trips by trip purpose among transit users and non-users who lived in the Rest of NYS were similar, as shown in Figure 3-12. The only exception was a noticeable portion of “other” purpose trips made by transit users.

Transit use shares of person trips by trip purpose were analyzed and presented in Table 3-1. These shares appeared to vary among trip purposes and between the two geographic regions. The 2009 NHTS data show that NYMTC transit users accounted for $45 \%$ of total commuting person-trips for earning a living); while less than $30 \%$ of transit users trips made by NYMTC residents were for other purposes (excluding “other/unknown” trip purpose) in 2009. Note that over half of the person trips (i.e., 53\%) were made for the purposes of "other or unknown" (including unreported) by NYMTC residents.

Table 3-1. Share of Transit User Person-Trips Taken by Trip Purpose and Region (2009 NHTS)

\begin{tabular}{lccc}
\hline \multicolumn{1}{c}{ Trip Purpose } & NYMTC & Rest of NYS & Total NYS \\
\hline Earning a living & $45 \%$ & $2 \%$ & $28 \%$ \\
Family \& personal business & $27 \%$ & $2 \%$ & $18 \%$ \\
School/ church & $28 \%$ & $2 \%$ & $19 \%$ \\
Social \& recreational & $29 \%$ & $3 \%$ & $19 \%$ \\
Other/ unknown & $53 \%$ & $9 \%$ & $41 \%$ \\
All purposes & $31 \%$ & $4 \%$ & $18 \%$ \\
\hline
\end{tabular}

Moreover, Table 3-1 indicates that the trip purpose generally had no effect on the transit-usage status among NYS residents who lived outside the NYMTC region. Specifically, transit users from the Rest of NYS accounted for about $2 \%$ of total person-trips in the region, regardless of their reasons for making those trips (except for other/unknown or unreported). As for NYMTC residents, trips made for other or unknown (including unreported) reasons by transit users that lived in the Rest of NYS also show a higher share than trips made for all other purposes (9\% versus $2 \%$ ). This pattern (i.e., higher shares of “other/unknown”) was consistent with those observed in Figure 3-11 and Figure 3-12.

\subsubsection{Mode Choice for Access to/Egress from Transit}

Table 3-2 shows that, regardless where NYS travelers lived, the most frequently used means for reaching transit (access mode) or departing from transit (egress mode) was walking; accounting for $85 \%$ of total person trips made by transit users from the Rest of NYS and about $89 \%$ for those who lived in NYMTC. The POV as the access/egress mode was more common among those who lived outside NYMTC. It is speculated by the researchers that, in addition to vehicle drop-offs or pick-ups, the availability of park-and-ride locations in regions outside NYMTC may influence this mode choice. In addition, as observed in Table 3-2, there is a significant use of 
bus/rail as access or egress mode by transit users in NYS, particularly in NYMTC. This could likely be for transfers made to/from the main transit segment during a trip.

Table 3-2. Access/Egress Mode Choices for Transit Trips - 2009 NHTS

\begin{tabular}{|c|r|r|r|r|r|r|}
\hline \multirow{2}{*}{$\begin{array}{c}\text { Main Access } \\
\text { Mode }\end{array}$} & \multicolumn{2}{|c|}{ NYMTC } & \multicolumn{2}{c|}{ Rest of NYS } & \multicolumn{2}{c|}{ Total NYS } \\
\cline { 2 - 7 } & $\begin{array}{c}\text { Number of } \\
\text { person trips }\end{array}$ & $\begin{array}{c}\text { Mode } \\
\text { share (\%) }\end{array}$ & $\begin{array}{c}\text { Number of } \\
\text { person trips }\end{array}$ & $\begin{array}{c}\text { Mode } \\
\text { share (\%) }\end{array}$ & $\begin{array}{c}\text { Number of } \\
\text { person trips }\end{array}$ & $\begin{array}{c}\text { Mode } \\
\text { share (\%) }\end{array}$ \\
\hline POV & $92,406,330$ & $3.5 \%$ & $8,598,937$ & $\mathbf{9 . 3 \%}$ & $101,005,267$ & $3.7 \%$ \\
\hline Bus/rail & $164,922,566$ & $\mathbf{6 . 2 \%}$ & $3,243,317$ & $3.5 \%$ & $168,165,882$ & $6.2 \%$ \\
\hline Walk & $2,359,888,080$ & $\mathbf{8 9 . 4 \%}$ & $78,192,349$ & $\mathbf{8 4 . 8 \%}$ & $2,438,080,429$ & $\mathbf{8 9 . 2 \%}$ \\
\hline Others & $23,488,895$ & $0.9 \%$ & $2,208,668$ & $2.4 \%$ & $25,697,563$ & $0.9 \%$ \\
\hline All modes & $2,640,705,871$ & $100.0 \%$ & $92,243,271$ & $100.0 \%$ & $2,732,949,141$ & $100.0 \%$ \\
\hline
\end{tabular}

\begin{tabular}{|c|r|r|r|r|r|r|}
\hline \multirow{2}{*}{$\begin{array}{c}\text { Main Egress } \\
\text { Mode }\end{array}$} & \multicolumn{2}{|c|}{ NYMTC } & \multicolumn{2}{c|}{ Rest of NYS } & \multicolumn{2}{c|}{ Total NYS } \\
\cline { 2 - 7 } & $\begin{array}{c}\text { Number of } \\
\text { person trips }\end{array}$ & $\begin{array}{c}\text { Mode } \\
\text { share (\%) }\end{array}$ & $\begin{array}{c}\text { Number of } \\
\text { person trips }\end{array}$ & $\begin{array}{c}\text { Mode } \\
\text { share (\%) }\end{array}$ & $\begin{array}{c}\text { Number of } \\
\text { person trips }\end{array}$ & $\begin{array}{c}\text { Mode } \\
\text { share (\%) }\end{array}$ \\
\hline POV & $50,021,896$ & $1.9 \%$ & $5,798,781$ & $\mathbf{6 . 3 \%}$ & $55,820,678$ & $2.0 \%$ \\
\hline Bus/rail & $240,953,175$ & $\mathbf{9 . 1 \%}$ & $6,056,344$ & $\mathbf{6 . 6 \%}$ & $247,009,520$ & $9.0 \%$ \\
\hline Walk & $2,309,605,195$ & $\mathbf{8 7 . 5 \%}$ & $78,715,778$ & $\mathbf{8 5 . 3 \%}$ & $2,388,320,973$ & $\mathbf{8 7 . 4 \%}$ \\
\hline Others & $39,588,217$ & $1.5 \%$ & $1,672,366$ & $1.8 \%$ & $41,260,583$ & $1.5 \%$ \\
\hline All modes & $2,640,168,483$ & $100.0 \%$ & $92,243,269$ & $100.0 \%$ & $2,732,411,754$ & $100.0 \%$ \\
\hline
\end{tabular}

\subsubsection{Average Trip Rates and Travel Distances by Transit Usage Status}

Analysis of the 2009 NHTS data was performed to see whether differences in terms of trip rates or other travel characteristics existed between New Yorkers who were transit users and those who were not. All trips conducted by NYS residents in 2009 were considered, regardless of mode of transportation utilized on each specific trip.

\subsubsection{Person trip rates}

On average, transit users took more person-trips per person than non-users. As seen in Figure 3-13, transit users in NYMTC took an average of 4.2 trips per person per day, while their nonuser neighbors averaged at 3.4 trips per person per day. Travelers from the Rest of NYS had a slightly higher per person trip rate on a typical travel day in 2009, about 4.4 for transit users and 3.7 for non-users. When the statistical uncertainties (i.e., standard errors of the estimated averages) were taken into consideration, the difference in per person trip rates was not statistically significant between transit users from NYMTC and those from the Rest of NYS (measured at a confidence level of 95\%). The regional difference between non-users (i.e., the average of 3.4 trips for NYMTC versus 3.7 trips for Rest of NYS), however, was statistically significant under the same confidence level (95\%). This is mainly because a much larger NHTS sample size was available for statistics associated with non-users, which resulted in smaller sample variations than those of transit users. 


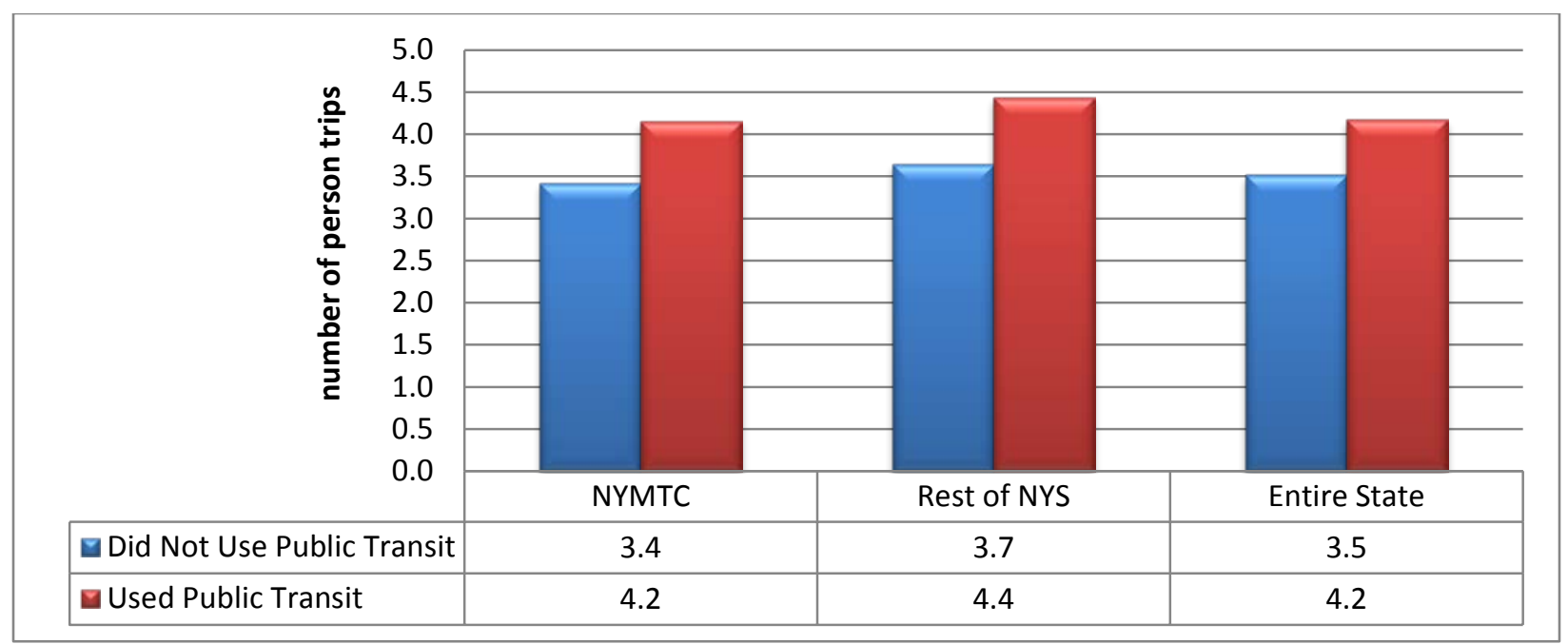

Figure 3-13. Average trip rate per person by transit use status and region, for daily person-trips (2009 NHTS).

\subsubsection{Person-mile-traveled per person}

As a whole, NYS transit users traveled an average of 20 person-miles per person daily, which was statistically different from the daily average of 27 person-miles for non-users in NYS. These average PMT rates by transit-usage status among NYMTC travelers, however, were not statistically different due to relatively high sample variations in the data. Figure 3-14 shows that non-transit users from NYMTC traveled an average of 22 person-miles per person per day in 2009; while transit users from the same region traveled a daily average of nearly 19 person-miles per person. The difference between these two NYMTC averages fell within their margin of errors, thus no significant evidence to suggest any influences due to transit-usage status in this region.

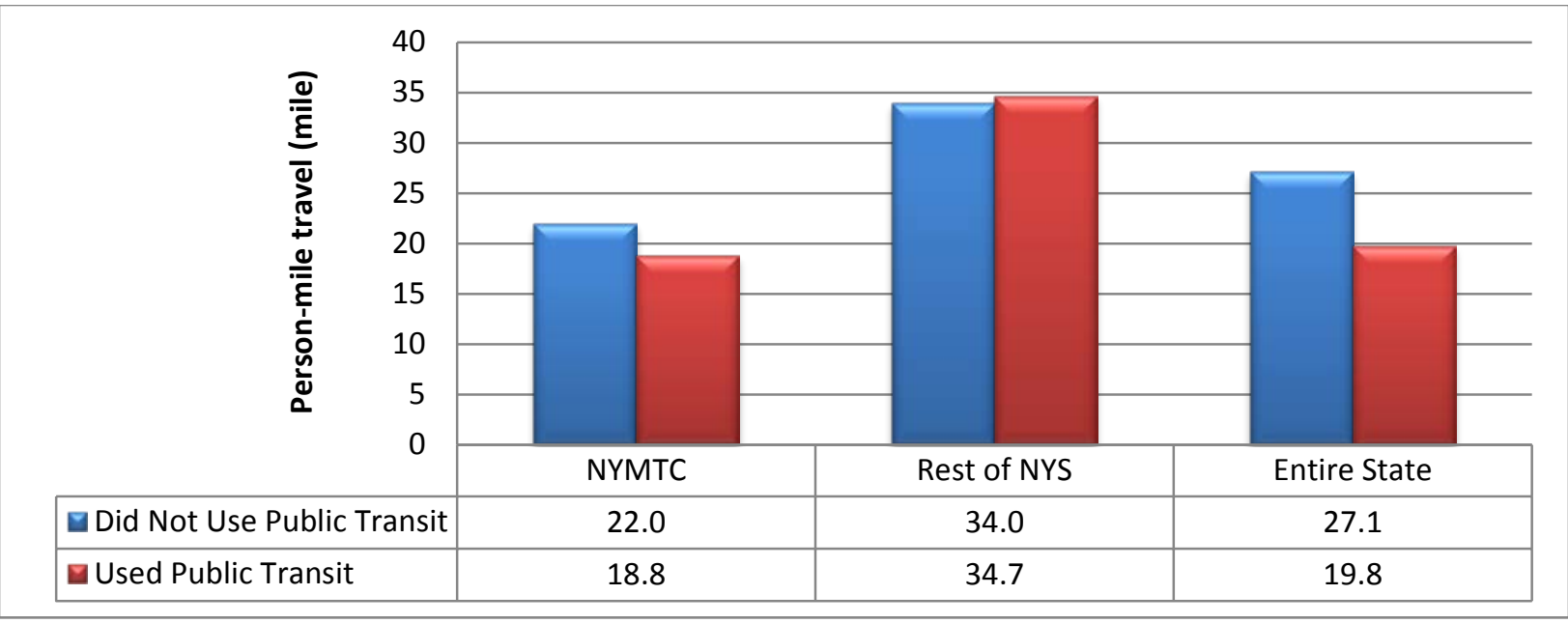

Figure 3-14. Average PMT by transit-use status (2009 NHTS).

(Note: three extreme PMT values eliminated from transit users in Rest of NYS) 
Figure 3-14 shows that the average number of PMT for NYS transit users who lived outside the NYMTC region was about the same as their non-user counterparts. Note that three records with daily PMT exceeding 1,000 miles were eliminated from the calculation of average PMT for transit users that lived in this region (i.e., Rest of NYS). Specifically, transit users who lived outside NYMTC had a daily average of 35 PMT per person (was 44 prior to removal of three outliers), which was not significantly different from the 34 PMT per person daily average for non-users from the same region. In terms of regional differences, regardless of transit usage status, a typical resident of NYMTC traveled significantly fewer daily person-miles on average than one who lived in the rest of the NYS.

\subsubsection{Average person-trip length}

A rough estimate of the average person-trip length can be derived using the averages of PMT and person trips (PT) presented above. For instance, by dividing average PMT by its corresponding average PT, one can obtain a simple estimate of 4.5 miles (calculated from 18.8/4.2 per trip for transit users in NYMTC and 6.4 miles per trip for non-users from the same region. Although this approach is easy, the accuracy of the resulting estimates (i.e., based on an "average over average" calculation) can be a concern. A more accurate estimate of average trip distance should be calculated from individual trips.

Based on the examination of average PT travel length (distance in miles) of the NYS residents, transit users in NYMTC traveled 5.2 miles, on average, for each of its PT; while non-transit users from the same region averaged to 6.7 miles per PT (Figure 3-15). On the other hand, transit users from the Rest of NYS traveled an average of 10.7 miles on a typical travel day in 2009; while non-users from the same region traveled about 9.5 miles per person-trip during the same year. While no differences in average PT distances could be identified between transit users and non-users from either NYMTC or the Rest of NYS, a regional difference in trip lengths was observed. A typical NYMTC traveler made significantly shorter trips on average than that made by travelers from the Rest of NYS, regardless of their transit usage status in 2009.

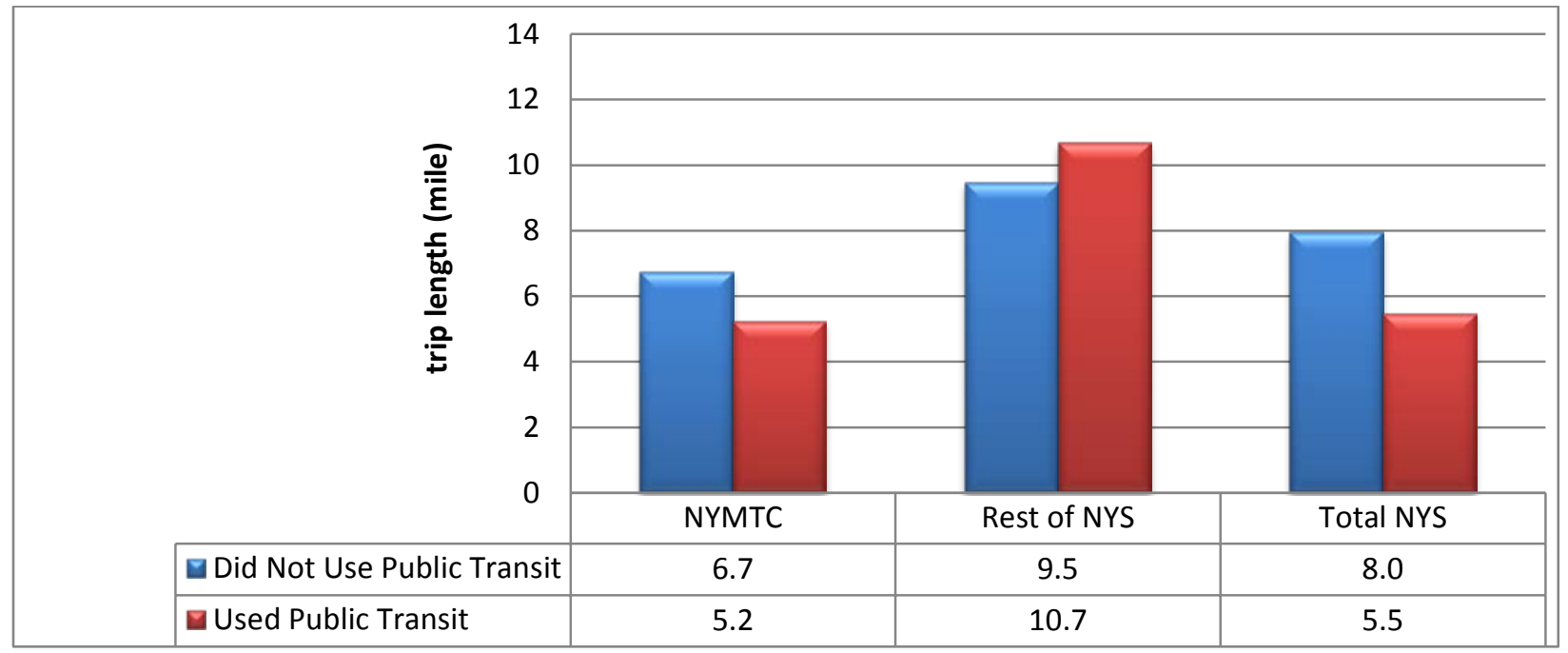

Figure 3-15. Average person-trip length (in miles) by transit use status and region (2009 NHTS). 


\subsubsection{Vehicle trip rates and average vehicle miles traveled per driver}

When restricted to trips made by drivers of POVs only, expectedly, transit users made a significantly fewer number of vehicle-trips per driver (Figure 3-16) than their counterpart nonusers, regardless of where they lived. Overall, non- users made about 3 vehicle-trips per driver in 2009, while transit users in NYMTC only took an average of 0.4 vehicle-trips per driver and those from the Rest of NYS also made less than one vehicle-trip per driver during the same time. In other words, there were no regional differences in vehicle trip (VT) rates among NYS drivers who lived in NYMTC or elsewhere in the state. Transit use status, however, did have an effect on the amount of driving made by NYS drivers.

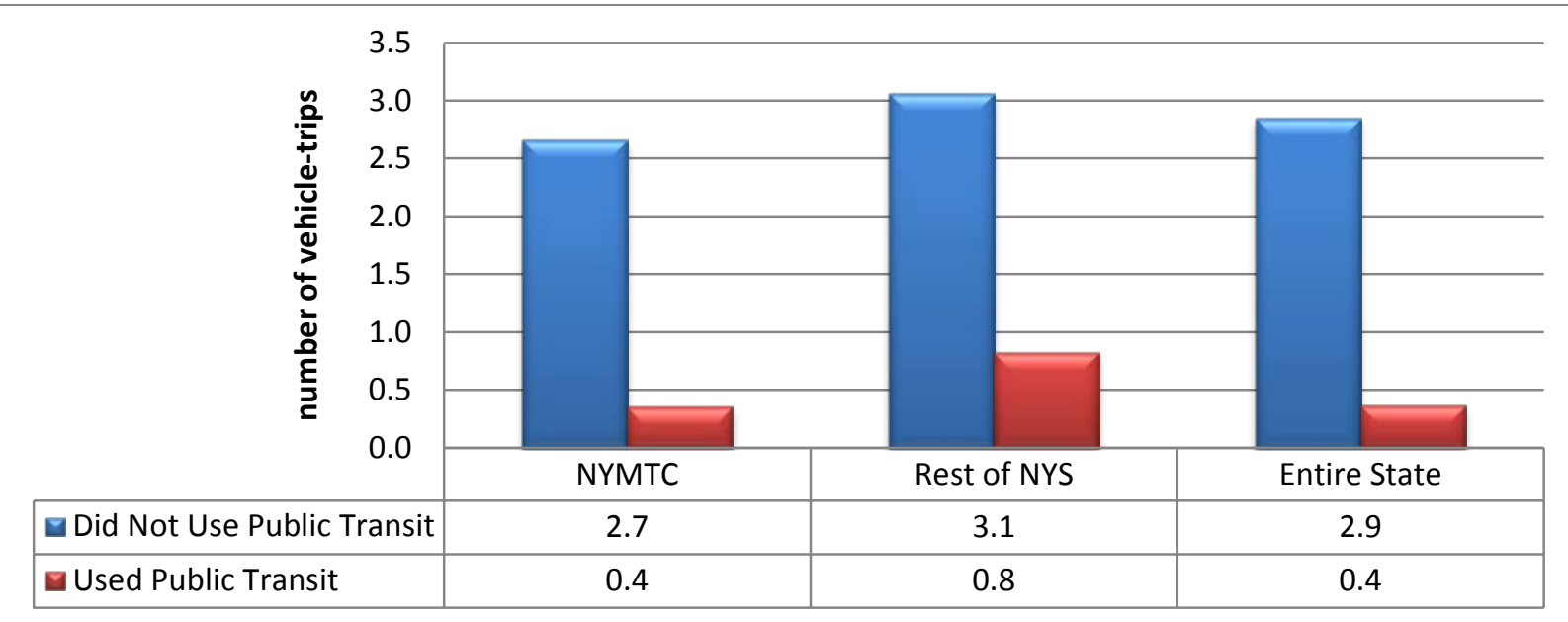

Figure 3-16. Average vehicle-trip rates per driver by transit use status and region (2009 NHTS).

Non-transit users also averaged significantly higher in VMT rates per driver in 2009. As shown in Figure 3-17, NYMTC transit users traveled an average of less than 4 miles by vehicle per driver while non-users from the same region drove a significantly longer average distance of 20 miles by vehicle per driver in the same year. Elsewhere in NYS, transit users drove an average 12.2 miles per driver and their non-user counterparts made more than twice that, over 28 miles on average by vehicle per driver in 2009.

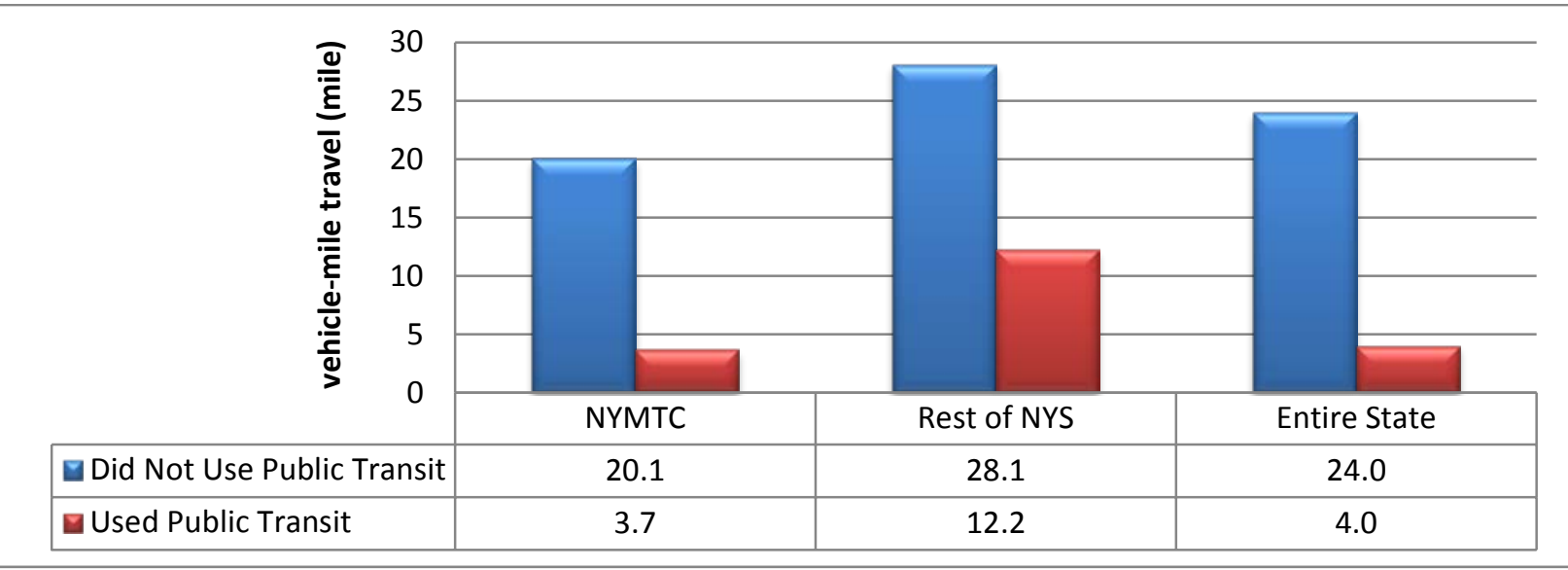

Figure 3-17. Average VMT per driver by transit use status by region (2009 NHTS). 


\subsubsection{Average vehicle-trip length}

Regarding average vehicle-trip length on trips made by NYS residents (measured in miles), Figure 3-18 shows that a typical transit user in NYMTC traveled an average of 11 miles per VT while a counterpart non-transit user traveled less than 8 miles per VT. Transit users from elsewhere in the NYS traveled 15 miles per VT on average and their non-user counterparts averaged only about 9 miles per VT. Because sample variations associated with trip-lengths were relatively large among transit users, differences in the average trip-lengths, between transit users and non-users (in both NYMTC and Rest of NYS), were not statistically significant, however.

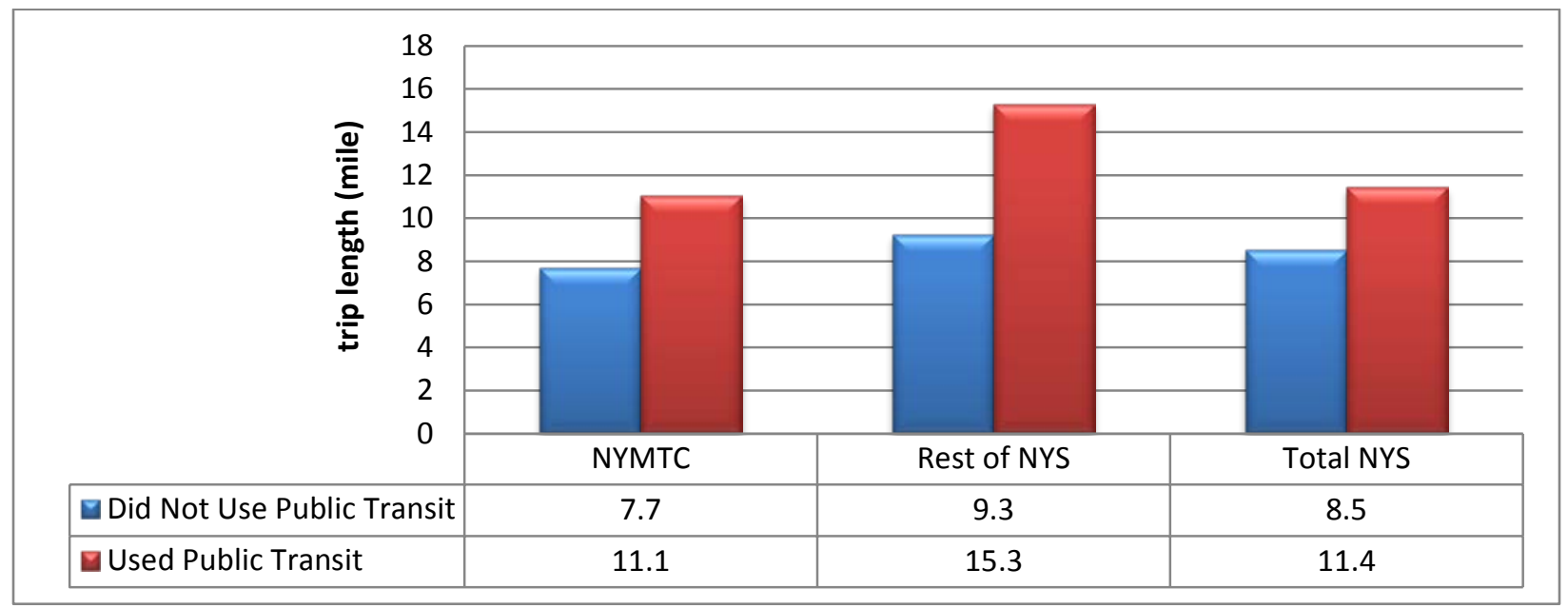

Figure 3-18. Average vehicle-trip length by transit use status and region (2009 NHTS).

\subsubsection{Average travel time per person-trip}

In terms of average per person-trip travel time (measured in minutes), transit users typically spent more time on their trips. Figure 3-19 shows transit users in NYMTC spent over $75 \%$ more time per person-trip on average than non-users from the same regions in 2009, and averaged about 35 minutes each trip for transit users, versus less than 20 minutes per trip for non-transit users. Similarly, a transit user from the Rest of NYS would take about 31 minutes to finish a trip in 2009, while his/her non-user counterpart spent only about 18 minutes on a trip-about $72 \%$ shorter in time. 


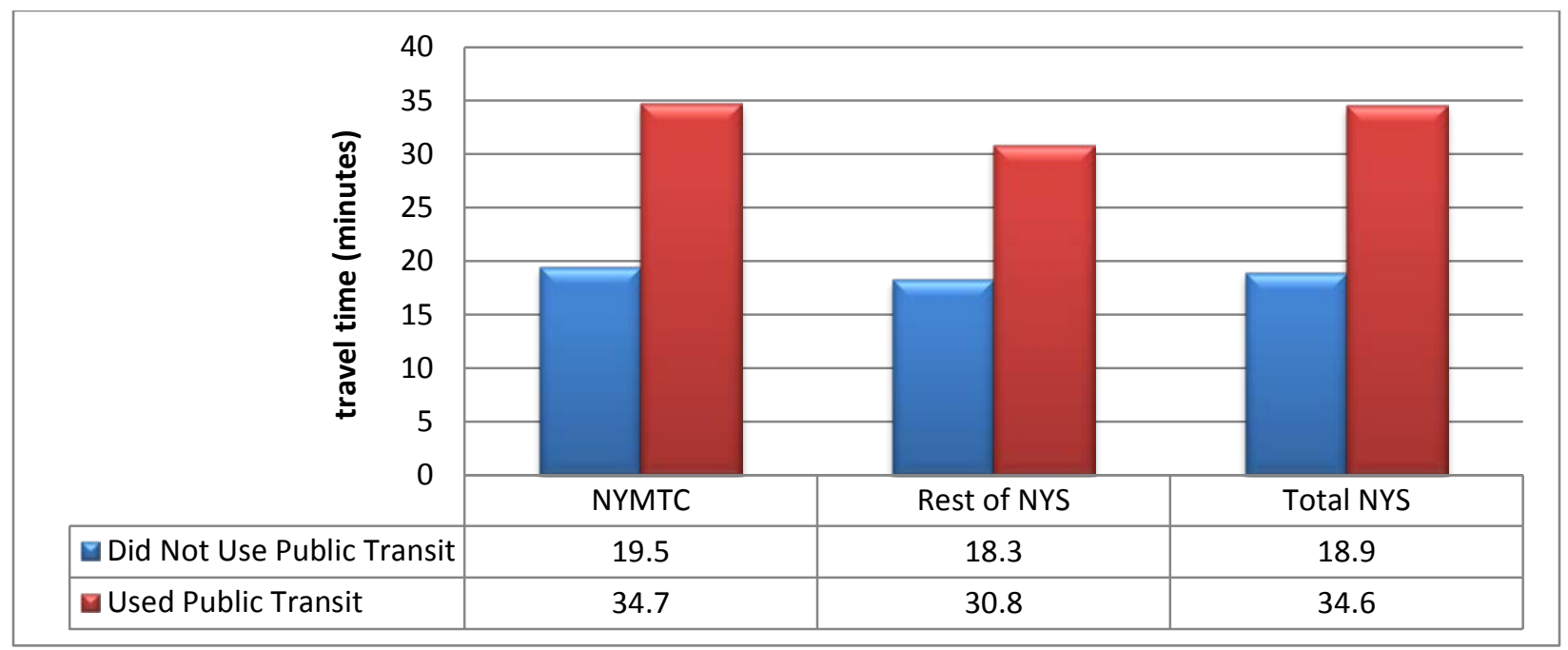

Figure 3-19. Average travel time per person-trip (in minutes) by transit use status (2009 NHTS).

The 2009 NHTS data indicated geographic regions had no significant effects on the average person-trip travel time. Transit usage, however, did show significant impacts to the average per person-trip travel time in each region.

\subsection{TRANSIT USAGE DURING PAST MONTH}

In addition to transit usage on the assigned travel day, NHTS also asked survey respondents to answer how often they used public transit in the past month. The intent of this question was to gather general traveler information from those who might be less frequent (i.e., non-regular) transit riders, as well as to capture transit usage by frequent transit users that happened to use different modes on their assigned travel days (e.g., transit commuters with assigned travel days on weekends). No specific details on trip characteristics were collected from these trips, however.

\subsubsection{Overview of Transit Usage in Past Month}

Using NHTS survey responses from the use of transit on travel day and in the past month, a cross-tabulation comparison of transit usage was summarized, by region, and presented in Table 3-3. As discussed in Section 3.1, about 27\% of NYMTC residents rode transit on their assigned travel days in 2009 while only about $2 \%$ from the Rest of NYS were transit users. These statistics are shown in the rightmost column of the table. Overall transit usage "in past month" is provided in the row titled "All population" within each region in Table 3-3; 56\% of residents in NYMTC used transit at least once during past month while $12 \%$ of those who lived in Rest of NYS did so in past month. That is, in addition to the $27 \%$ "travel day" transit users that lived in NYMTC, 33\% of NYMTC population had also used transit in varying degrees during 2009. Similarly, besides the $2 \%$ transit riders that lived outside NYMTC, another $10 \%$ of that region's population had also used transit for some of their travel in 2009. 
Table 3-3. Comparison of Transit Use between Travel Day and Past Month (2009 NHTS)

\begin{tabular}{|c|r|r|r|r|r|r|}
\hline \multirow{2}{*}{$\begin{array}{c}\text { Status on Use of } \\
\text { Public Transit on } \\
\text { Travel Day }\end{array}$} & \multicolumn{2}{|c|}{$\begin{array}{c}\text { Public Transit-Use Status in Past Month } \\
\text { Did Not Use Public } \\
\text { Transit }\end{array}$} & $\begin{array}{c}\text { Used Public } \\
\text { Transit }\end{array}$ & \multicolumn{2}{c|}{ Total } \\
\cline { 2 - 6 } & $\begin{array}{c}\text { Number } \\
\text { of Person }\end{array}$ & $\begin{array}{c}\text { Percent } \\
\text { of total }\end{array}$ & $\begin{array}{c}\text { Number } \\
\text { of Person }\end{array}$ & $\begin{array}{c}\text { Percent } \\
\text { of total }\end{array}$ & $\begin{array}{c}\text { Number } \\
\text { of Person }\end{array}$ & $\begin{array}{r}\text { Percent } \\
\text { of Total }\end{array}$ \\
\hline \multicolumn{7}{|c|}{ NYMTC } \\
\hline Did Not Use Public Transit & $4,669,396$ & $40 \%$ & $3,866,661$ & $33 \%$ & $8,536,057$ & $73 \%$ \\
\hline Used Public Transit & 495,173 & $4 \%$ & $2,720,322$ & $23 \%$ & $3,215,495$ & $27 \%$ \\
\hline All population & $5,164,568$ & $44 \%$ & $6,586,983$ & $56 \%$ & $11,751,552$ & $100 \%$ \\
\hline \multicolumn{7}{|c|}{ Rest of NYS } \\
\hline Did Not Use Public Transit & $5,749,816$ & $88 \%$ & 649,676 & $10 \%$ & $6,399,492$ & $98 \%$ \\
\hline Used Public Transit & 16,446 & $0 \%$ & 114,312 & $2 \%$ & 130,758 & $2 \%$ \\
\hline All population & $5,766,262$ & $88 \%$ & 763,988 & $\mathbf{1 2 \%}$ & $6,530,250$ & $100 \%$ \\
\hline
\end{tabular}

Based on Table 3-3, one can derive that nearly half of those who lived in NYMTC and indicated non-transit use on their assigned travel day reported using transit in past month (3.9 million persons out of the total 8.5 million persons-first row under NYMTC-about 45\% (resulted from dividing 33\% by73\%)). On the other hand, only about 15\% of NYMTC residents (dividing 10\% by $98 \%)$ who used transit on their travel day said that they did not use transit in past month $(0.5$ million persons out of the total 3.2 million persons - second row under NYMTC). Since transituse was not common outside NYMTC, only about $10 \%$ of those who responded as non-users on travel days had used transit at least once during past month (0.6 million persons out of total 6.4 million persons - first row under Rest of NYS). On the other hand, about $12 \%$ of those lived outside NYMTC who indicated transit use on their assigned travel day did not use transit for any travel activities during past month (16 thousand persons out of the 130 thousand persons second row under Rest of NYS).

Examining transit usage on these "past month" transit users further, Table 3-4 shows the breakdown of NYMTC and Rest of NYS residents who said they used transit during past month, categorized by their frequencies of transit usage. The categories used in Table 3-4 assumed a 30day month for the length of a "past month" and the "week" includes all seven days (both weekday and weekend). The "transit use frequency" category was determined based on surveyreported number of times transit was used in the past month. Specifically, the definition of each transit use category is given in Table 3-5.

Table 3-4. Number of Transit Users by Average Frequency of Use during Past Month (Persons with at least one transit trip in past month)

\begin{tabular}{crrrrr}
\hline $\begin{array}{c}\text { Frequency of } \\
\text { transit use }\end{array}$ & \multicolumn{2}{c}{ NYMTC } & \multicolumn{2}{c}{ Rest of NYS } & \multicolumn{1}{l}{ Rest of US } \\
\hline$<=1$ per week & $1,761,048$ & $26.7 \%$ & 400,955 & $52.5 \%$ & $17,046,374$ \\
$1-2$ per week & 706,287 & $10.7 \%$ & 115,744 & $15.1 \%$ & $4,365,642$ \\
2 -5 per week & $1,520,536$ & $23.1 \%$ & 153,254 & $20.1 \%$ & $6,538,435$ \\
$<=1$ per day & $1,167,192$ & $17.7 \%$ & 39,020 & $5.1 \%$ & $2,515,235$ \\
1-2 per day & $1,164,948$ & $17.7 \%$ & 38,909 & $5.1 \%$ & $2,320,469$ \\
Over 2 per day & 266,972 & $4.1 \%$ & 16,107 & $2.1 \%$ & 688,382 \\
All users & $\mathbf{6 , 5 8 6 , 9 8 3}$ & $\mathbf{1 0 0 \%}$ & $\mathbf{7 6 3 , 9 8 9}$ & $\mathbf{1 0 0 \%}$ & $\mathbf{3 3 , 4 7 4 , 5 3 7}$ \\
\hline
\end{tabular}


Table 3-5. Definition of Categories for Transit Use in Past Month

\begin{tabular}{cc}
\hline Use category & $\begin{array}{c}\text { Number of times transit was used in } \\
\text { past month }\end{array}$ \\
\hline$<=1$ per week & 4 or less \\
$1-2$ per week & Over 4, up to 9 \\
$2-5$ per week & Over 9 , up to 21 \\
$<=1$ per day & Over 21, up to 30 \\
$1-2$ per day & Over 30, up to 60 \\
Over 2 per day & Over 60 \\
\hline
\end{tabular}

Over half of the past-month transit users who lived in the Rest of NYS region rode transit no more than once a week on average over the past month. Only about $12 \%$ of past-month transit users from this area used transit in a more frequent manner, possibly on a regular daily basis. On the other hand, about a quarter of past-month transit users from the NYMTC area could be considered as occasional transit riders (with less than once per week), while nearly $40 \%$ of them used transit more than 5 times per week, on average over the past month (i.e., took transit more than 21 times in the past 30 days). One could expect that part of these past-month frequent transit users might be transit commuters that NHTS failed to capture due to an assigned "nonwork" travel day. The distribution of past-month transit use frequency by region (measured by percent of persons that used transit in past month) is presented in Figure 3-20. The patterns for Rest of NYS and Rest of U.S. were similar in most cases.

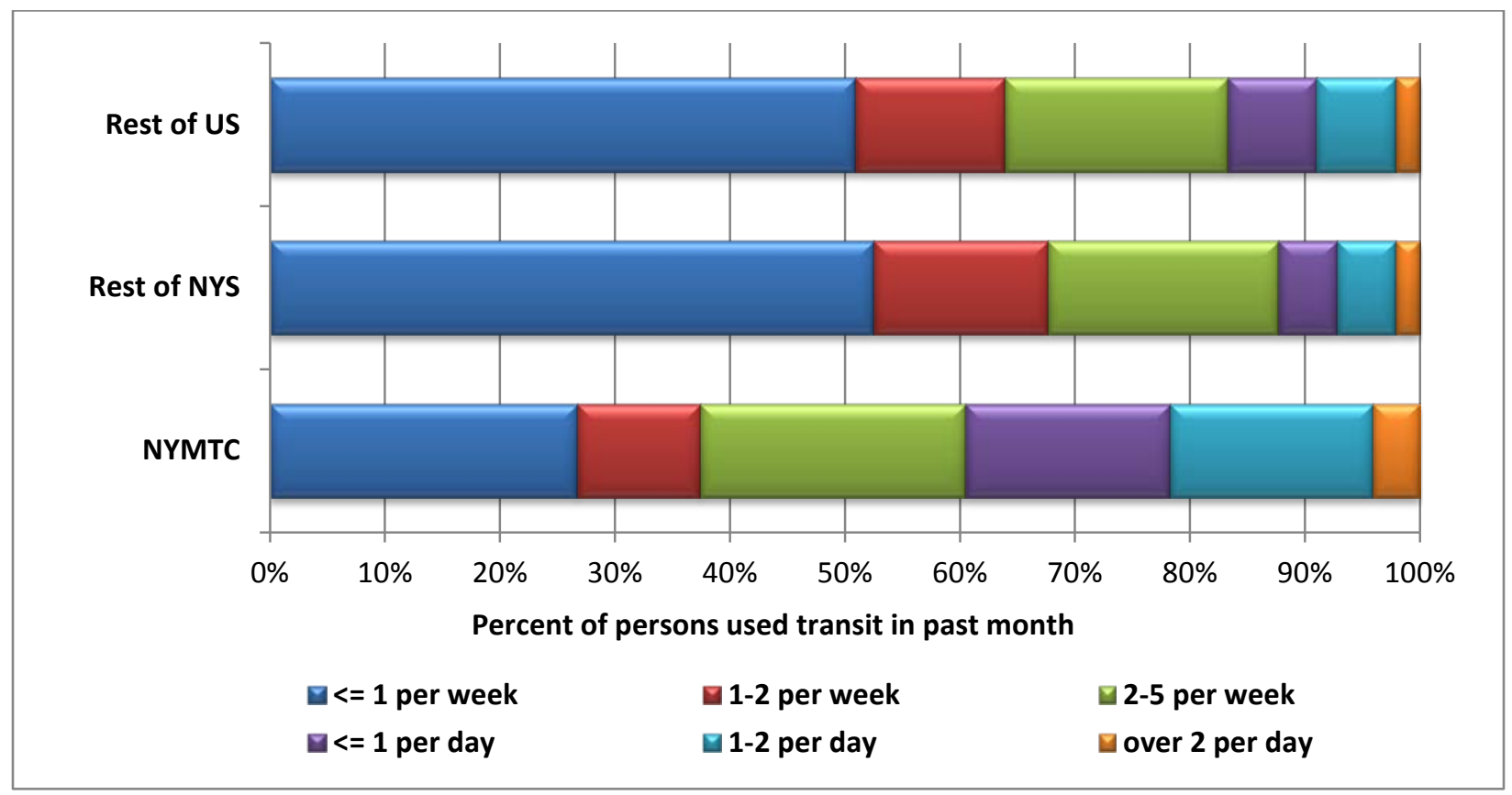

Figure 3-20. Distribution of “past month" transit users by transit use and region.

\subsubsection{Impacts of Household Size on Transit Use in Past Month}

As mentioned above, transit use in past month captured not only those who traveled regularly via transit (daily transit users) but also occasional transit users, as well as travelers that used transit only on specific days (e.g., weekday only). Therefore, it was not surprising to see that all 
percentages associated with past month transit use were significantly higher than transit usage based on travel days.

Similar to daily transit users (Section 3.1.1), people from single-person households had a higher likelihood of using transit, at least once during the month prior to their assigned travel day, than their multiple-person household travelers. This is true among residents in both regions (NYMTC and the Rest of NYS). Nearly 70\% of NYMTC residents from single-person households used transit during the month leading their assigned travel day, while about 50-60\% of those from multiple-person households in the region did so. The differences between single-person households and multiple-person households (see Figure 3-21) were somewhat smaller than that among daily transit users (Figure 3-3), however. Regional differences, between NYMTC and Rest of NYS were evident for all household sizes.

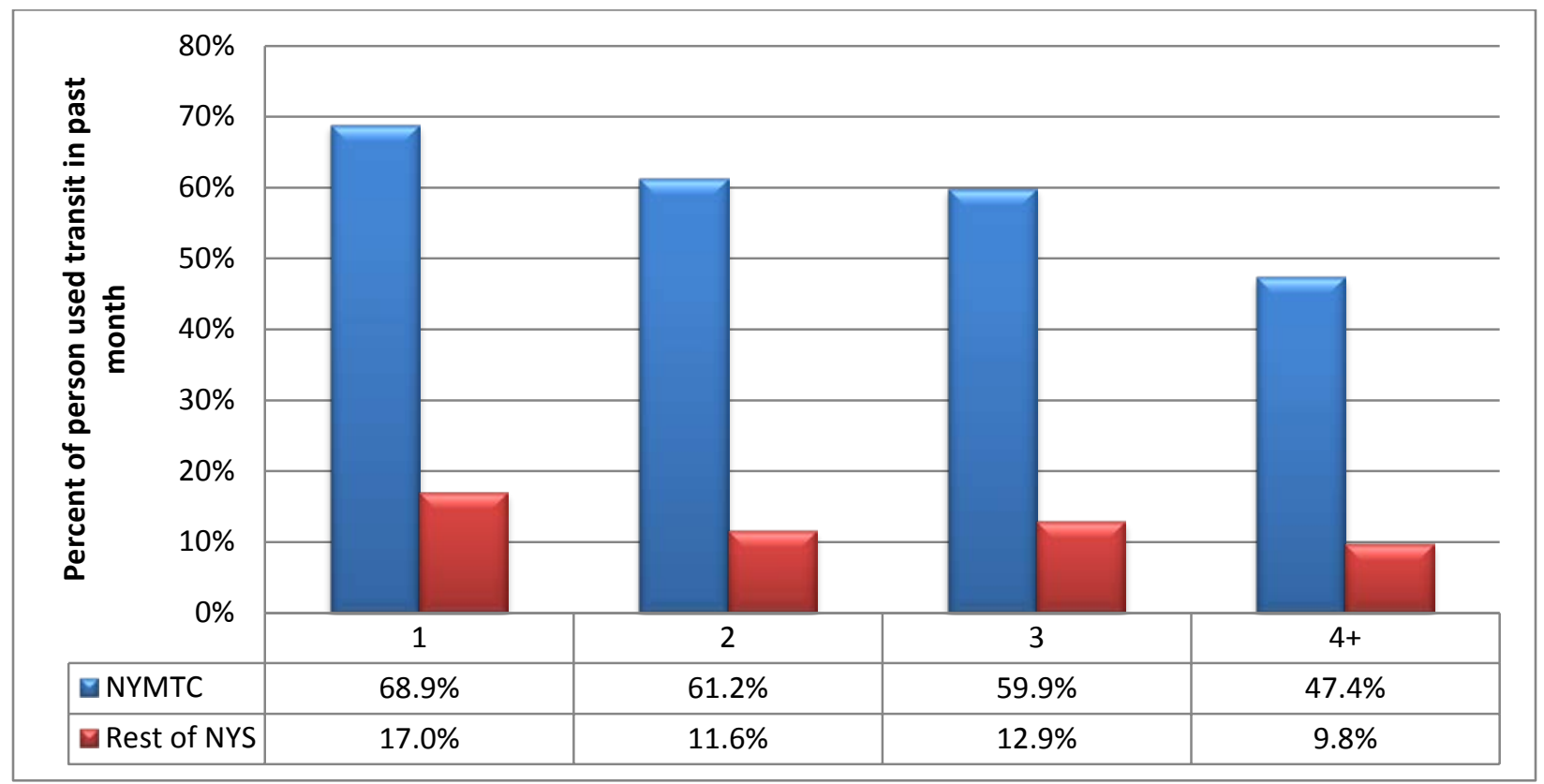

Figure 3-21. Percent of persons that used transit in past month by household size (2009 NHTS).

\subsubsection{Influences from Vehicle Ownership on Transit Use in Past Month}

As for the daily transit users (Figure 3-4), Figure 3-22 shows that NYMTC residents from zerovehicle households had a significantly higher likelihood of transit use during the past month than their neighbors that owned vehicles. This higher share of "past month" transit usage among zero-vehicle households was actually more visible among people who lived in the Rest of NYS - 44\% of transit use among households without vehicles versus roughly $10 \%$ for those who owned for or more vehicles. 


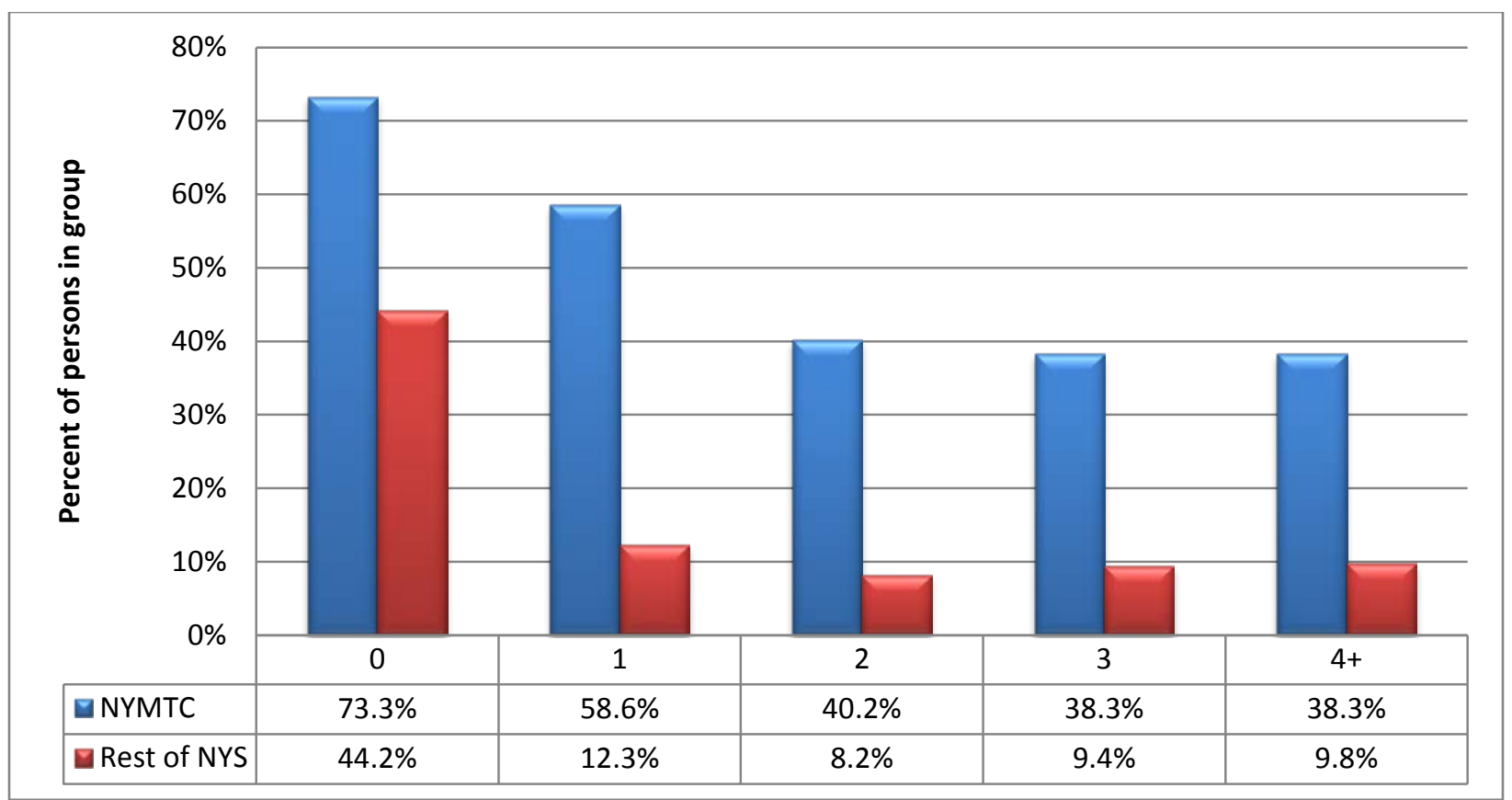

Figure 3-22. Percent of persons used transit in past month by household vehicle ownership.

Looking at the distribution of vehicle ownership by transit use status during the past month period, Figure 3-23 reveals that about $40 \%$ of past-month transit users from NYMTC households did not own any vehicles in 2009; while only about $20 \%$ of their non-user neighbors came from zero-vehicle households. Unlike Figure 3-5, which shows a significant share of zero-households among travel-day transit users who lived in the Rest of NYS, distribution of vehicle ownership in past-month transit users from the Rest of NYS region was quite similar to the one for past-month non-users from NYMTC. Nonetheless, nearly all persons that lived outside NYMTC who did not use transit during the past month came from households that owned vehicles; less than 4\% were from zero-vehicle households. This pattern was consistent with non-users from the Rest of NYS in Figure 3-5. 


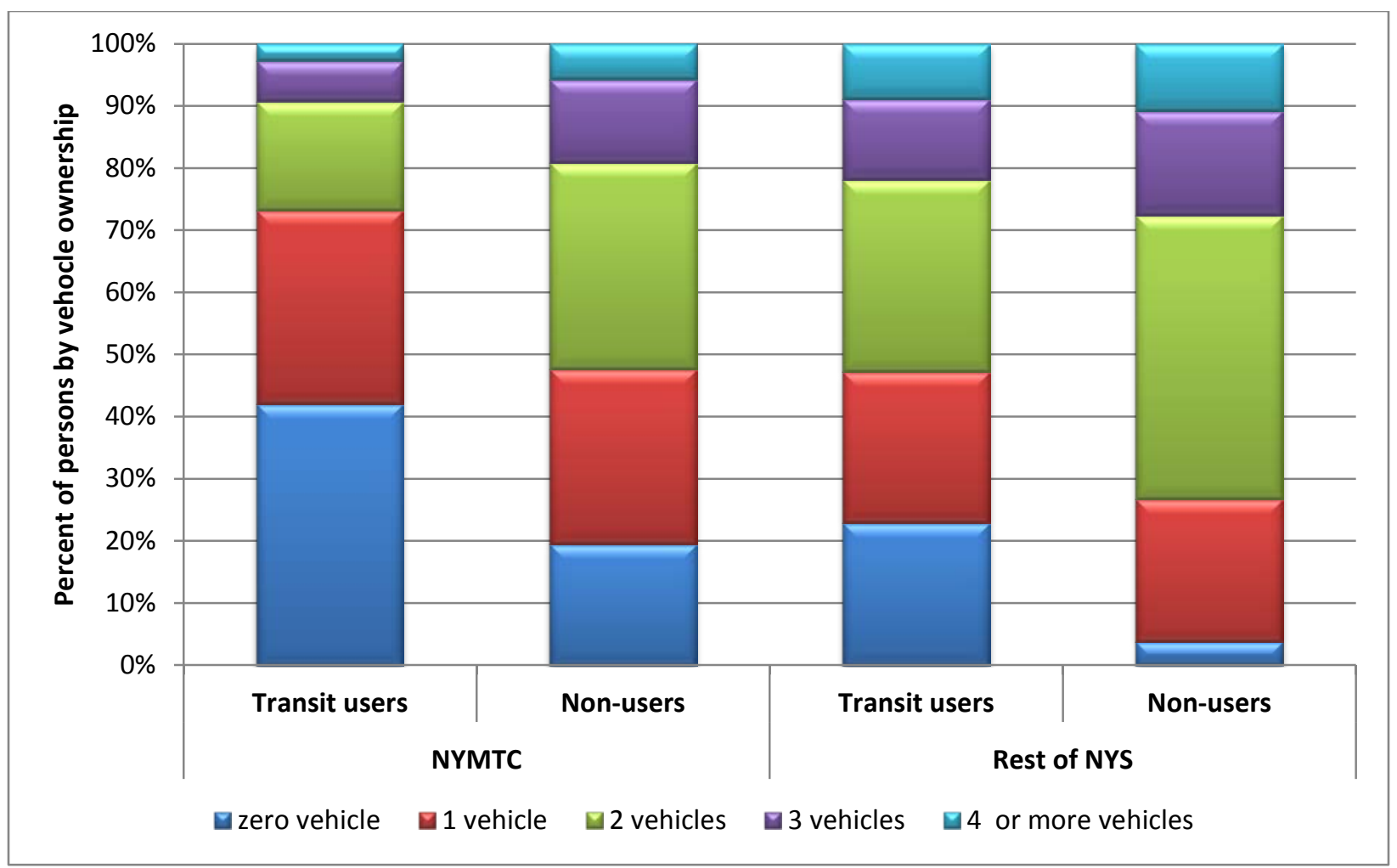

Figure 3-23. Distribution of vehicle ownership by past month transit use status by region.

\subsubsection{Difference in Past Month Transit Use by Age}

Unlike questions associated with transit use on travel-day, information on "transit usage in the past month" was only gathered from persons age 15 years and older in the households. Similar to the pattern shown in Figure 3-6for transit usage by age on the travel day, Figure 3-24 also revealed a declining trend in transit usage as NYS residents aged except for the oldest group in NYMTC. Although only about 15\% of NYMTC elderly residents (person age 65 years and older) took transit on their assigned travel day, Figure 3-25 specified that nearly half of these elderly has used transit at least once within a month prior to the assigned travel day. For residents living outside NYMTC, the share of past-month elderly transit users rose to 7\%, from the share of 1\% based on transit-day transit usage. Expectedly, higher shares of younger New Yorkers used transit to conduct their daily activities as well as for travel made during the past month than their counterpart elderly NYS residents. 


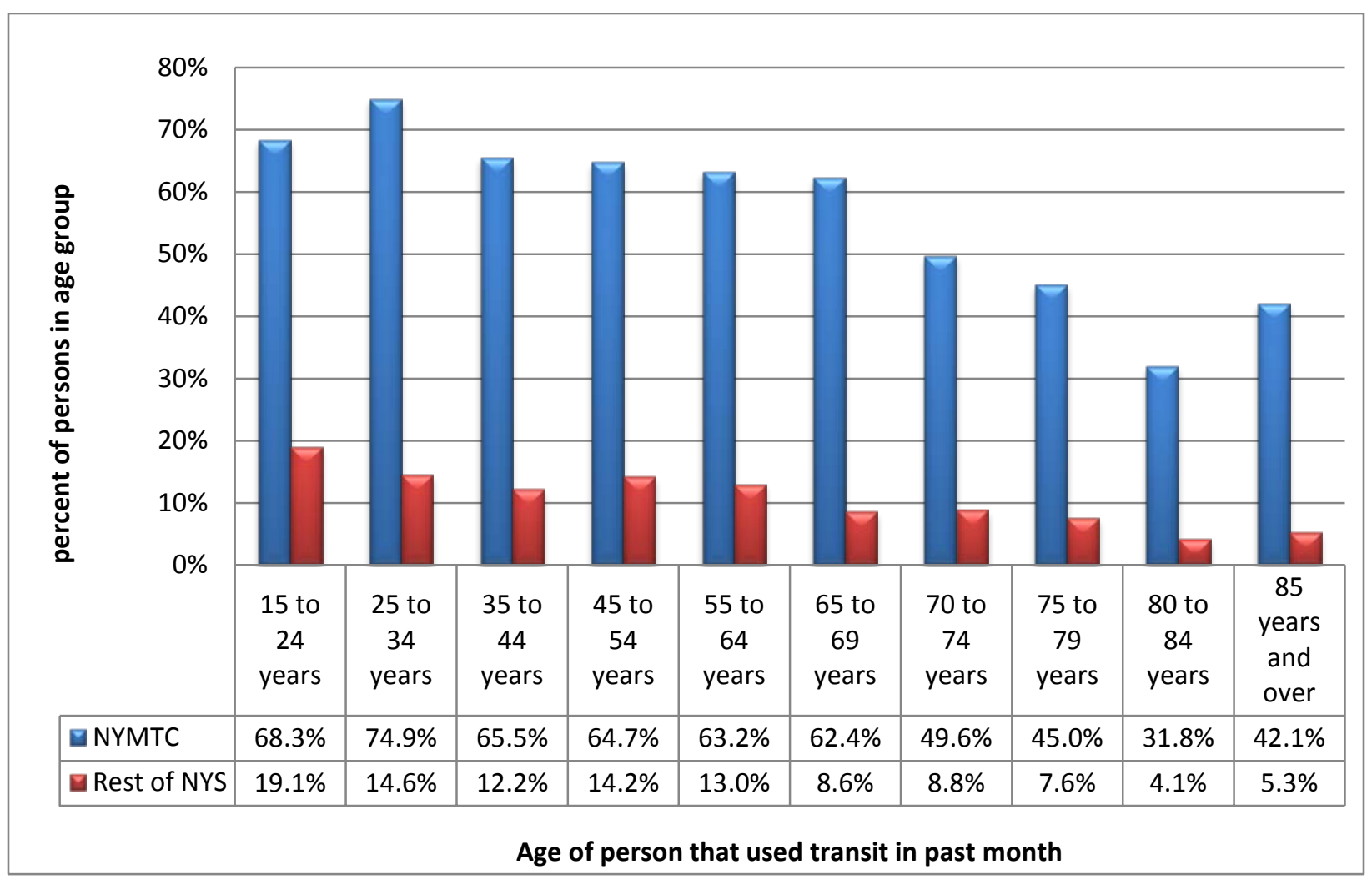

Figure 3-24. Share of persons that used transit in past month by age group (2009 NHTS).

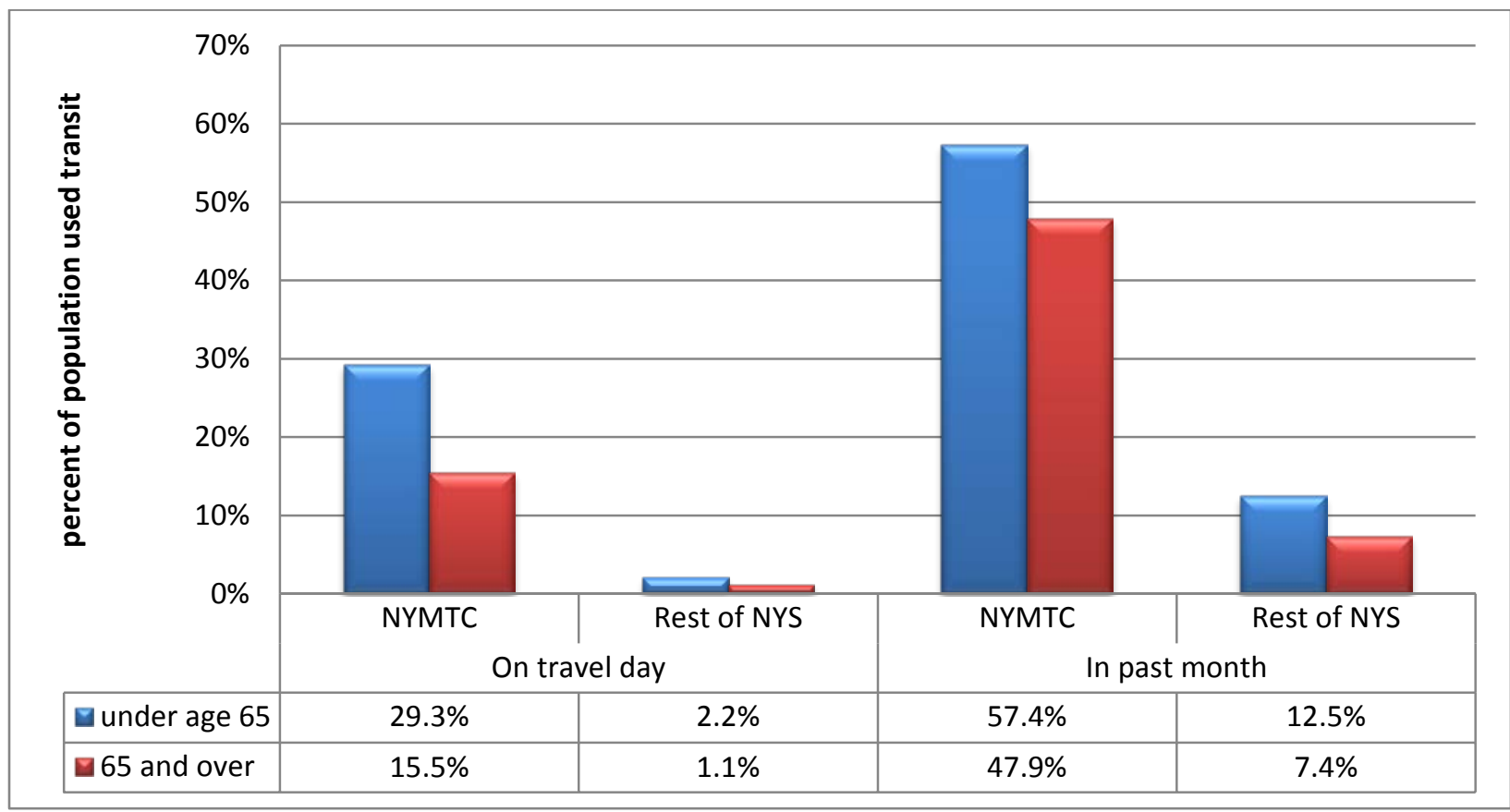

Figure 3-25. Share of transit users on travel day versus past month (2009 NHTS). 


\subsubsection{Past Month Transit Use by Household Income Group}

When examining past-month transit usage among NYMTC residents, Figure 3-26 reveals that the overall household income level of these transit users did not pose a significant influence to transit use shares for these residents. Outside NYMTC, residents from the very-low income group (under $\$ 20,000$ ), however, were about twice as likely to use transit in the past month when compared to people from other income groups.

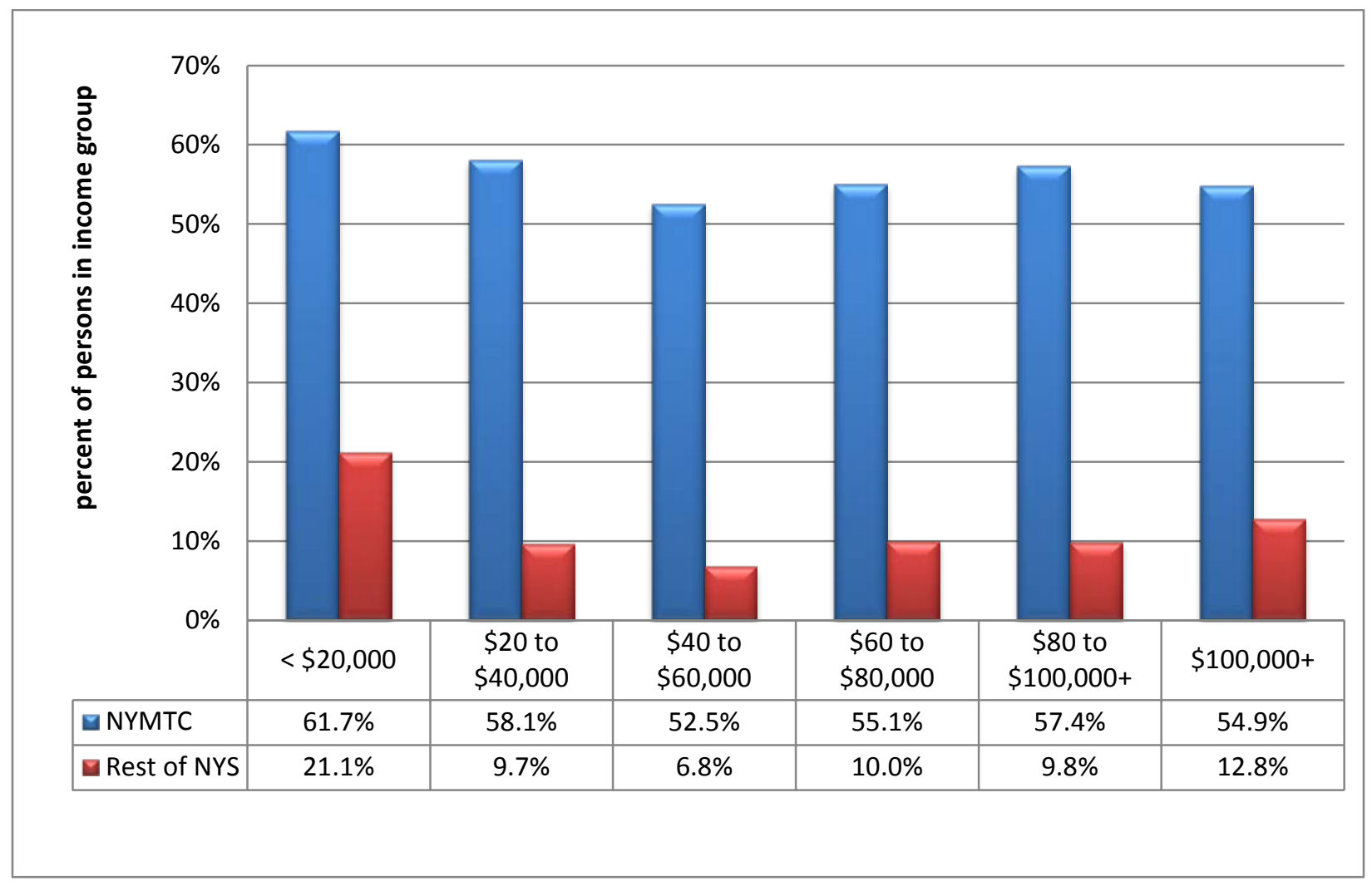

Figure 3-26. Share of past-month transit users by household income group (2009 NHTS).

Among transit-users who made at least one transit trip during the past month, their income distributions were displayed in Figure 3-27. For ease of reference, income distributions based on general populations (i.e., all residents regardless of transit usage) in their corresponding regions are also presented in the same figure. As in the case of daily transit users (Figure 3-9), income distributions for past-month transit users were nearly identical for the two regions (NYMTC and Rest of NYS). In other words, there did not appear to have a regional impact on income distributions of these transit users. When comparing income distributions from all residents in the NYMTC region, it was evident that 26\% of past-month transit users in NYMTC came from the highest income group ( $\$ 100,000$ or more) households; in fact, this income group accounted for less than $19 \%$ of the whole NYMTC population. Similarly, Figure 3-27 shows that over 25\% of past-month transit users from the Rest of NYS belong to households with the highest income group; while this income group represented only about $21 \%$ of all households in the region. That is, regardless of regional differences, high-income NYS residents were more likely to use transit within a month in 2009 than NYMTC residents were. 


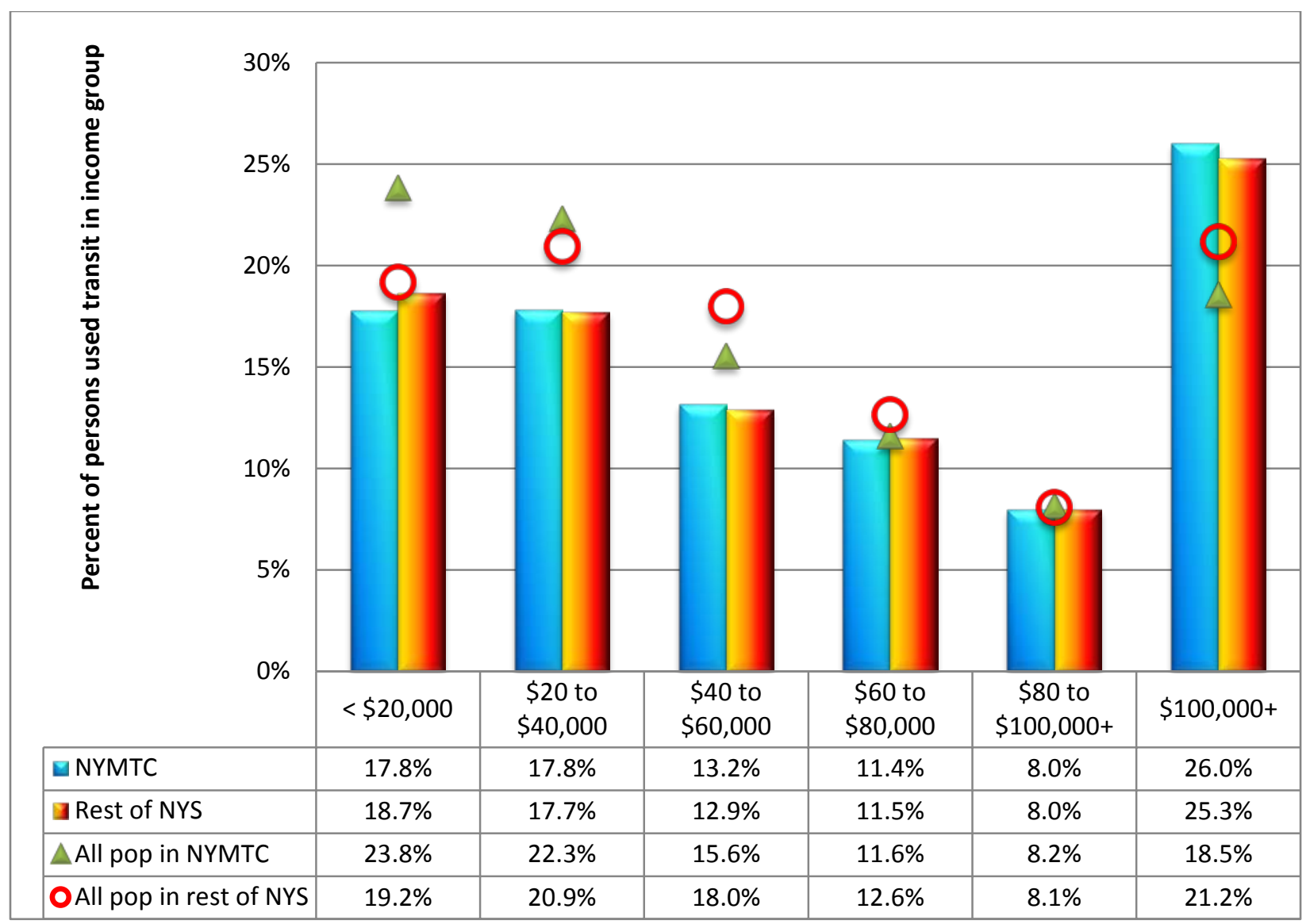

Figure 3-27. Distribution of household income for past-month transit users and general populations by region (2009 NHTS).

\subsubsection{Relationship between Past Month Transit Usage and Trip Purpose}

With the exception of travel for school or church purpose, past-month transit users who lived in NYMTC conducted over 60\% of the region's total person-trips made for all purposes in 2009 (see Table 3-6). As shown in Table 3-6, the share of person-trips made by NYMTC past-month transit users for "school/church" purpose was significantly smaller at 38\% and the Rest of NYS share was even smaller at $9 \%$.

Table 3-6. Share of Person-Trips Taken by Past-Month Transit Users by Trip Purpose by Region (2009 NHTS)

\begin{tabular}{cccc}
\hline Trip Purpose & NYMTC & Rest of NYS & Total NYS \\
\hline Earning a living & $69 \%$ & $12 \%$ & $47 \%$ \\
Family \& personal business & $60 \%$ & $12 \%$ & $43 \%$ \\
School/ church & $38 \%$ & $9 \%$ & $28 \%$ \\
Social \& recreational & $58 \%$ & $13 \%$ & $42 \%$ \\
Other/ unknown & $69 \%$ & $19 \%$ & $55 \%$ \\
\hline All purposes & $59 \%$ & $14 \%$ & $47 \%$ \\
\hline
\end{tabular}


The distributions of person-trips by purpose for past-month transit users and non-users who lived in NYMTC and the Rest of NYS are presented in Figure 3-28 and Figure 3-29, respectively. The difference between shares of person trips made by NYMTC past-month transit users and those of non-users for the purpose of school/church activities is clearly illustrated in Figure 3-28.

\begin{tabular}{|c|c|c|c|}
\hline \multicolumn{4}{|c|}{$100 \%$} \\
\hline \multirow{10}{*}{ 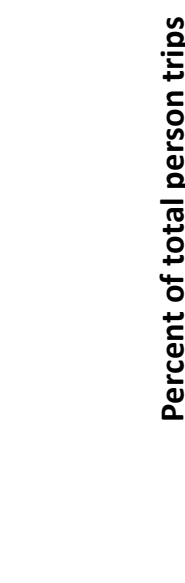 } & $90 \%$ & & \\
\hline & $80 \%$ & & \\
\hline & $70 \%$ & & \\
\hline & $60 \%$ & & \\
\hline & $50 \%$ & & \\
\hline & $40 \%$ & & \\
\hline & $30 \%$ & & \\
\hline & $20 \%$ & & \\
\hline & $10 \%$ & & \\
\hline & $0 \%$ & Did Not Use Public Transit & Used Public Transit \\
\hline Unreporte & & $51,353,292$ & $94,784,089$ \\
\hline O Other & & $61,342,622$ & $154,453,289$ \\
\hline Social and & onal & $1,732,407,191$ & $2,421,016,850$ \\
\hline$\square$ School/Ch & & $938,936,394$ & $563,576,906$ \\
\hline Family \& F & Business & $2,716,500,327$ & $4,084,454,803$ \\
\hline Darning a & & $844,901,516$ & $1,875,935,869$ \\
\hline
\end{tabular}

Figure 3-28. Distribution of NYMTC person trips by trip purpose and past-month transit use status (2009 NHTS).

While only about $6 \%$ of all person trips made by NYMTC transit users were for school/church related travels, the same type of trips accounted for about $15 \%$ of person-trips taken by non-users from the same region. This pattern was not as visible in Figure 3-11 where daily transit users from NYMTC were considered. Similar to travel-day trips, although at a lesser degree of difference, past-month transit users from NYMTC took a higher percent of person-trips for commuting than those of non-users from the same region.

For persons living in the Rest of NYS, as shown in Figure 3-29, past-month transit use status had very little influence on the distributions of person trips by travel purpose. This pattern was nearly identical to the results presented in Figure 3-12, showing the distribution of person trips by transit usage on the travel day. 


\begin{tabular}{|c|c|c|c|}
\hline \multicolumn{4}{|c|}{$100 \%$} \\
\hline \multirow{10}{*}{ 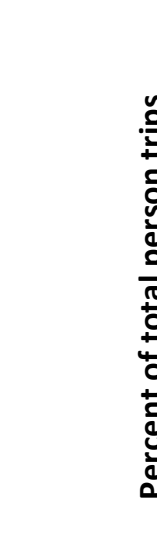 } & $90 \%$ & & \\
\hline & $80 \%$ & & \\
\hline & $70 \%$ & & \\
\hline & $60 \%$ & & \\
\hline & $50 \%$ & & \\
\hline & $40 \%$ & & \\
\hline & $30 \%$ & & \\
\hline & $20 \%$ & & \\
\hline & $10 \%$ & & \\
\hline & U\% & Did Not Use Public Transit & Used Public Transit \\
\hline Unrepor & & $69,918,514$ & $11,470,959$ \\
\hline DOther & & $39,769,644$ & $13,509,901$ \\
\hline Social ar & onal & $2,073,716,722$ & $315,764,797$ \\
\hline$\square$ School/C & & $723,422,396$ & $73,731,721$ \\
\hline Family 8 & Business & $3,237,341,866$ & $455,362,642$ \\
\hline Earning & & $1,516,954,037$ & $210,254,130$ \\
\hline
\end{tabular}

Figure 3-29. Distribution for Rest of NYS resident person-trips by trip purpose and transit use in past month (2009 NHTS).

\subsubsection{Average Trip Rates and Travel Lengths by Past-Month Transit Use Status}

This section summarizes results from analysis on the 2009 NHTS data to see whether past-month transit usage posed any influence on trip rates and travel distance/duration for NYS residents. Geographic differences between NYMTC and the Rest of NYS were also reviewed in this analysis. Statistics presented include average trip rate (person-trip per person and VT per driver), average travel distance (in miles), average trip duration (in minutes), and other parameters.

\subsubsection{Person trip rates by transit usage in past month}

Figure 3-30 shows that, on average, past-month transit users from NYMTC and the Rest of NYS traveled at the same trip frequency, making nearly four person-trips per day. The geographic difference between non-users in the two regions was statistically significant with average persontrip rate of 3.4 for NYMTC versus 3.6 in regions outside NYMTC (both estimates had a very small margin of error). Non-users in NYMTC also made statistically fewer numbers of trips on average (3.4 trips) than the Rest of NYS transit users who took at least one transit trip during past month (3.8 trips). On the other hand, past-month transit usage did not present significant impacts on average person-trip rates for residents that lived in the Rest of NYS. Specifically, the average trip rate of 3.9 for past-month transit users who lived in the Rest of NYS area was not statistically significant (at 95\% confidence level) from the average rate of 3.6 for non-users from the same region. 


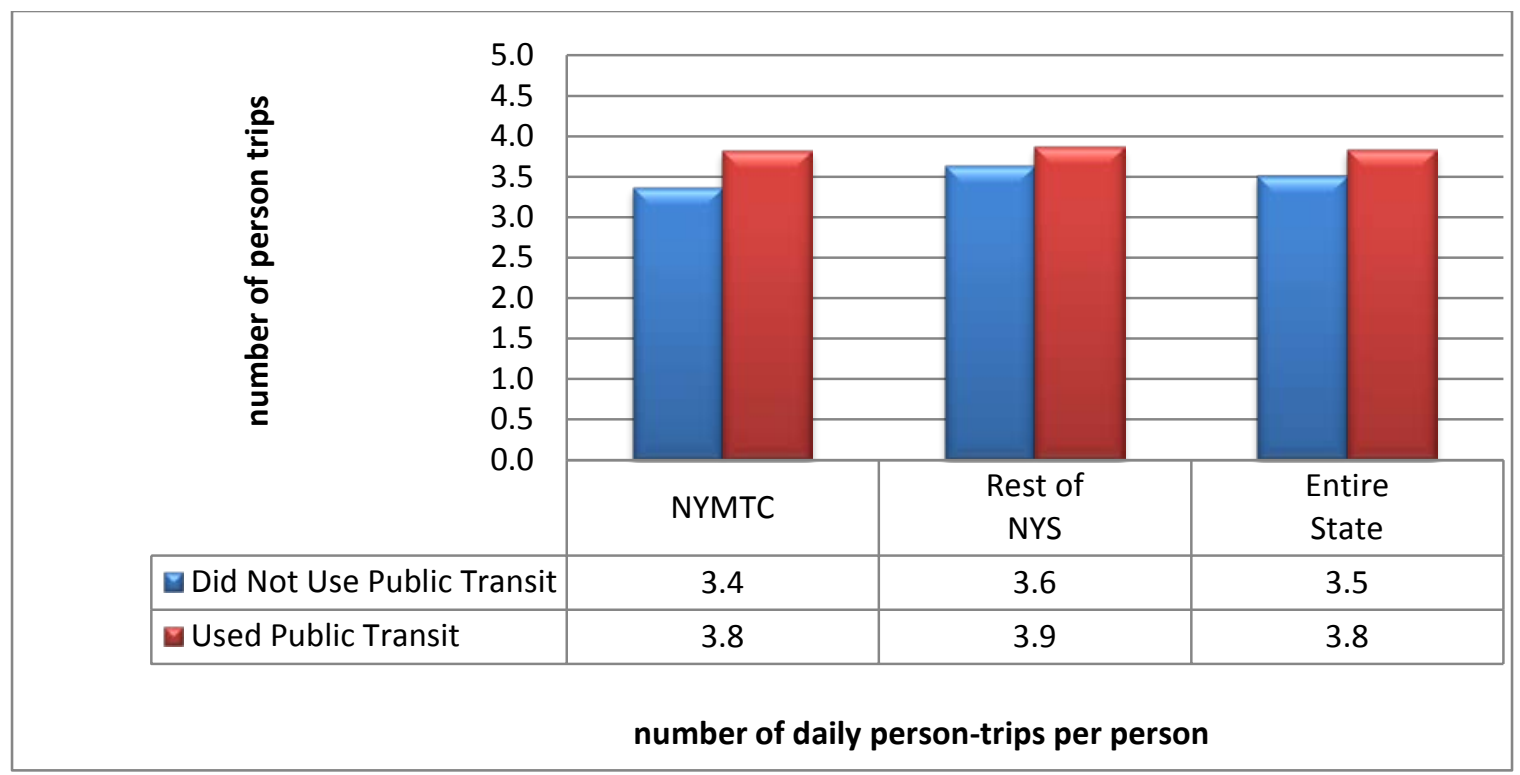

Figure 3-30. Average person-trip rate by past-month transit use status (2009 NHTS).

\subsubsection{Person-mile-traveled per person by transit use in past month}

Reviews of the average PMT rates, shown in Figure 3-31, reveal the existence of a substantial geographic difference. Specifically, a typical resident of NYMTC traveled significantly fewer PMT than one who lived in the Rest of NYS, regardless of their past-month transit usage status. The average daily PMT rate for a NYMTC resident was about 21 miles regardless if transit was used or not in last month.

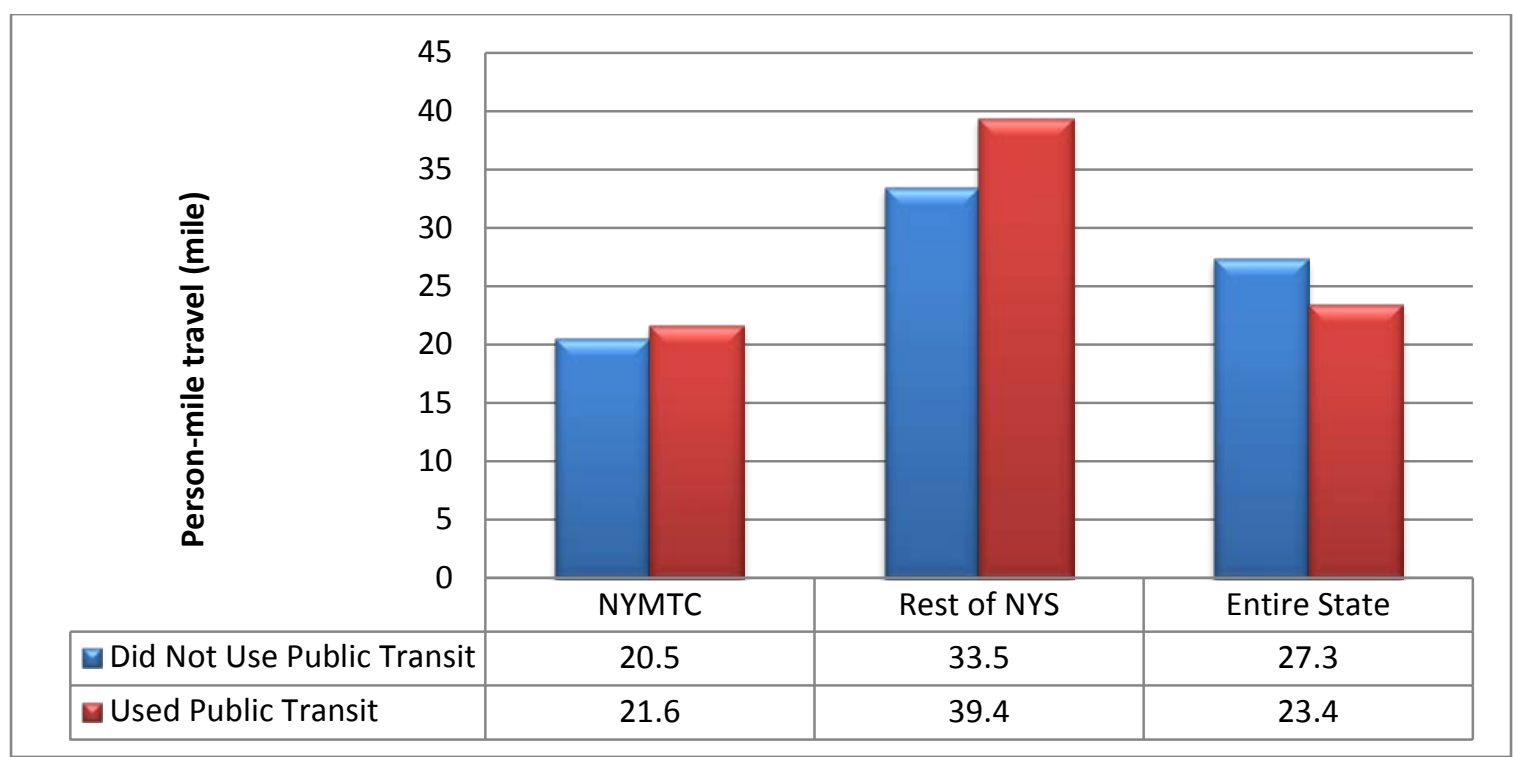

Figure 3-31. Average PMT by past-month transit use status (2009 NHTS).

On the contrary, the average daily PMT rate for individuals who lived in the Rest of NYS and did not use transit during the prior month was around 34 miles; while a past-month transit user from the same region traveled an average of 39 miles per person-trip per day. Because the 
margin of error for the average PMT by past-month transit user was relatively high ( 8 miles), the difference between 34 and 39 therefore was not statistically significant. Removal of two outliers from the calculation of average PMT per person for past-month transit users that lived in the Rest of NYS reduced the average to about 35 miles with a margin of error at 4 miles which is still not significantly different from the average PMT of non-users from the same region.

\subsubsection{Average vehicle trip rates and average VMT per driver}

Average VT rates per driver by non-users of transit, regardless of travel day (see Figure 3-16) or during the past month (shown in Figure 3-32), were very similar within the same regions. These averages were quite different among transit users, however, both by region and by travel period (i.e., travel day versus past month). Analysis of 2009 NHTS data by past-month transit use status and by geographic area revealed that both factors (transit use status and region) indeed had significant effects on the amount of driving made by NYS residents. Specifically, transit users from either region drove fewer trips than non-users from the same region.

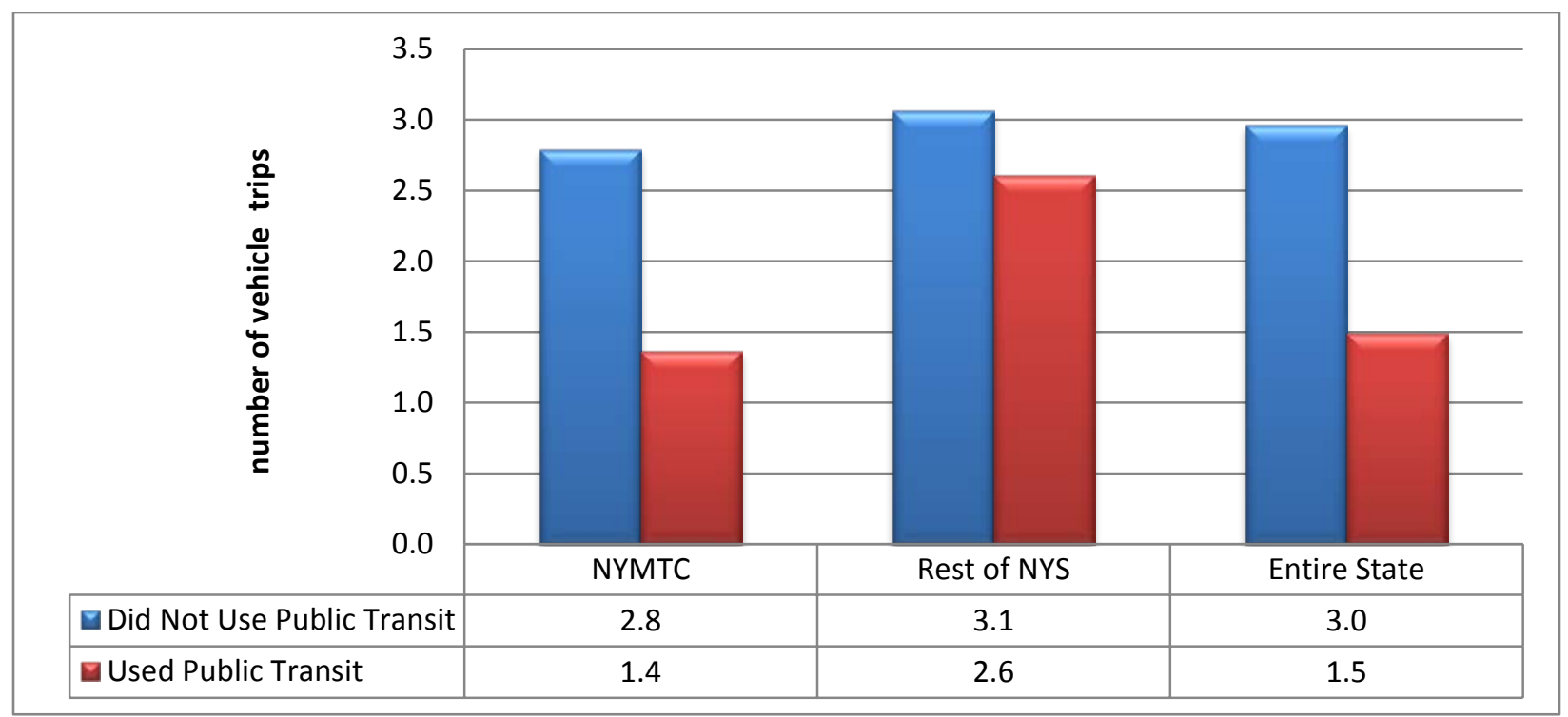

Figure 3-32. Average vehicle-trip rate per driver by past-month transit use status (2009 NHTS).

As presented in Figure 3-32, past-month transit users from NYMTC on average made 1.4 vehicle trips per driver, which was half of the average trip rate took by non-users. For those who lived outside NYMTC, past-month transit users made an average of 2.6 vehicle trips per driver while their non-user counterpart neighbors took 3.1 vehicle trips per driver. Furthermore, non-users from NYMTC drove slightly less frequently than non-users from the Rest of NYS (2.8 vs. 3.1 vehicle trips, respectively).

The average VMT per driver rates for non-users in the past month (see Figure 3-33) also stayed nearly the same as those of non-users on the travel day (shown in Figure 3-17) for each region. Clearly, regional differences were visible in both transit usage groups, in which residents from NYMTC drove fewer miles than those lived in Rest of NYS. Specifically Figure 3-33 shows that, on average, NYMTC drivers who were non-users made 20 vehicle-miles per trip vs. 27 miles per trip for non-users from the Rest of NYS. The average per-driver VMT rates were 11 
miles compared to 27 miles for past-month transit users in NYMTC and Rest of NYS, respectively.

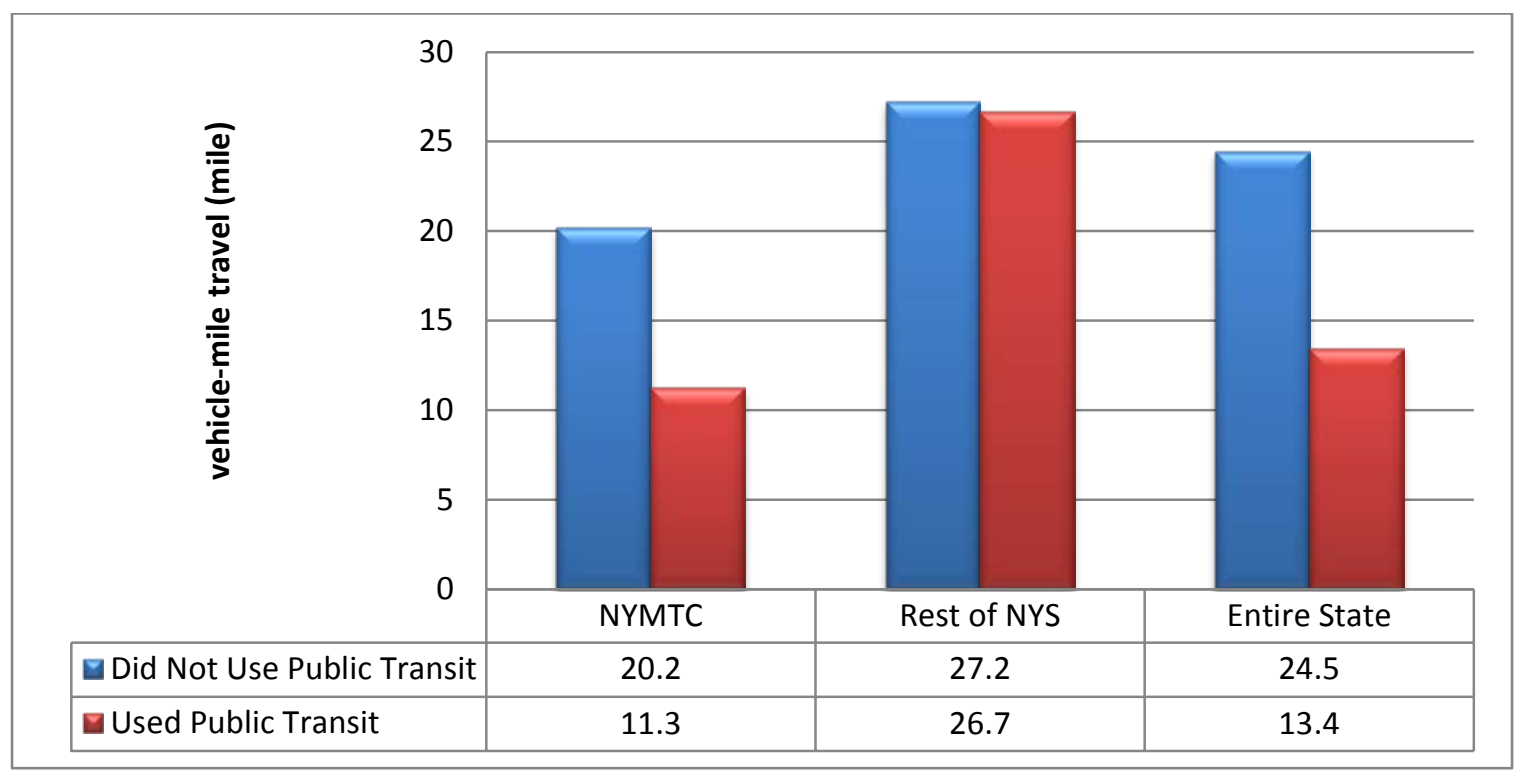

Figure 3-33. Average VMT per driver by past-month transit use status (2009 NHTS).

\subsubsection{Average travel time and trip length by transit usage in past month}

In addition to regional differences (between NYMTC and Rest of NYS), NYS travelers used transit during the past month also had a significant effect on their overall average daily travel time per trip. As seen in Figure 3-34, travelers from NYMTC spent longer times on their daily trips than those who lived in the Rest of NYS, an average of about 5 minutes more per trip for transit users (those who made at least one transit trip during past month) and 2 minutes more per trip for non-users.

Figure 3-34 shows that past-month transit users made longer trips (in minutes) than those who did not use transit for any trips made during the last month — true in both regions analyzed in this study. NYMTC past-month transit users traveled 27 minutes per trip on average on a daily basis, while daily trips made by the Rest of NYS only lasted about 20 minutes per trip on average. Similarly, past-month transit users that lived outside NYMTC traveled an average of 22 minutes per trip but non-users from the same region traveled an average of only 18 minutes on each trip. 


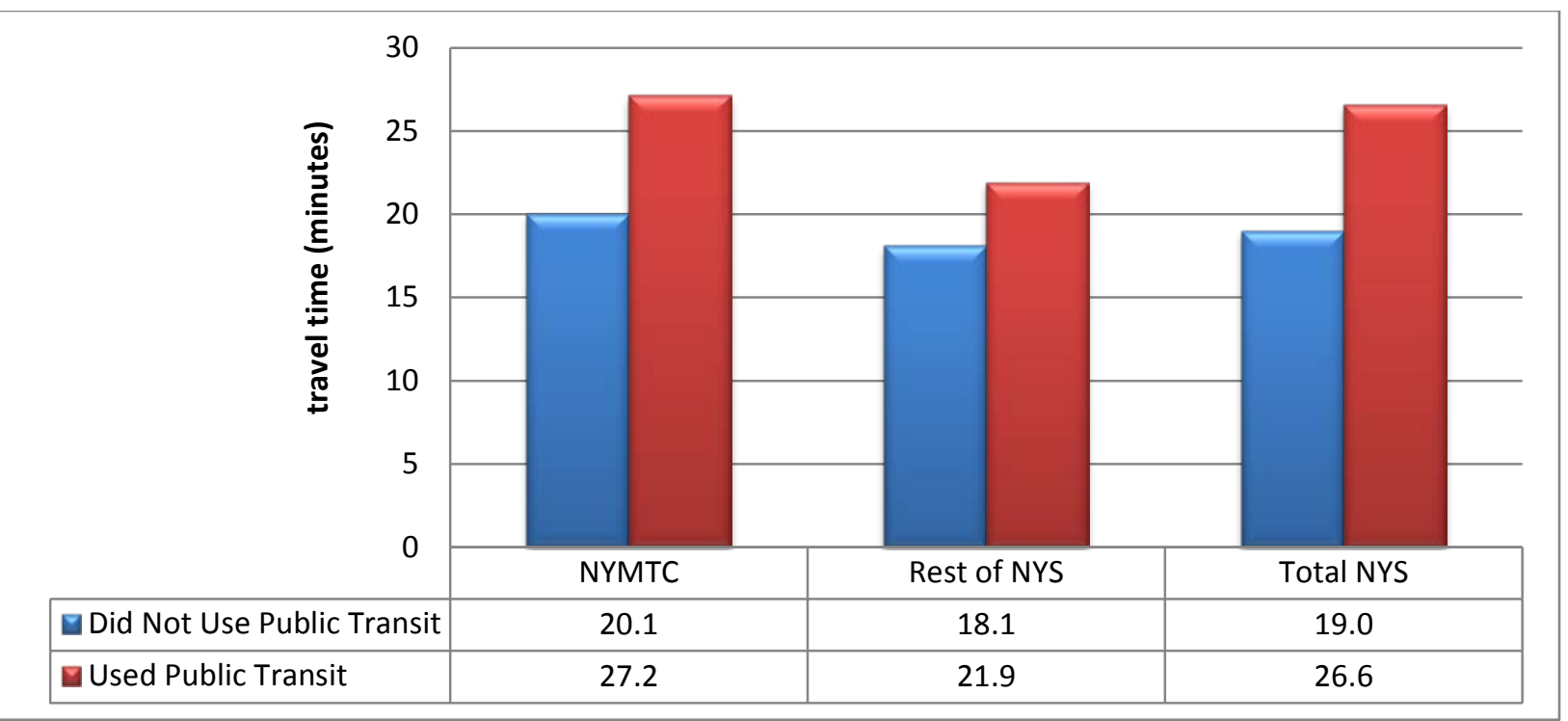

Figure 3-34. Average travel time per person-trip (in minutes) by past-month transit use status.

When measured by trip length (in miles), however, it did not appear that the past-month transit usage had any impact on the average trip lengths for travel conducted by residents within the same region. Figure 3-35 indicates an average of slightly over 6 miles per trip for residents of NYMTC, no matter if they had taken transit during the last month or not. Similarly, residents from the Rest of NYS traveled an average of about 9 to 10 miles on each of their trips; there was no significant difference between the transit users and non-users from this region.

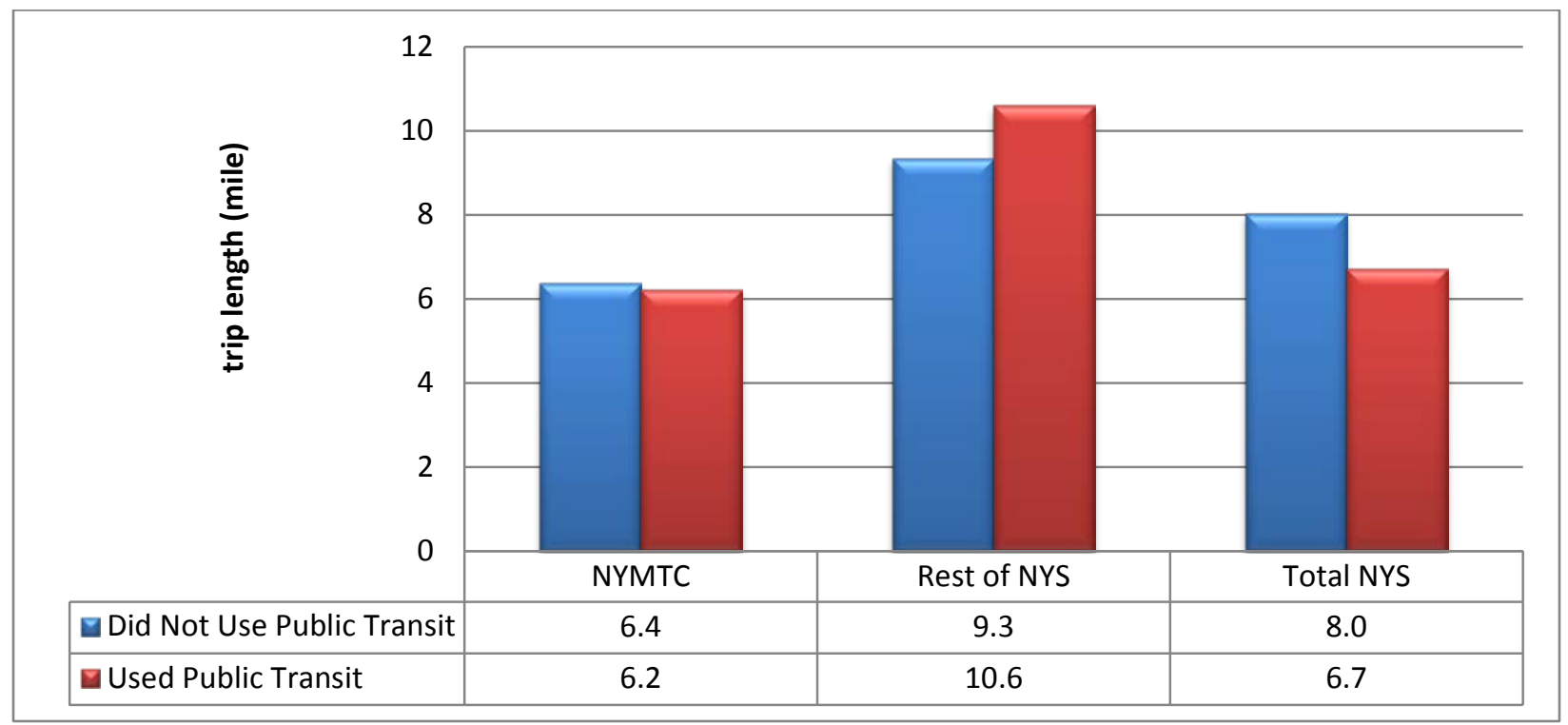

Figure 3-35. Average person-trip length (in miles) by past-month transit use status.

In terms of average trip length (in miles) per vehicle-trip, which accounts for vehicle travel only (i.e., travel by POV), regional differences are visibly seen in Figure 3-36. On average, those who did not use transit for any of their trips made during past month took slightly shorter vehicle trips than those who used transit at least once during the same period. The differences between the two populations (by transit use status), however, were not statistically significant, mainly due to 
their relatively high variations in data (thus a wider margin of error) for the past-month transit user group. The regional differences among non-users was significant, where the daily vehicletrip length average for travelers in NYMTC was 7 miles and those from the Rest of NYS logged an average of 9 miles per vehicle-trip.

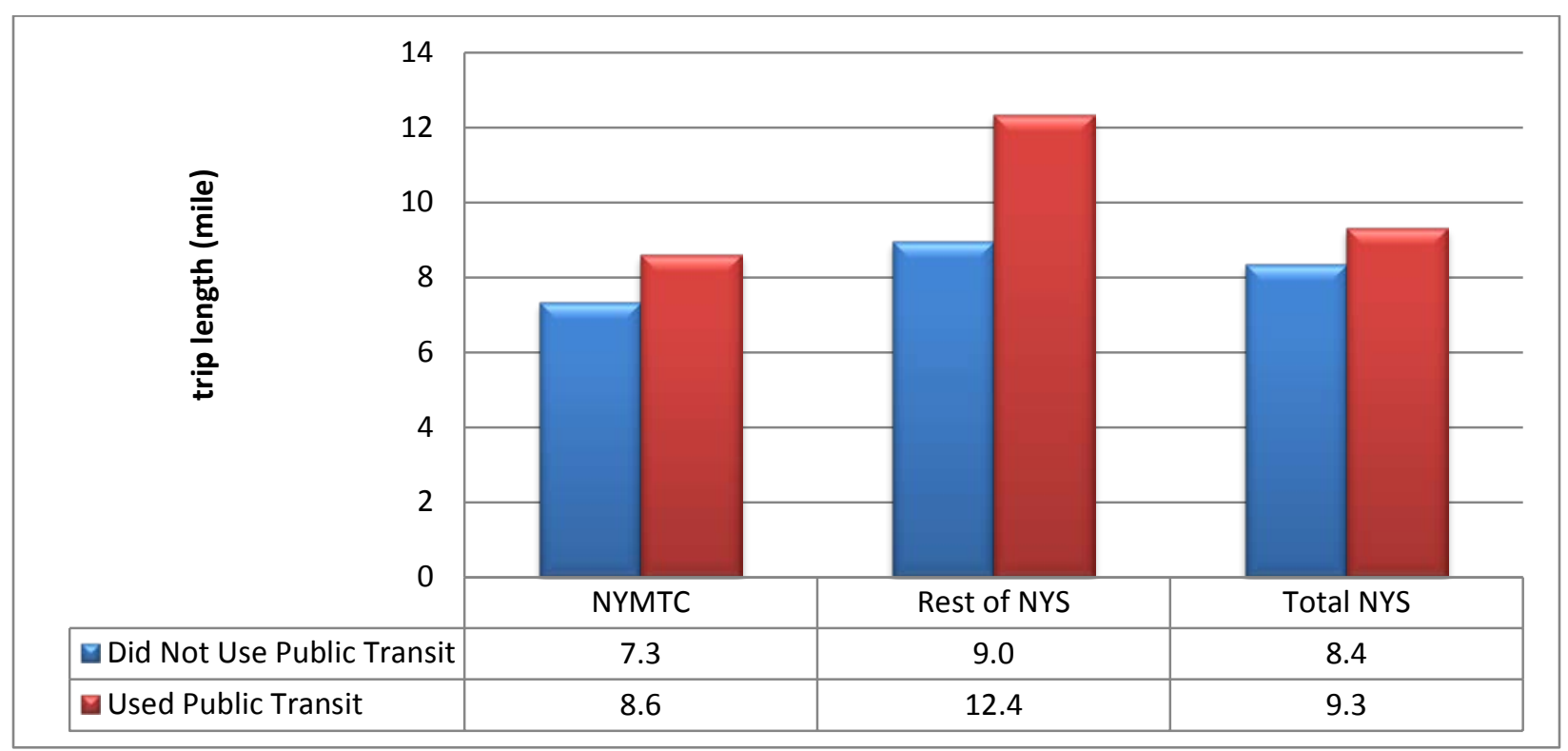

Figure 3-36. Average vehicle-trip length (in miles) by past-month transit use status (2009 NHTS). 


\section{DISTANCE TO TRANSIT FOR DAILY TRANSIT USERS}

The 2009 NHTS data was further examined to determine whether distances to transit have any impact on one's transit use in the region. Note that "distance to transit" in this context was measured by the great-circle distance between a household location and its nearest transit stop. Although three transit sheds were addressed in Section 2 (i.e., 1-, 2.5- and 5-miles), most discussions in this section focus on the 1-mile transit shed. A distance of 2.5 miles would require approximately an hour of walking time, when measured by the commonly acceptable walking speed of 0.25 mile per 5-minute. Thus, very few people would be willing to travel that far to reach transit, unless they were using other means to access transit. Recall in Section 2 of this report, nearly $80 \%$ of the NYS population is located within the 1-mile transit shed, which means living within a 1-mile radius of a transit station/stop. This coverage suggests that sufficient samples from the 2009 NHTS are obtainable to allow meaningful analyses of NYS regional travel behaviors.

\subsection{DEMOGRAPHIC CHARACTERISTICS BY DISTANCE TO TRANSIT}

The intensity of transit network services within the NYMTC region was clearly visible from the map displayed in Figure 1-1. Consequently, it was not surprising to find that $88 \%$ of NYMTC households reside within 1-mile of transit stations/stops. Outside NYMTC, as seen in Figure $4-1$, around $54 \%$ of NYS households lived within the same distance. On the other hand, nearly $30 \%$ of NYS households that lived in Rest of NYS were located beyond 5-miles away from any transit stops, which was almost nonexistent among NYMTC households.

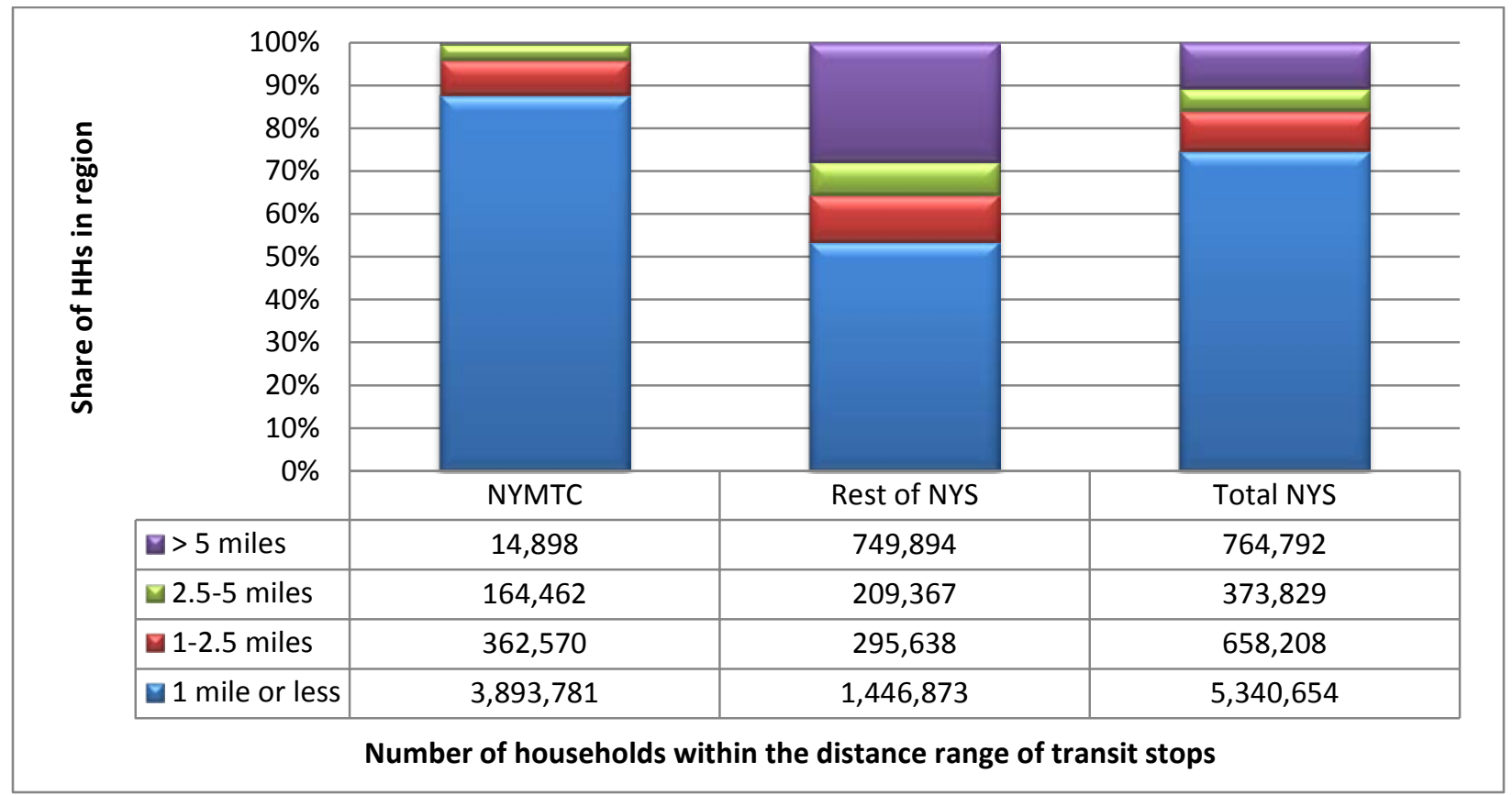

Figure 4-1. Distribution of number of households in region by distance to transit (2009 NHTS). 


\subsubsection{Association of Household Size with Distance to Transit}

As seen in Figure 4-2, NYMTC households are located farther away from transit as the household size increased. While $93 \%$ of the population from single-person households lived within 1-mile of transit stops, only about $84 \%$ of those from $4+$ person households in the same region did. Similarly, in Figure 4-3, 61\% of residents from single-person households in the Rest of NYS lived within 1-mile of transit stops, but only $47 \%$ of their neighbors from the $4+$ person households lived in the same region.

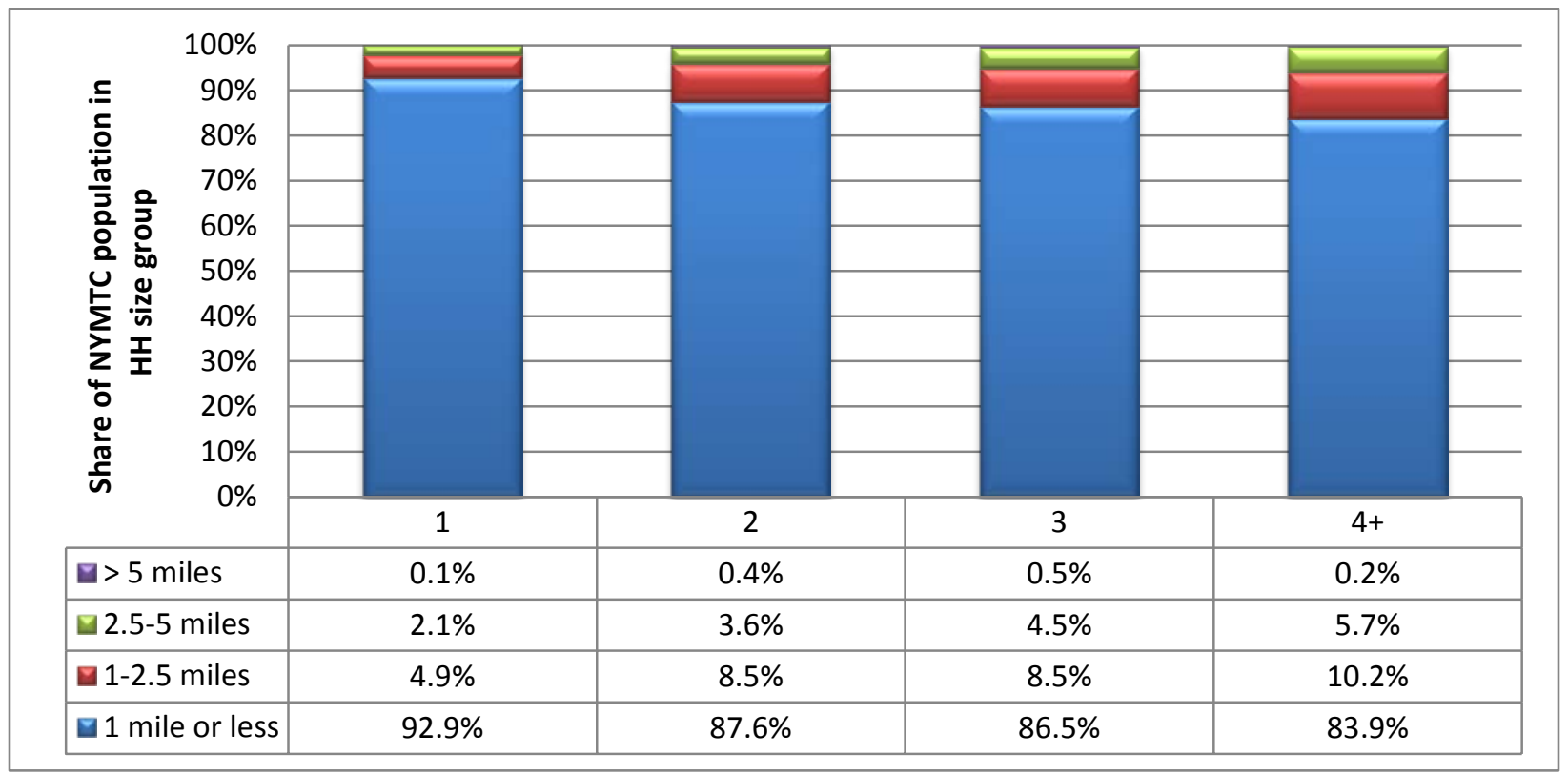

Figure 4-2. Distribution of persons in NYMTC by household size and distance to transit.

\begin{tabular}{|c|c|c|c|c|c|}
\hline \multicolumn{6}{|c|}{$100 \%$} \\
\hline \multirow{10}{*}{ 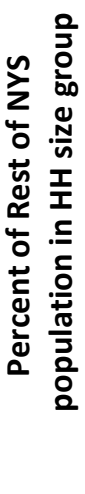 } & $90 \%$ & & & & \\
\hline & $80 \%$ & & & & \\
\hline & $70 \%$ & & & & \\
\hline & $60 \%$ & & & & \\
\hline & $50 \%$ & & & & \\
\hline & 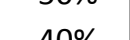 & & & & \\
\hline & $30 \%$ & & & & \\
\hline & $20 \%$ & & & & \\
\hline & $10 \%$ & & & & \\
\hline & $0 \%$ & 1 & 2 & 3 & $4+$ \\
\hline \multicolumn{2}{|c|}{$\square>5$ miles } & $25.3 \%$ & $29.2 \%$ & $29.3 \%$ & $28.0 \%$ \\
\hline \multicolumn{2}{|c|}{$\square 2.5-5$ miles } & $5.4 \%$ & $7.5 \%$ & $9.4 \%$ & $9.8 \%$ \\
\hline \multicolumn{2}{|c|}{ 1-2.5 miles } & $7.8 \%$ & $11.7 \%$ & $9.6 \%$ & $14.7 \%$ \\
\hline \multicolumn{2}{|c|}{ 1 mile or less } & $61.4 \%$ & $51.5 \%$ & $51.7 \%$ & $47.4 \%$ \\
\hline
\end{tabular}

Figure 4-3. Distribution of persons in Rest of NYS by household size and distance to transit. 


\subsubsection{Distance to Transit and Household Vehicle Ownership}

There is no surprise to see that most of the zero-vehicle households in NYS lived near transit, particularly those that lived in NYMTC. Figure 4-4 shows that nearly all people from zerovehicle households in NYMTC lived within a 1-mile radius of transit stops. Their neighbors who owned three or more vehicles in their households, on the other hand, were more likely to live farther away from transit stops.

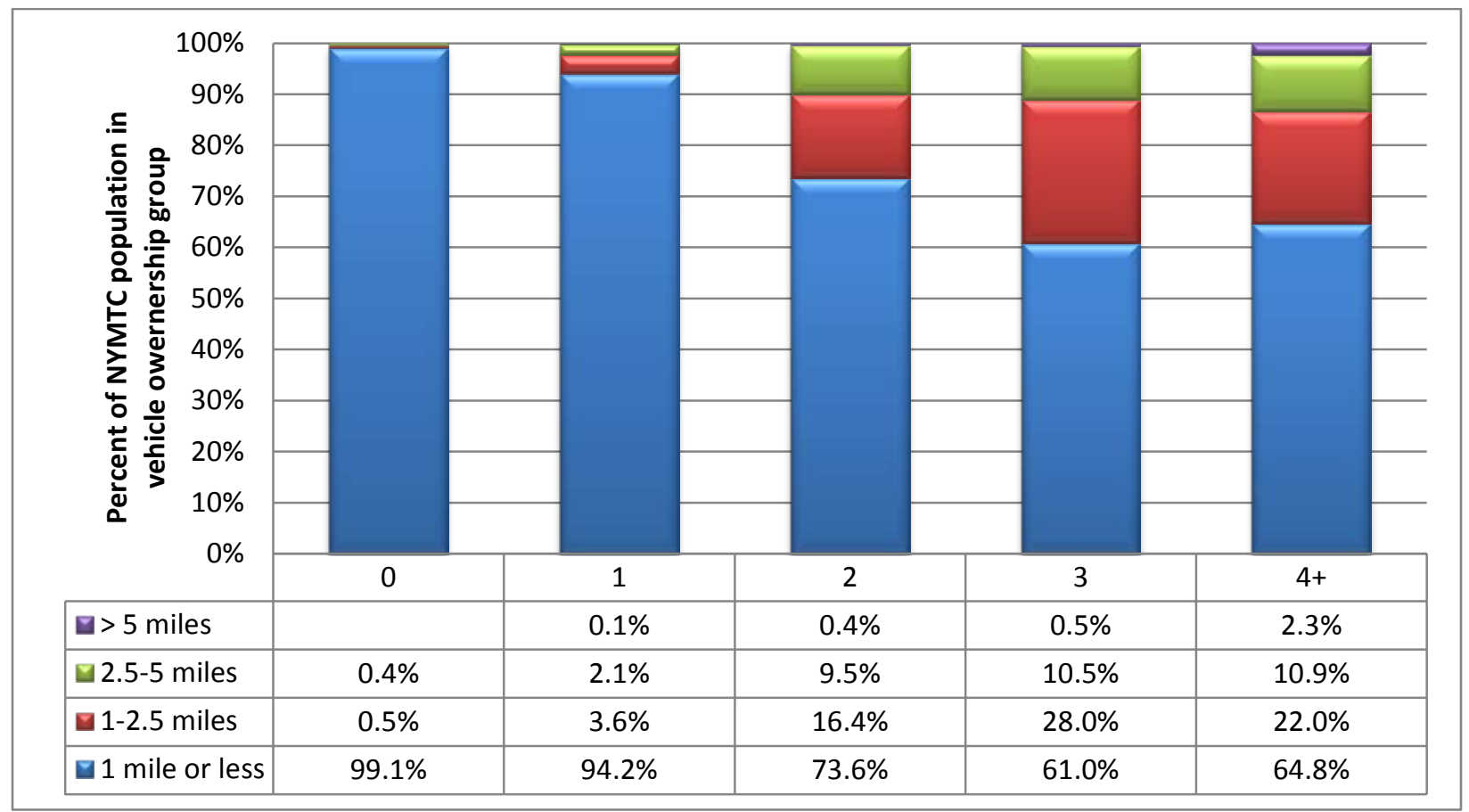

Figure 4-4. Distribution of persons in NYMTC by vehicle ownership and distance to transit.

People from the Rest of NYS (Figure 4-5) also reflected a similar relationship between the distance to transit and the number of vehicles owned in their households. While $74 \%$ of residents from no-vehicle households that lived in the Rest of NYS area resided within 1-mile of transit stops, only around $40 \%$ of those that owned $3+$ vehicles in the household lived in the same region. Regardless of vehicle ownership, Figure 4-5 also shows that a significant portion of the population from the Rest of NYS households lived more than 5-miles away from transit stops. This could be attributed to the fact that transit systems for the Rest of NYS are generally concentrated within a limited area (e.g., downtown, city center), while the population is spread across a wider region. 


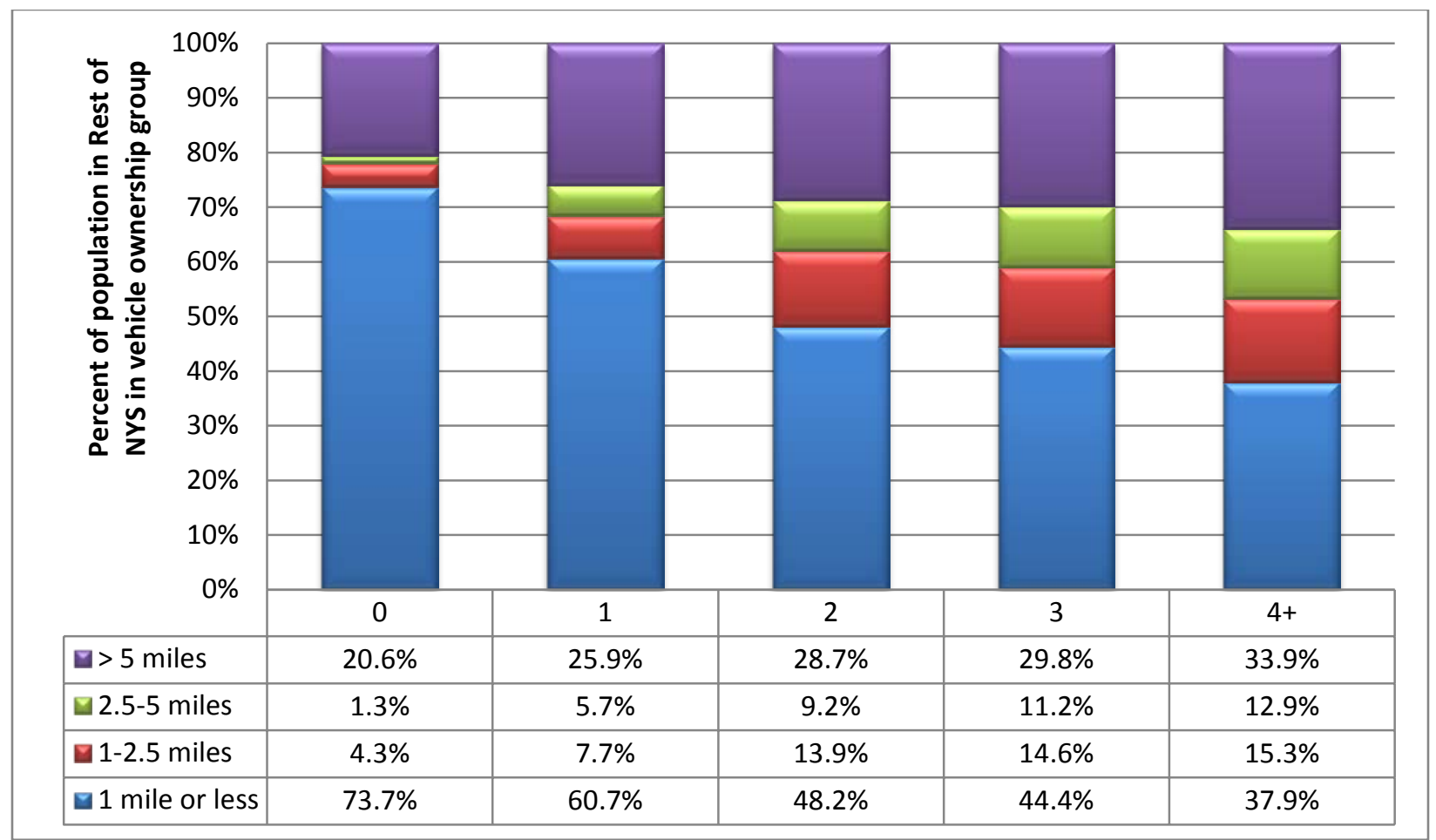

Figure 4-5. Distribution of persons in Rest of NYS by vehicle ownership and distance to transit.

\subsubsection{Household Income and Distance to Transit}

Distributions of distance to transit by household income group for NYMTC residents also reflect the large portion of population living within close proximity of transit stops (i.e., within a onemile radius) in the region, regardless of their income categories. A declining trend in shares of the population living in this closest range, as the household income increased, is clearly visible in Figure 4-6. Over $90 \%$ of the NYMTC population from households with an annual income of under $\$ 40,000$ lived within one mile of transit stops, while only about $77 \%$ of their neighbors from the highest income households lived within the same distance from transit.

For residents of the Rest of NYS (i.e., those living outside NYMTC), where transit use was not as common, household income has a lesser impact on where they lived, in terms of distance to transit services. According to 2009 NHTS data, as shown in Figure 4-7, roughly half of the population in every income group from the Rest of NYS lived within the closest range (one mile) to transit services in 2009. This echoed the overall demographic characteristic of this region as shown in Figure 4-1. 


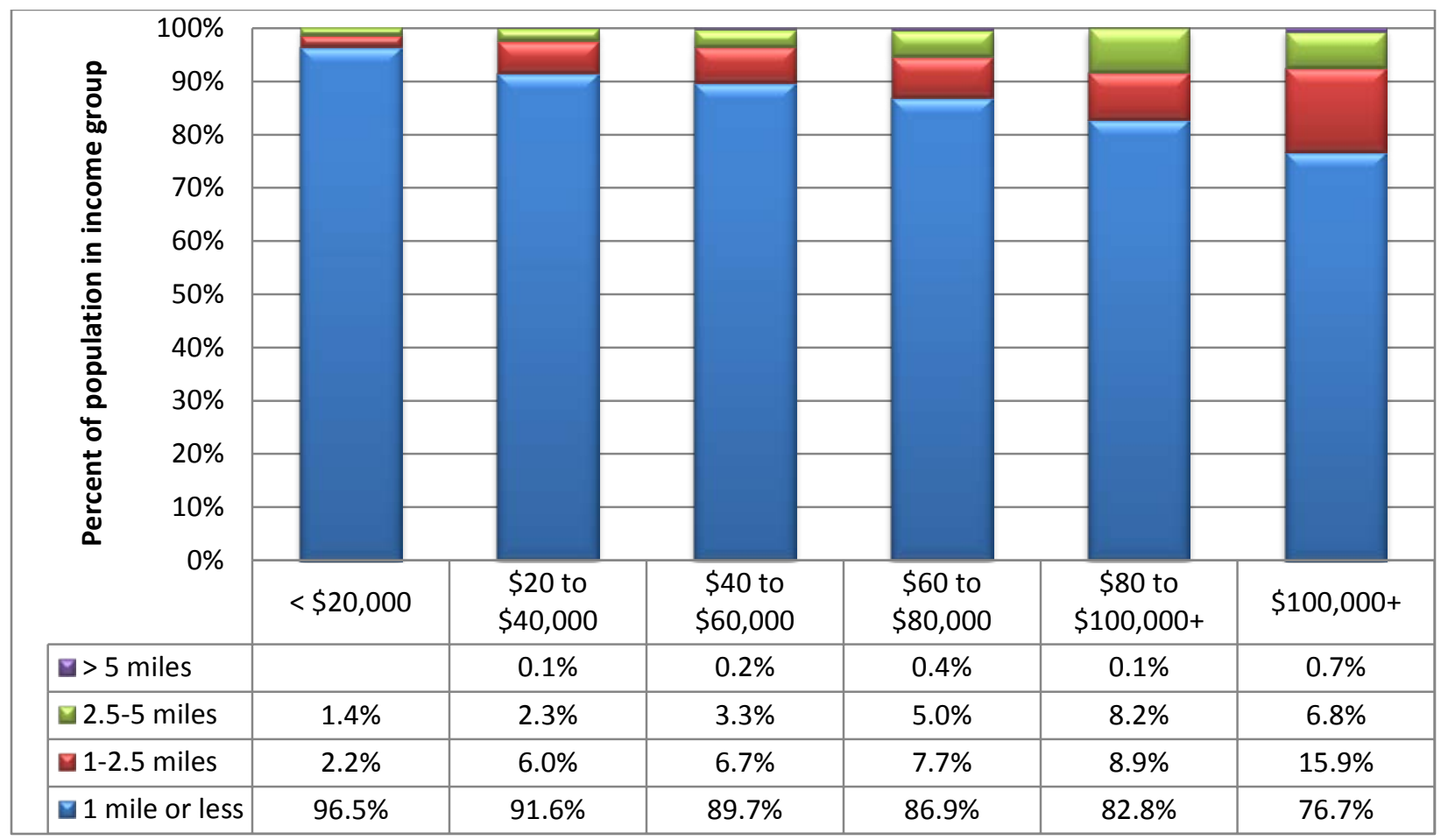

Figure 4-6. Distribution of NYMTC population by household income and distance to transit.

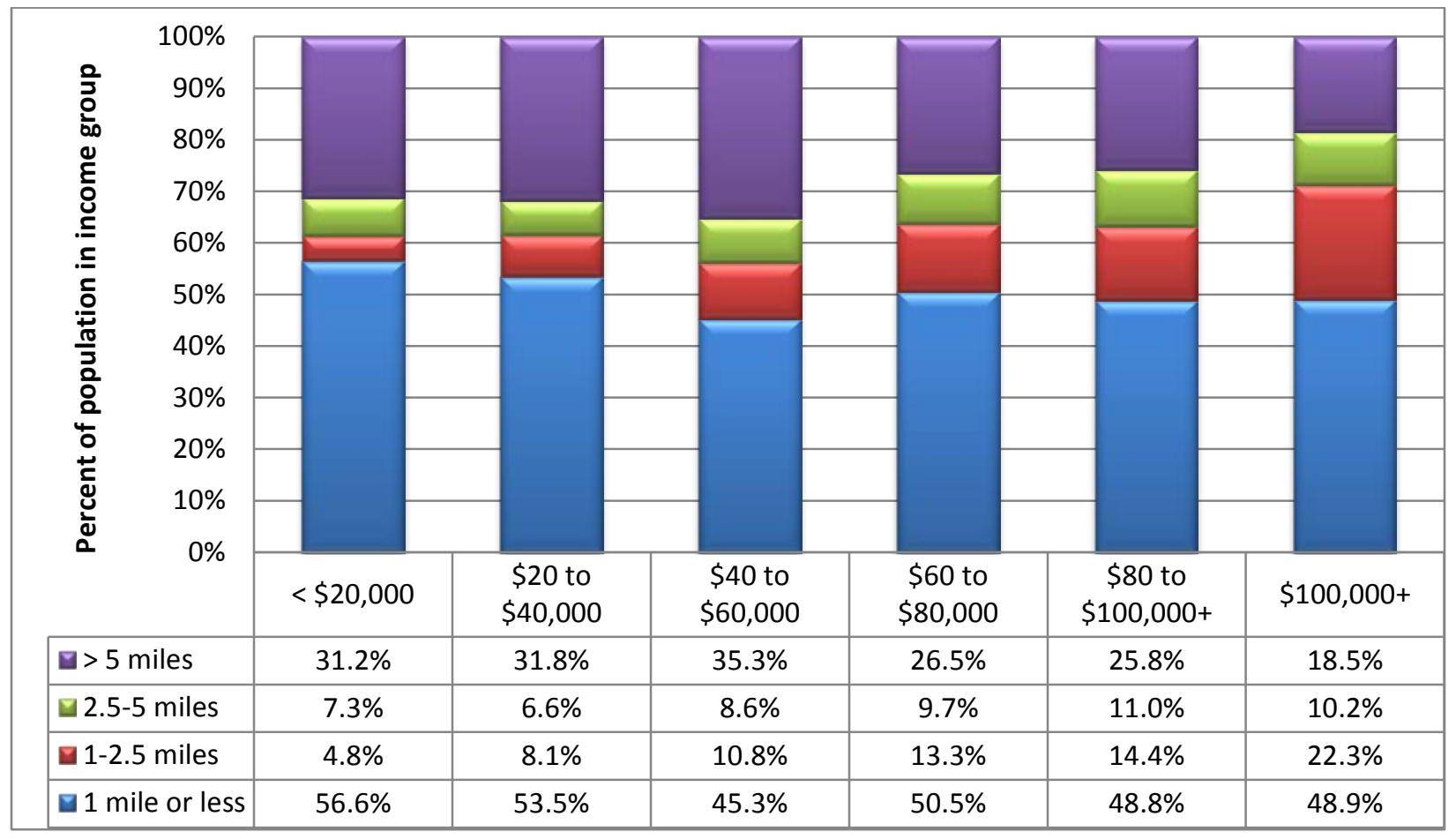

Figure 4-7. Distribution of population by household income and distance to transit in Rest of NYS. 


\subsubsection{Influence of Distance to Transit on Elderly Travelers}

Distance to transit appeared to have no significant impact on where NYS households were located in relationship to transit stops, when compared between the elderly (aged 65 and older) and their younger counterparts. As seen in Figure 4-8, roughly 87\% of NYMTC's population and half of those who lived in the Rest of NYS, regardless of their age group, lived within a 1mile radius of transit stops. This was consistent within each of the demographic regions.

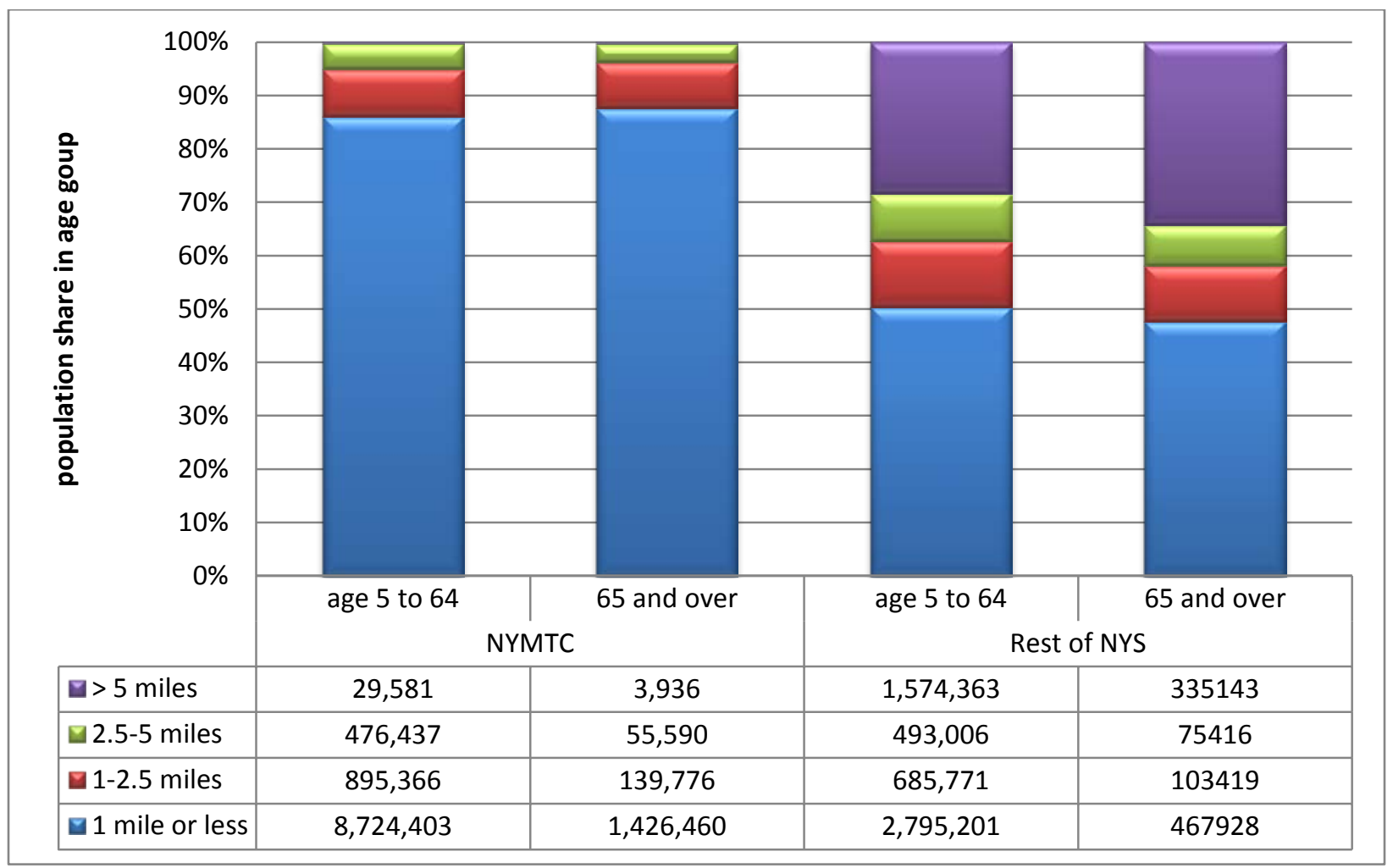

Figure 4-8. Distribution of NYS population by distance to transit and age group status.

\subsection{IMPACTS OF DISTANCE TO TRANSIT ON TRAVEL CHARACTERISTICS}

An examination of the relationships between trip purpose and distances to transit revealed no noticeable patterns or differences in trips made by residents from the NYMTC or those of the Rest of NYS. The only exception was for trips made by the NYMTC residents that lived outside the 5-miles radius of transit stops, which only accounted for less than $0.5 \%$ of total trips. That is, overall, distance to transit had no impact on a NYS person's travel on a daily basis. Additional reviews on travel behavior impacts associated with distance to transit are summarized below.

\subsubsection{Impacts on Mode Choice for Daily Trips}

In view of mode choice for daily travel activities, a close proximity to transit appears to have a significant impact on increasing transit use. Among NYMTC residents, as summarized in Table $4-1$, transit share (as main mode) accounted for over $18 \%$ of all trips made by those who lived within a one-mile radius of transit stops. Beyond the one-mile distance, shares of trips with 
transit as their main modes reduced dramatically to $2 \%$ or lower. Note that most NYMTC residents ( $88 \%$ by household counts) lived in areas within one-mile radius of transit stops, and, as a whole, transit accounted for nearly 16\% of trips made by residents of the NYMTC in 2009.

Table 4-1. Mode Shares by Distance to Transit in NYS (2009 NHTS)

\begin{tabular}{|c|c|c|c|c|c|c|c|c|}
\hline \multirow{2}{*}{$\begin{array}{c}\text { Main } \\
\text { mode } \\
\text { used }\end{array}$} & \multicolumn{4}{|c|}{ NYMTC } & \multicolumn{4}{|c|}{ Rest of NYS } \\
\hline & $\begin{array}{l}<=1 \\
\text { mile }\end{array}$ & $\begin{array}{l}1-2.5 \\
\text { miles }\end{array}$ & $\begin{array}{l}2.5-5 \\
\text { miles }\end{array}$ & $>5$ miles & $\begin{array}{l}<=1 \\
\text { mile }\end{array}$ & $\begin{array}{l}1-2.5 \\
\text { miles }\end{array}$ & $\begin{array}{l}2.5-5 \\
\text { miles }\end{array}$ & $>5$ miles \\
\hline POV & $44.5 \%$ & $80.9 \%$ & $84.1 \%$ & $90.0 \%$ & $81.3 \%$ & $87.6 \%$ & $87.9 \%$ & $86.4 \%$ \\
\hline Walk/bike & $32.8 \%$ & $11.5 \%$ & $8.3 \%$ & $9.4 \%$ & $12.4 \%$ & $7.8 \%$ & $7.0 \%$ & $9.2 \%$ \\
\hline Transit & $18.2 \%$ & $2.3 \%$ & $2.2 \%$ & $0.1 \%$ & $1.6 \%$ & $0.2 \%$ & $0.3 \%$ & $0.2 \%$ \\
\hline Others & $4.6 \%$ & $5.2 \%$ & $5.4 \%$ & $0.4 \%$ & $4.7 \%$ & $4.4 \%$ & $4.8 \%$ & $4.2 \%$ \\
\hline All mode & $100.0 \%$ & $100.0 \%$ & $100.0 \%$ & $100.0 \%$ & $100.0 \%$ & $100.0 \%$ & $100.0 \%$ & $100.0 \%$ \\
\hline
\end{tabular}

Outside NYMTC, those who lived within 1-mile radius transit stops also had a significantly higher likelihood of using transit as main mode for their trips than others from the same region. Table 4-1shows that residents living in the Rest of NYS and within one-mile of transit stops had a mode share for transit at $1.6 \%$, versus less than $0.3 \%$ for residents farther away from transit stops within the same region. According to a separate analysis of the 2009 NHTS data, transit used as a main mode for daily trips accounted only about $0.2 \%$ of all trips made by residents living in the Rest of NYS.

\subsubsection{Influence of Distance to Transit on Travel Behaviors}

\subsubsection{Trip Frequencies}

Information displayed in Figure 4-9 suggests that distance to transit had no effect on trip frequencies, in terms of average daily person-trips per person, among the Rest of NYS travelers. No geographic regional differences can be identified in trip rates by distance to transit either. Note that Figure 4-9 shows the average trip rate was higher (5.5 trips) for those who lived over 5-miles away from transit stops in NYMTC. However, this statistics was based on a rather small number of trips (accounting for less than $0.5 \%$ of all trips from the residents of NYMTC), thus making this estimate less precise (i.e., with higher margin of error).

In terms of vehicle-trip rates per driver, Figure 4-10 shows that NYMTC residents that lived within one-mile of transit stops took an average of 1.6 vehicle trips; while all others from the same region (who lived over one-mile away from transit stops) made over 3 vehicle trips daily per driver. No effects from the distance to transit, to average vehicle-trip rates per driver, can be observed from trips made by drivers who lived in the Rest of NYS, however. 


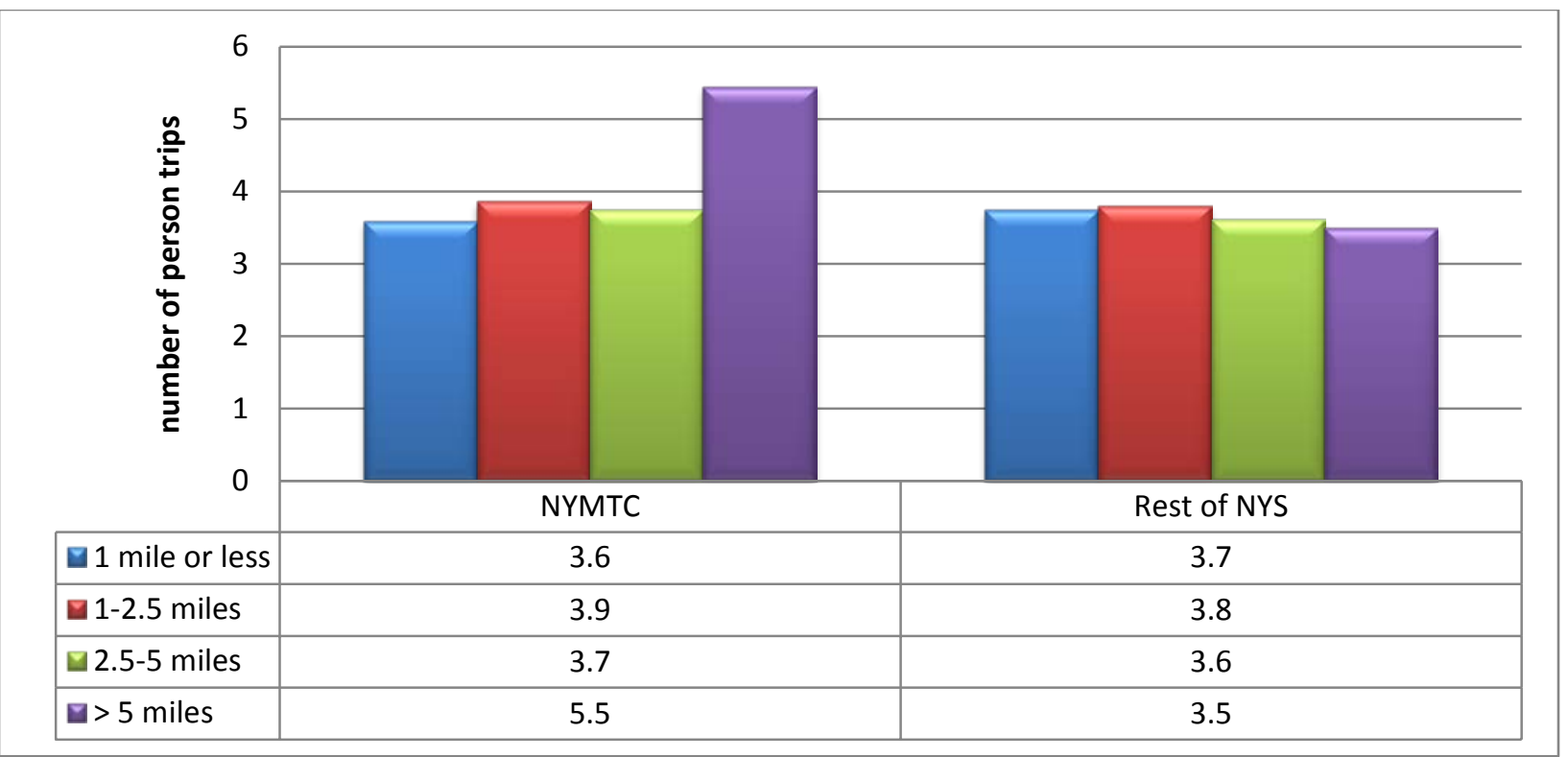

Figure 4-9. Average daily person-trip rates by distance to transit by region (2009 NHTS).

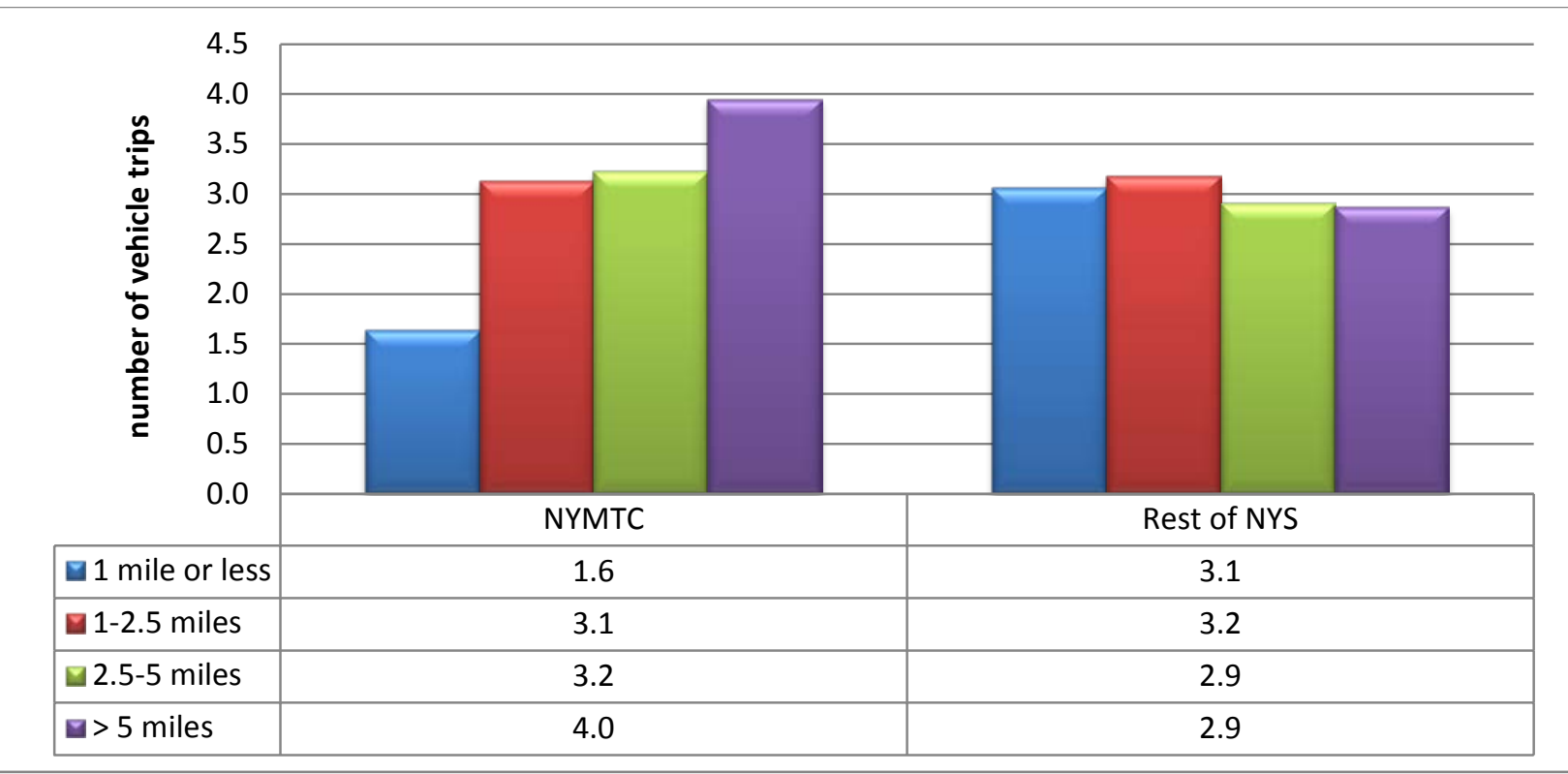

Figure 4-10. Average daily vehicle-trip rates by distance to transit by region (2009 NHTS).

\subsubsection{Measures of PMT per Person and VMT per Driver}

When measuring travel performance by PMT per person and VMT per driver, presented in Figure 4-11 and Figure 4-12 respectively, NYMTC residents that lived within the closest proximity of transit stops attributed to the least amount of PMT per person, as well as the smallest average in VMT per driver. Specifically, of those NYMTC residents who lived within one-mile of transit stops, their average PMT per person was 19 miles and VMT per driver was 12 miles; while all other NYMTC residents averaged more than 31 PMT per person and over 28 VMT per driver. Recall that about $80 \%$ of the NYMTC population resided in the region within a 
1-mile radius of transit stops, thus their averages were very consistent with those estimated from past-month transit users in NYMTC (see Figure 3-31 on PMT and Figure 3-33 for VMT).

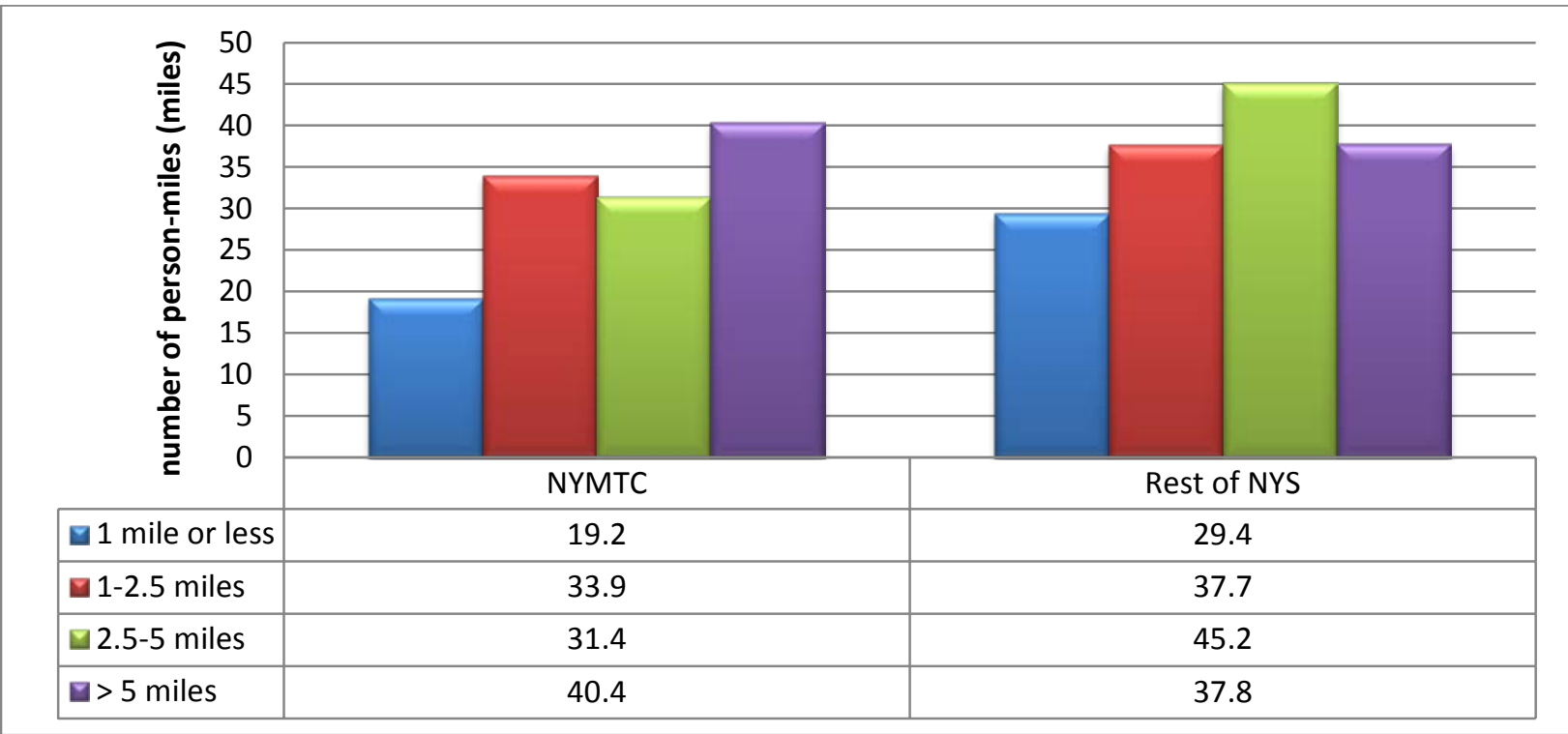

Figure 4-11. Average PMT per person by distance to transit (2009 NHTS).

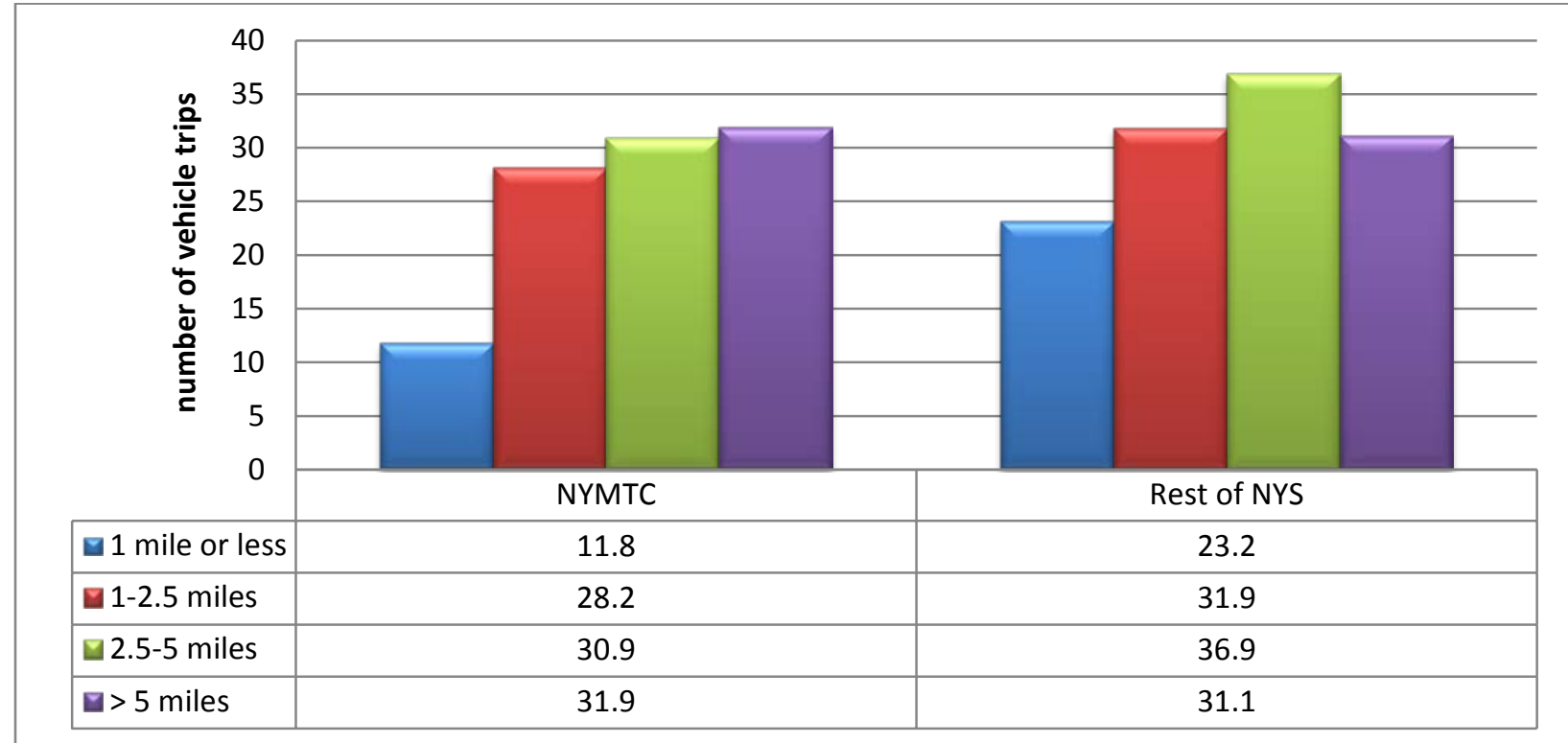

Figure 4-12. Average VMT per driver by distance to transit (2009 NHTS).

Outside NYMTC, the population that lived within one-mile radius of transit stops made an average of 29 miles for PMT per person and 23 VMT per driver; while all other residents from the same region had 38 or more miles (Figure 4-11) for average per-person PMT and over 32 miles (Figure 4-12) for per-driver VMT during 2009. The latter set of averages was very similar to those estimated based on past-month transit users from the Rest of NYS region (Figure 3-31 and Figure 3-33). 


\subsubsection{Average Travel Time and Trip Length}

Average daily travel time (in minutes) was longer for residents of NYMTC that lived inside the 1-mile transit shed, when compared to their neighbors from the same region and all those that lived in the Rest of NYS. Figure 4-13 shows that NYMTC residents from the 1-mile transit shed on average spent 25 minutes per person-trip on their travel days; while their counterparts from the Rest of NYS traveled an average of 17 minutes per trip during the same period. There was no evidence showing significant regional differences on average travel times for those who lived outside the 1-mile transit sheds.

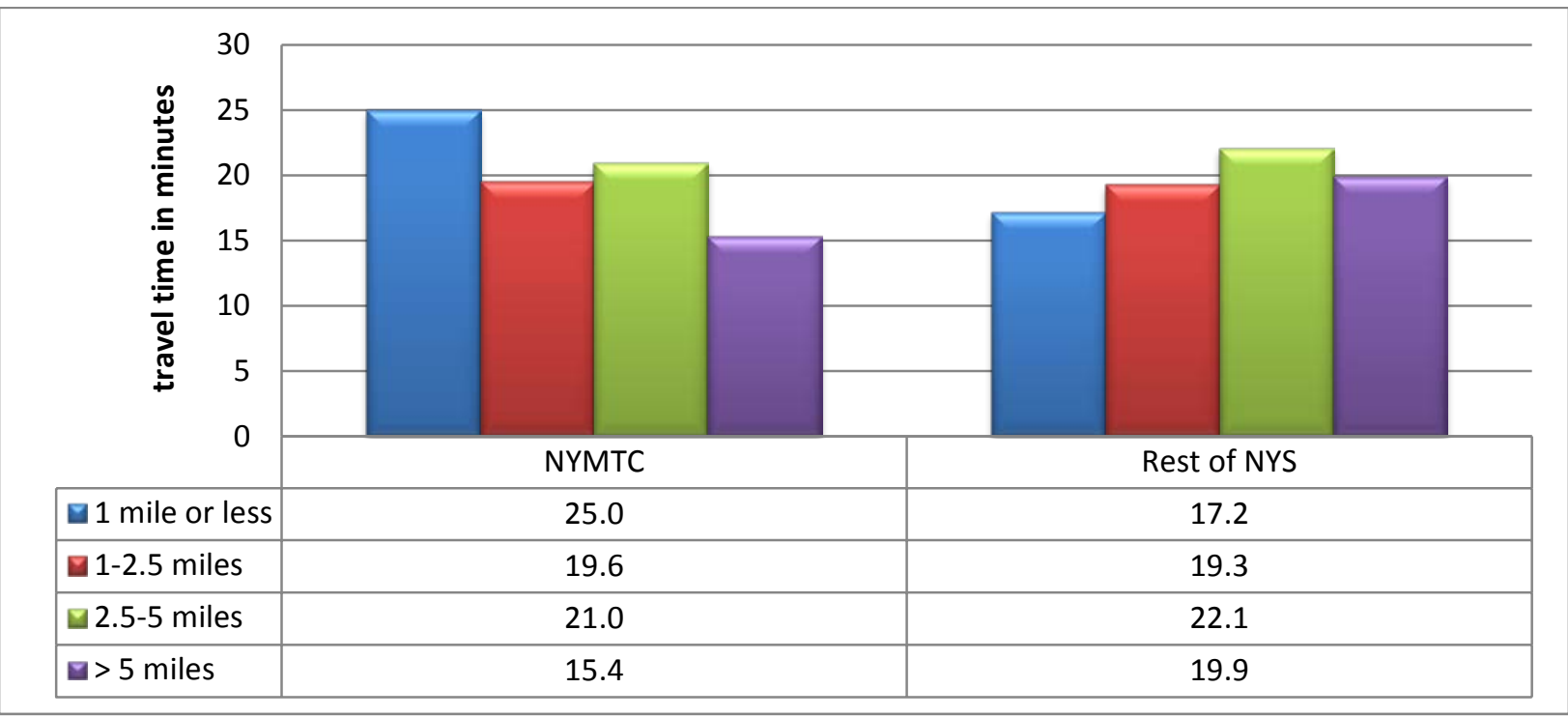

Figure 4-13. Average travel time (minutes) by distance to transit (2009 NHTS).

In terms of average travel distances (in miles), Figure 4-14 shows that a typical person within a 1-mile transit shed of NYMTC traveled an average of 6 miles on per daily trips during 2009. During the same period, a typical person from the 1-mile transit shed for the Rest of NYS traveled, on average, 8 miles per trip.

For travel made by POV, Figure 4-15 shows that there was no visible regional difference among those who lived within the 1-mile transit shed in NYS. These drivers traveled around 7.5 miles per driver per trip on average regardless of region. Outside the 1-mile transit shed area, a typical NYMTC person traveled an average of about 9 miles in VMT per driver per trip while his/her counterpart from the Rest of NYS traveled over 11 miles of VMT per driver per trip. Due to small NHTS 2009 sample sizes in regions outside the 1-mile transit shed for NYMTC, however, the margin of error for those average estimates generally are larger (i.e., with a wider range of uncertainty). As a result, a statistical significance on "visibly different" values may be rejected (i.e., not statistically significant). 


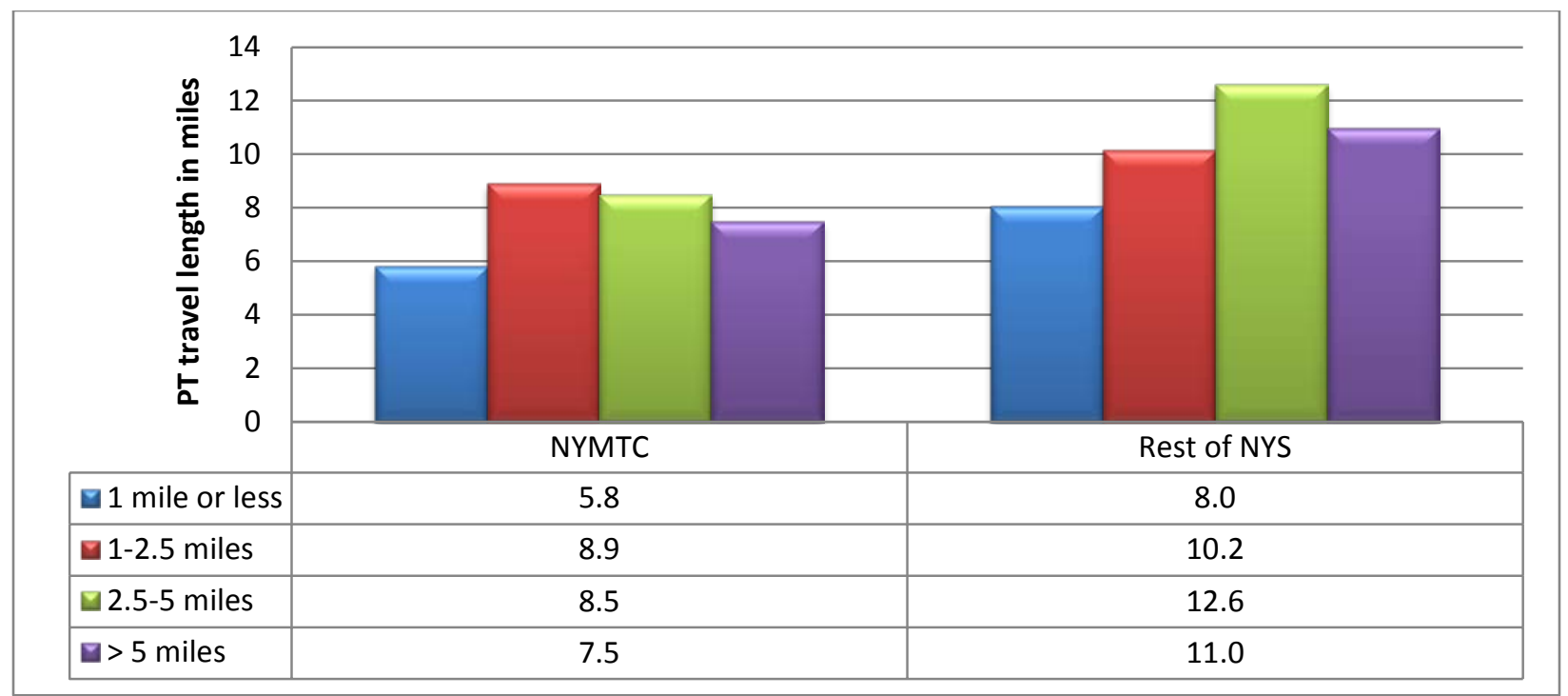

Figure 4-14. Average person-trip length (miles) by distance to transit (2009 NHTS).

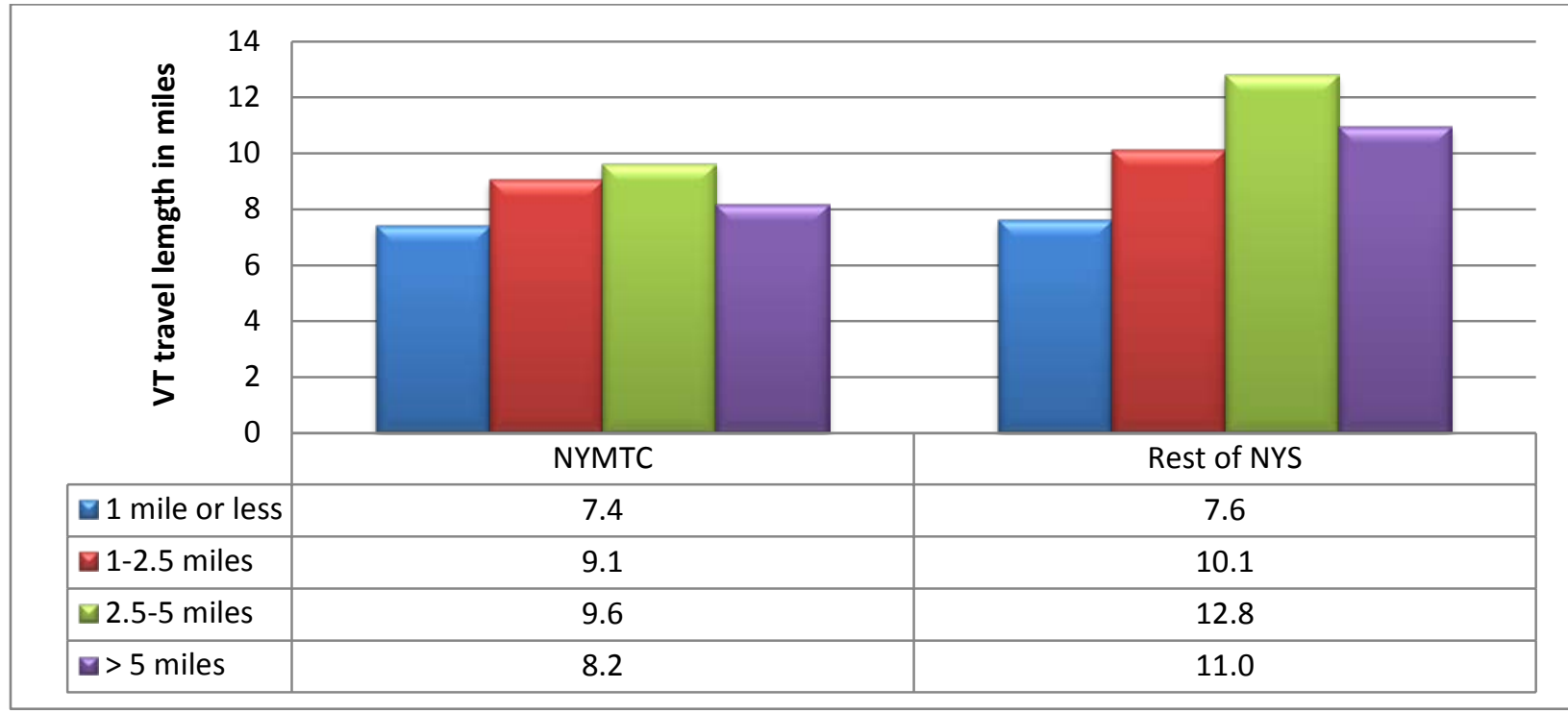

Figure 4-15. Average vehicle-trip length (miles) by distance to transit (2009 NHTS).

\subsection{DAILY TRANSIT USAGE ON PERSONS LIVING IN 1-MILE TRANSIT SHED}

Additional analyses that focused only on daily transit usage by NYS residents who lived within the one-mile transit shed were also conducted and their results were summarized below. As the summary presented in Figure 4-16 shows, about 44\% of all NYMTC household travelers located within the 1-mile transit shed used transit as their means for daily travel in 2009. This was equivalent to about $31 \%$ of its total regional population, i.e., people living within the 1-mile transit shed in NYMTC. Not surprisingly, these transit-user shares were higher than results presented in Figure 3-1 (slightly under 40\% of households) and Figure 3-2 (about 27\% of the population), which included all households and persons within the entire NYMTC region. This appears to reflect a possible effect of close proximity to transit services on transit usage in the NYMTC. 


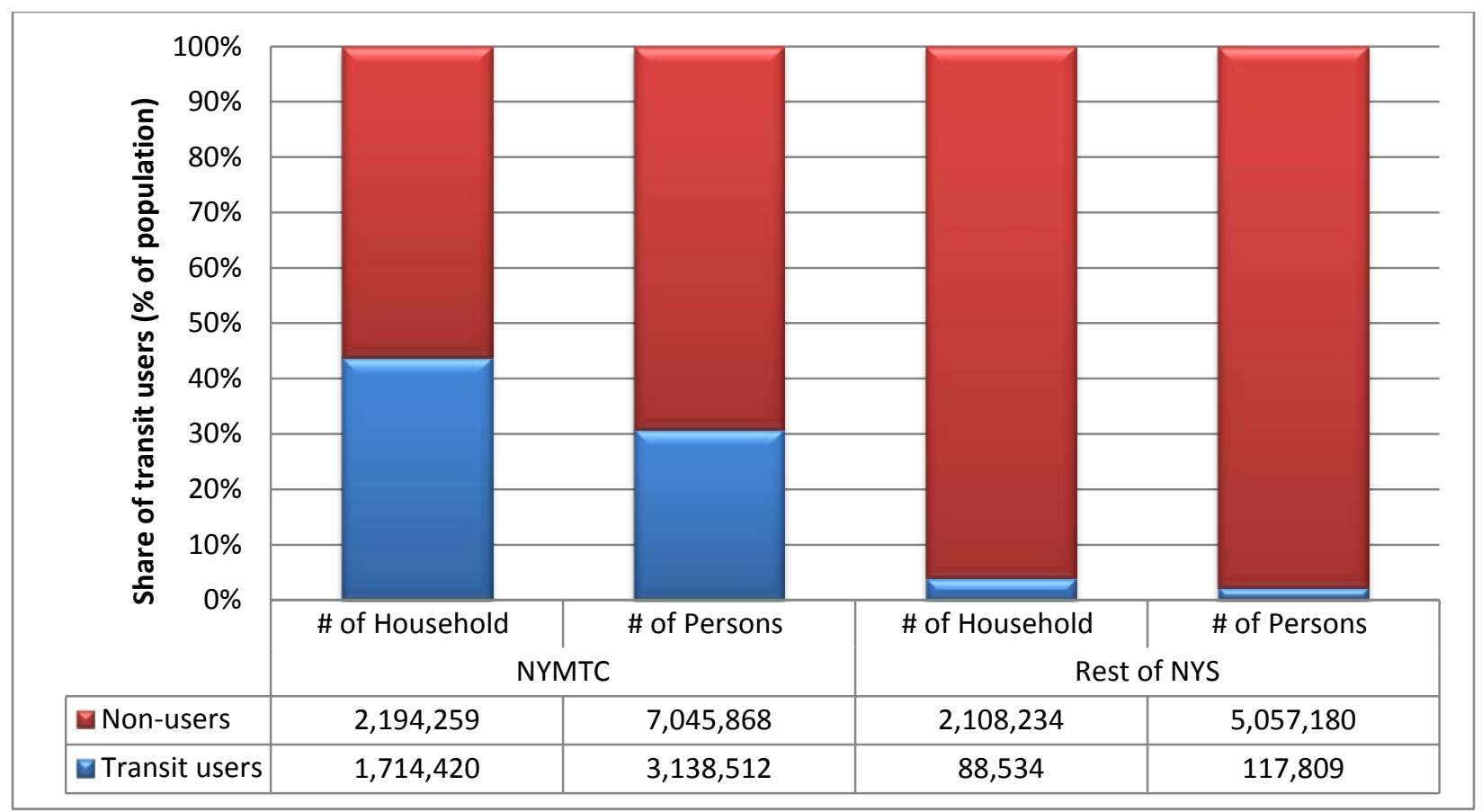

Figure 4-16. Shares and numbers of transit users based on households/persons living within 1-mile transit shed, by region (2009 NHTS).

For the Rest of NYS, Figure 4-16 shows that about 4\% of households (or 2.3\% of population) living within the 1-mile transit shed were transit users. No significant differences were found when compared with transit usage by the entire group of households and population that lived in the region, where transit users represented $3.7 \%$ of households and $2.0 \%$ of population.

\subsubsection{Relationships between Transit Usage and Household Characteristics}

With the exception of transit users who lived within the 1-mile transit shed in the Rest of NYS, results shown in Figure 4-17 do not reveal any significant differences or patterns in the distributions of population by transit usage and household size. The share of transit users from single-person households appears to be significantly higher for those who lived in close proximity of transit within the Rest of NYS area. Note that transit users only accounted for about $2 \%$ of all the population that lived within the 1-mile transit shed in the Rest of NYS, however.

By vehicle ownership, distributions displayed in Figure 4-18 show that over half of transit users who lived in the 1-mile transit shed were from zero-vehicle households, regardless of their region of residency. Close proximity to transit generally occurred in areas of more urban settings (e.g., downtown), which can be attributed to not owning any vehicles. Again, not owning any vehicles was also a choice made by many residents of NYMTC. Therefore, it should not be a surprise to see that over a third of all non-users who lived within the 1-mile transit shed of NYMTC came from zero-vehicle households. 


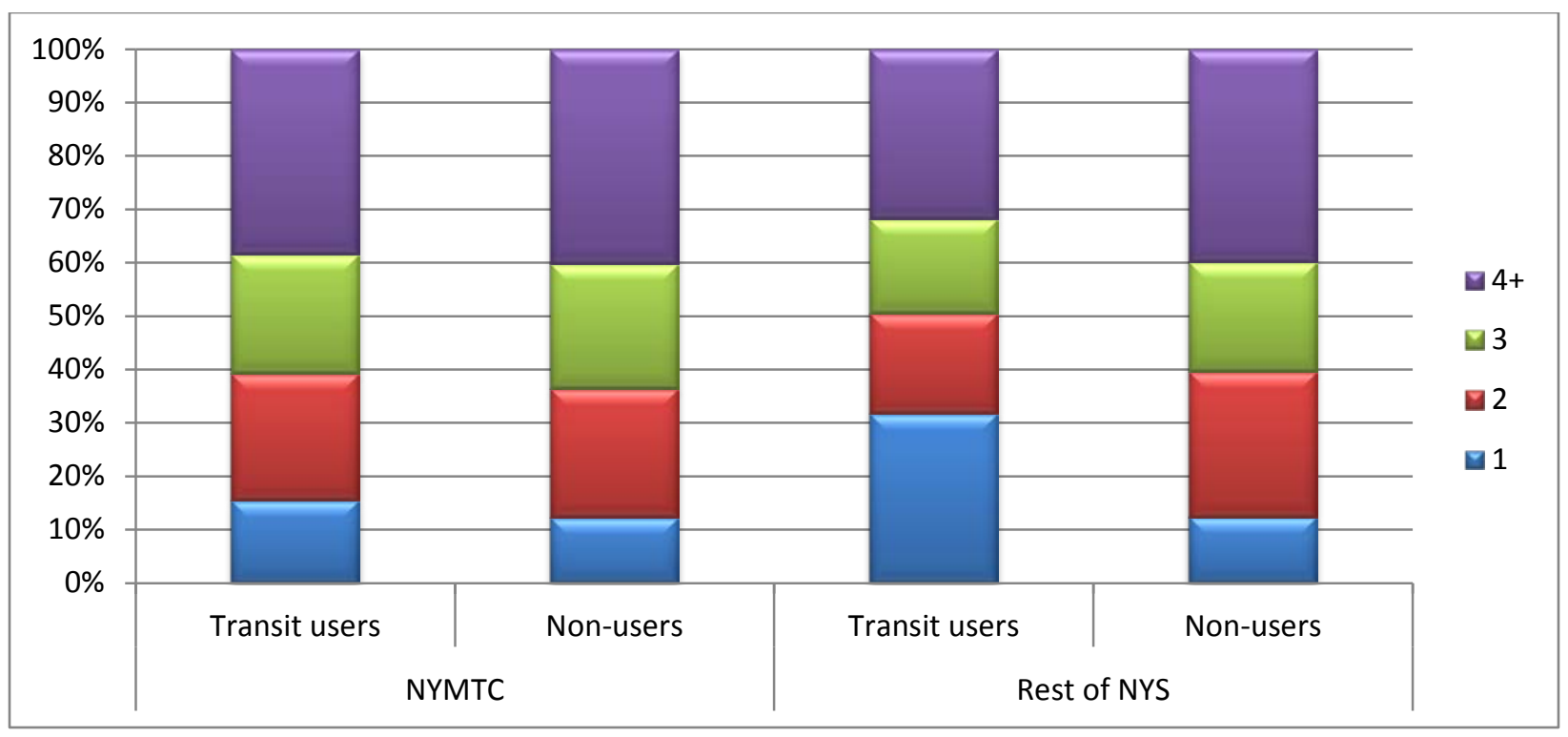

Figure 4-17. Distributions of population within 1-mile transit shed by household size, transit status, and region (source: 2009 NHTS).

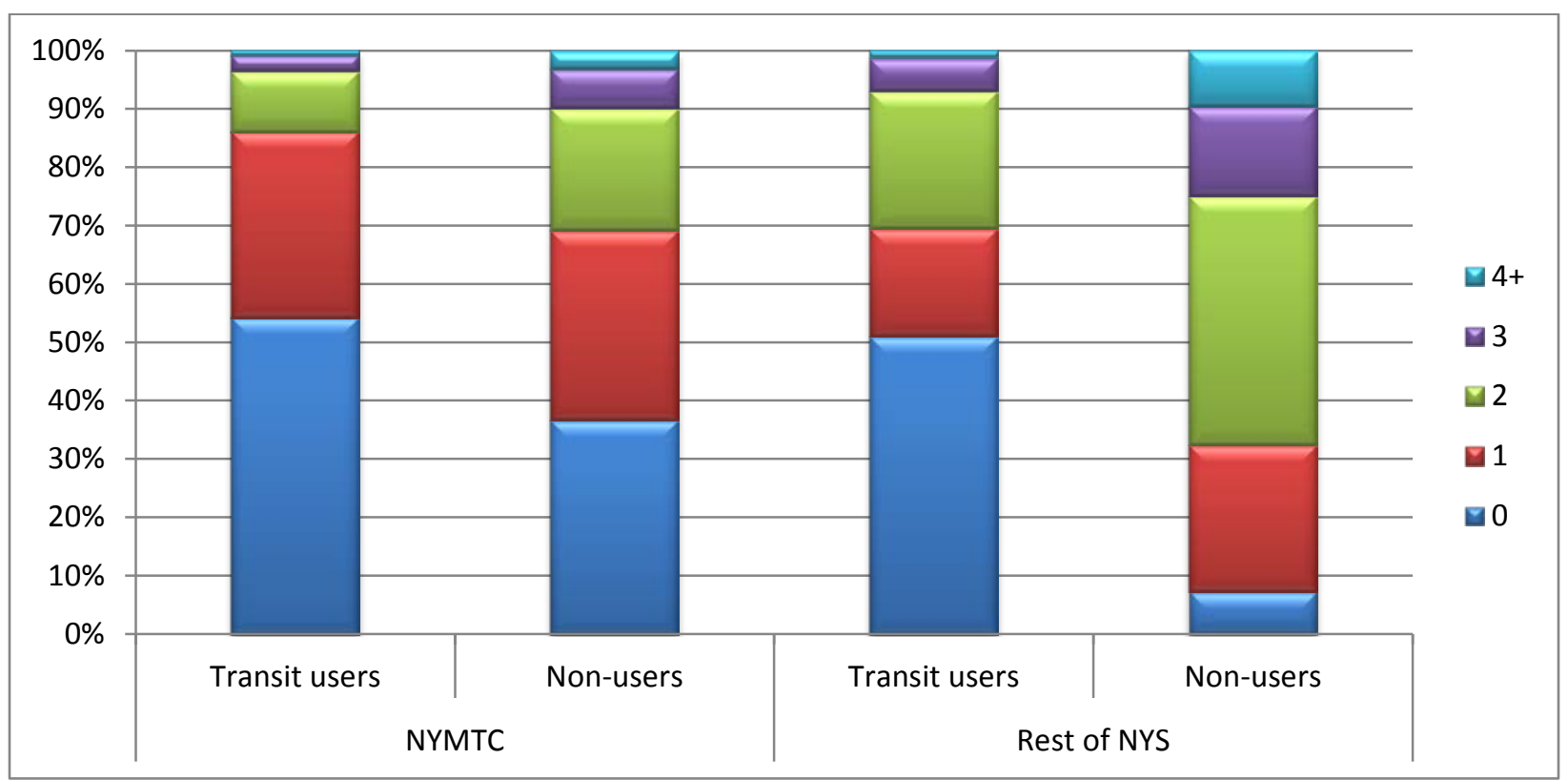

Figure 4-18. Distributions of population within 1-mile transit shed by vehicle ownership, transit status, and region (source: 2009 NHTS).

When examining these populations by household income categories, as shown in Figure 4-19, over $60 \%$ of transit users who lived within 1-mile transit shed in the Rest of NYS region were from households of the two lowest income-categories. This same population (i.e., household within 1-mile transit shed and from the two lowest income groups) accounted for about $45 \%$ among NYMTC residents. No significant difference was found among non-users from lower income groups within the two regions. 


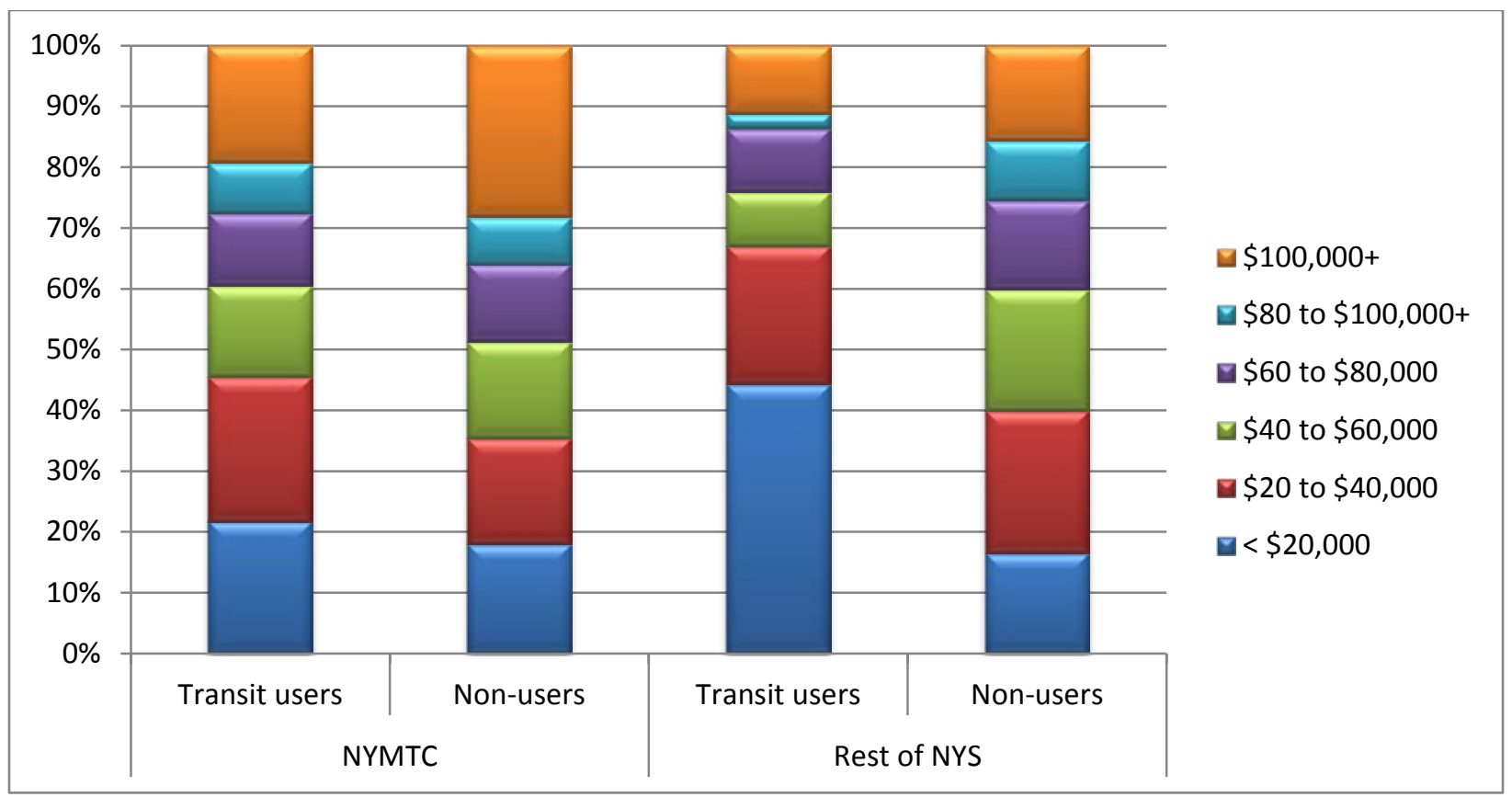

Figure 4-19. Distributions of households within 1-mile transit shed by household income, transit status, and region (source: 2009 NHTS). 


\section{COMMUTING BY TRANSIT}

\subsection{JOURNEY TO WORK}

In addition to examining travel behaviors of NYS transit users, data on the use of public transportation from the ACS, conducted by the U.S. Census Bureau, was also briefly reviewed. Note that transportation related ACS data is only available for work trips, i.e., a worker's travel from home to work place, also known as Journey to Work (JTW). The unit of measure for the ACS-associated transportation data is typically by worker, rather than trips as in the NHTS. This section used ACS data to investigate annual trends associated with transit usage by workers within NYS. This summary was prepared with the intent to provide additional information regarding worker-commuting activities by transit in NYS.

\subsubsection{Trends in Transit Mode Share for Commuting}

Based on annual ACS data, Figure 5-1 compares the mode shares of POV (car, truck, or van) and transit (public transportation) over the period from 2005 to 2013 for workers of NYMTC. The percent of workers that used transit for commuting clearly shows an increasing trend, while use of POV declined over the same time. ACS “public transportation” included bus or trolley bus, streetcar or trolley car, subway or elevated railroad, and ferryboat.

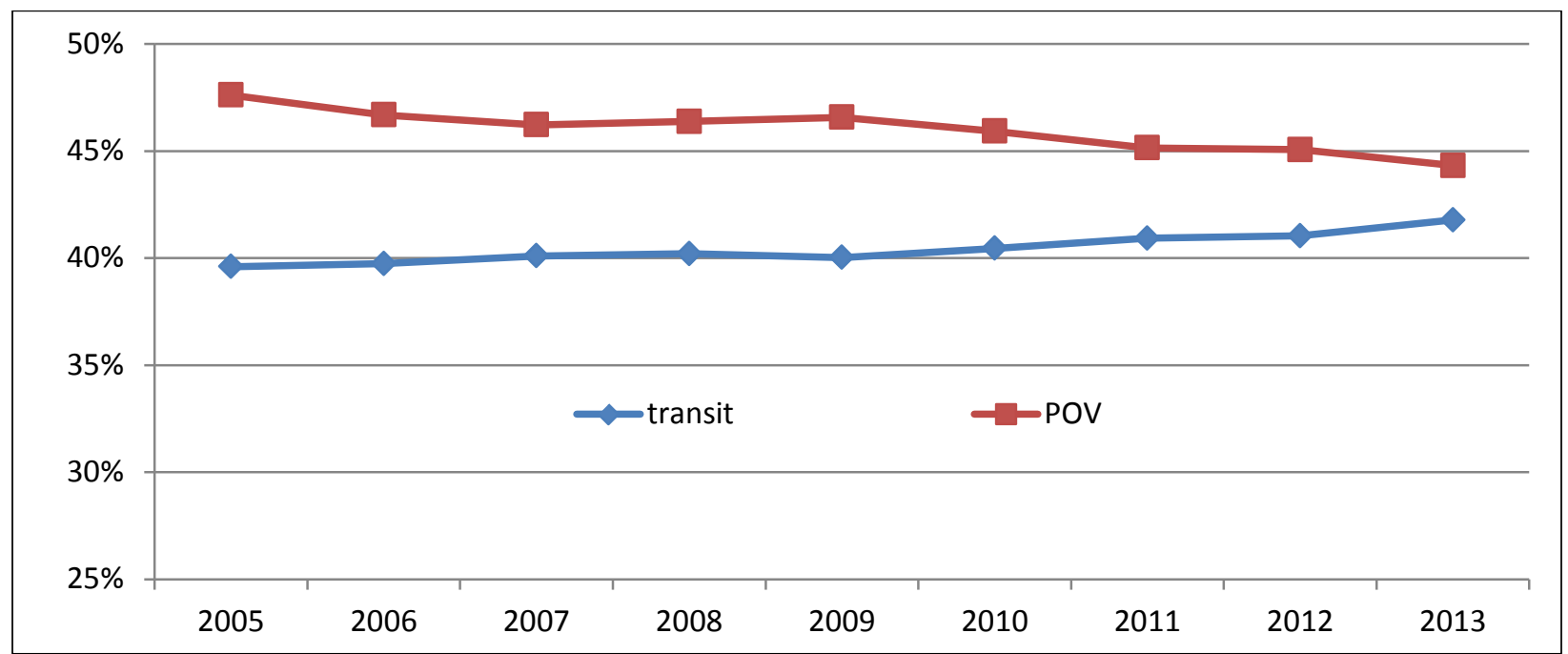

Figure 5-1. Transit and POV mode commuting shares for NYMTC workers (ACS data).

Over this 9-year period from 2005 to 2013, the total number of NYMTC workers increased more than 9\%, from about 5.3 million workers in 2005 to 5.8 million workers in 2013. Transit commuting, however, grew at a higher rate of more than $15 \%$ during the same 9 -year period, with 2.11 million workers using transit for commuting in 2005 to 2.44 million workers commuting by transit in 2013.

Transit commuting accounted for only a small share among workers living in the Rest of NYS. Typically around $2.5 \%$ of workers commuted using transit over the years from 2006 to 2013, with only about $2 \%$ in 2005 . Figure 5-2 uses two axes for displaying share of transit commuter 
(left side, in black) and commuting by POV (right side, in red) because of their large difference in scale. Total worker population in the Rest of NYS region changed slightly, about a 3\% increase from 2005 to 2013, representing about 3 million workers in 2005 and fewer than 3.2 million workers in 2013. Transit commuting, on the other hand, went from 65 thousand workers in 2005 to about 84 thousand workers in 2013, resulting in a 28\% increase. Note that, some of the increases in transit commuting might be due to the addition of transit services in recent years. Furthermore, Figure 5-1 and Figure 5-2 show trend lines for shares of POV and transit, reflecting nearly a mirror image of one another.

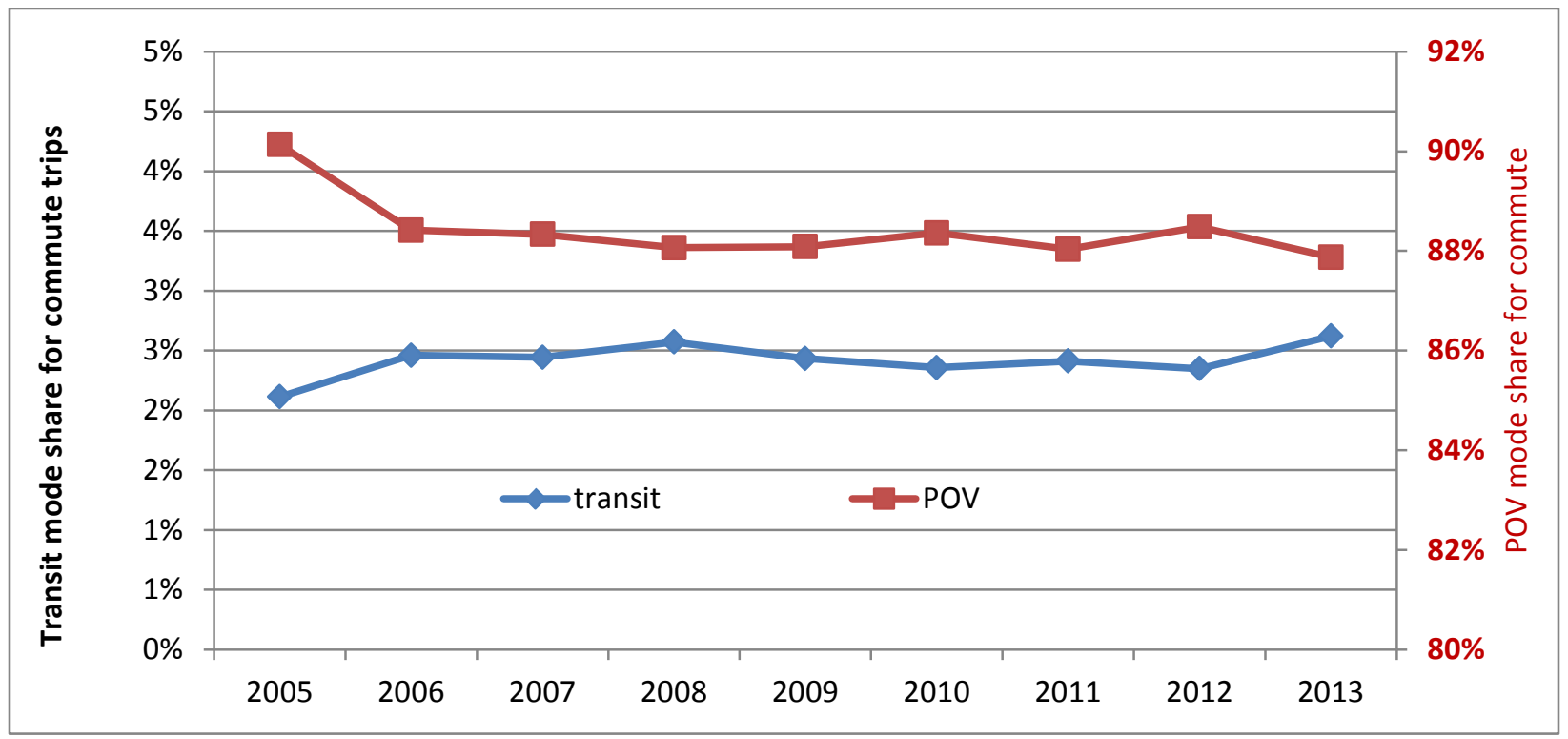

Figure 5-2. Transit and POV commuting mode shares for workers that was from the Rest of NYS (ACS data).

\subsubsection{Age Impact on Transit Commuting}

Consistent with findings from the 2009 NHTS, elderly New Yorkers were less likely to travel by transit than their younger counterparts were. Figure 5-3 shows this age difference using the ACS data for NYMTC workers. While over $40 \%$ of workers under age 65 commuted by transit during the period from 2005 to 2013; less than $30 \%$ of their elderly counterparts commuted by transit over the same period. Generally, transit commuting in NYMTC for both age groups shows an increasing trend over this timeframe. 


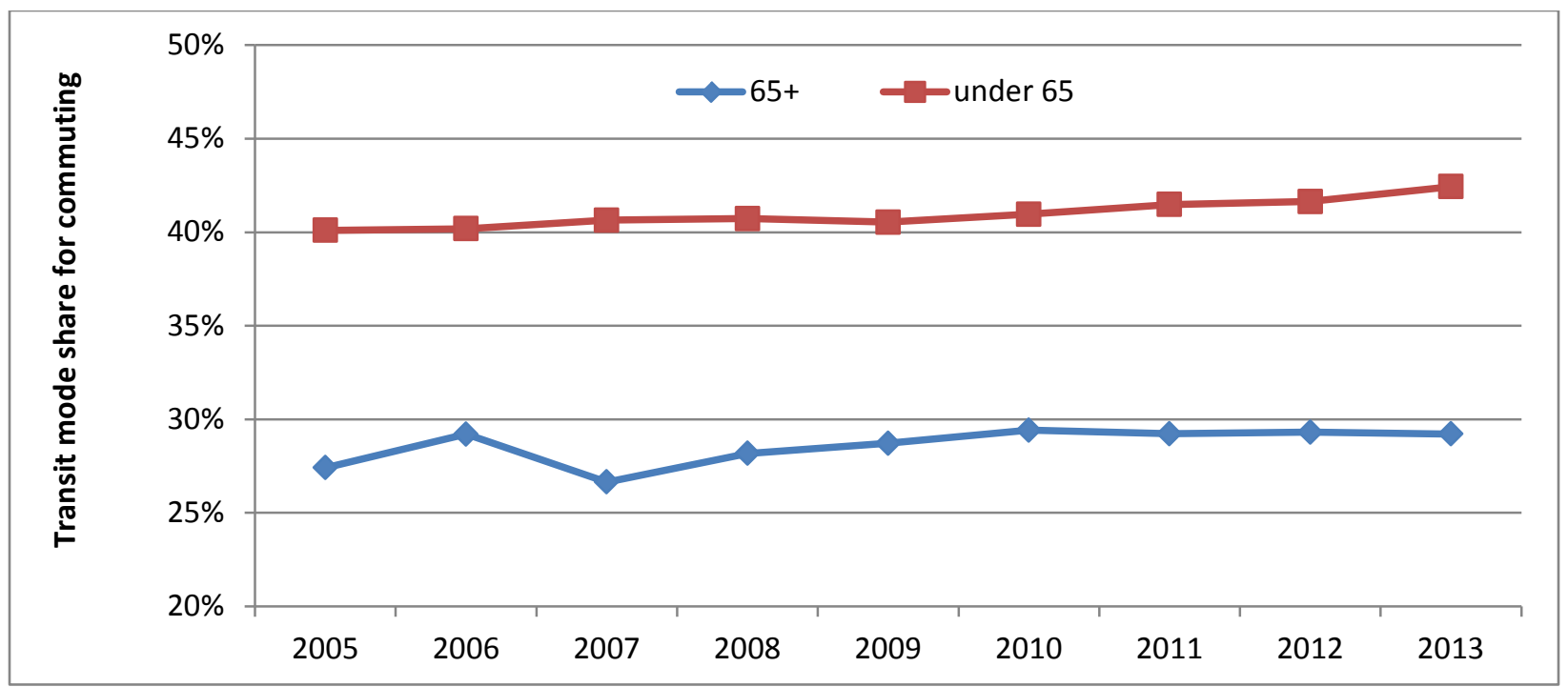

Figure 5-3. Transit commuting share by age group for workers in NYMTC (ACS data).

As pointed out previously, overall only about $2.5 \%$ of workers from the Rest of NYS commuted by transit. Because the majority of workers were younger than 65 years old, their transit commuting shares (shown in Figure 5-4) closely resembled those displayed in Figure 5-2. The transit commuting shares seen in Figure 5-4 presented a rather stable pattern for several years with a relatively higher increase from 2012 to 2013. The overall shares of transit commuting for elderly workers from the Rest of NYS (see Figure 5-4), on the other hand, revealed an overall declining pattern prior to 2013. The reason for the visible "cycle” pattern in transit shares of elderly workers seen in Figure 5-4 is unclear.

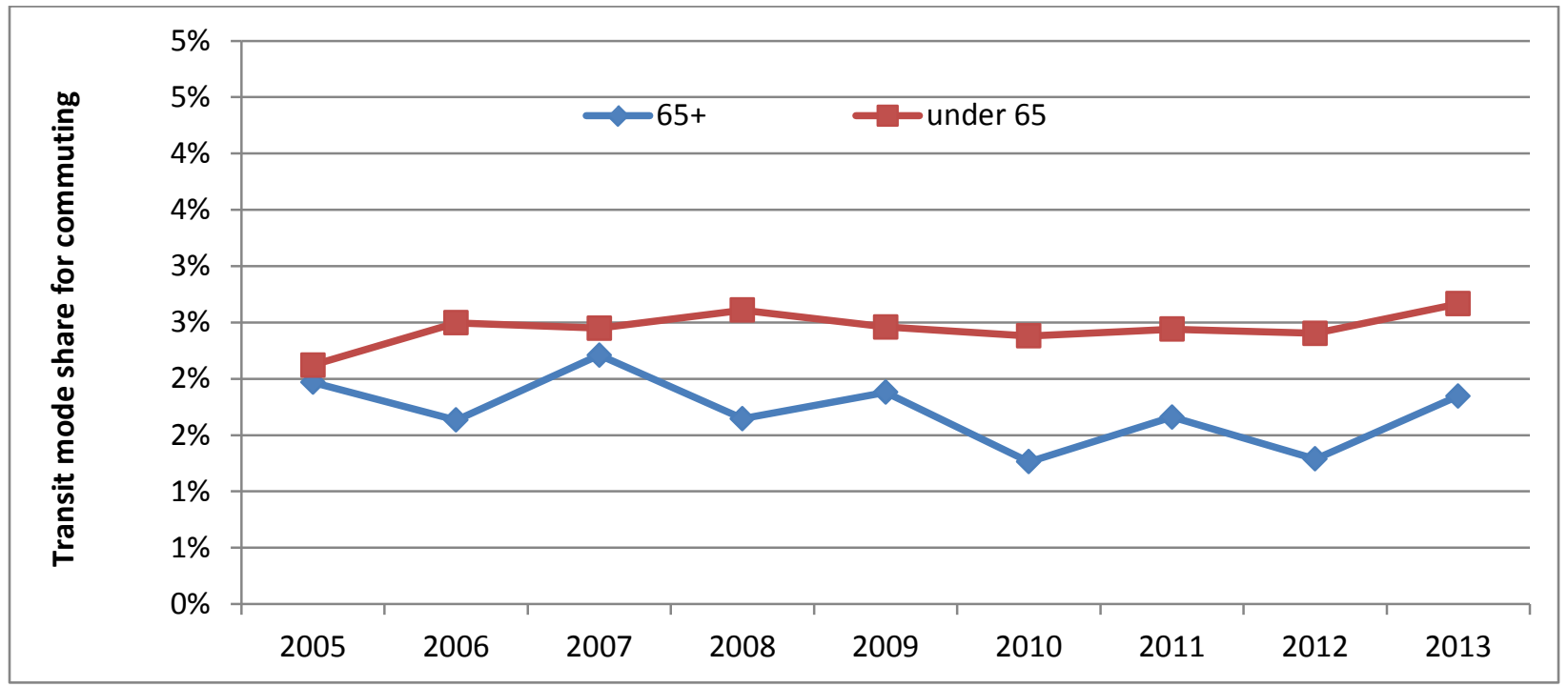

Figure 5-4. Transit commuting share by age group for workers in Rest of NYS (ACS data).

\subsubsection{Travel Time to Work by Transit}

Census data suggested that on average travel time to work (in minutes) for NYS worker commuters using transit consistently was longer than for their counterparts that commuted via 
other modes. Specifically, Figure 5-5 shows that transit commuters spent about twice as much time traveling for work as others, regardless of geographic regions (either NYMTC or Rest of NYS). While average travel time for transit commuting by NYMTC workers stayed around 50 minutes, over the period from 2005 to 2013, average non-transit commuting time during the same timeframe was only about 25 minutes. For workers from the Rest of NYS, transit commuting typically took over 45 minutes while non-transit commuting for workers from the same region was only about 20 minutes.

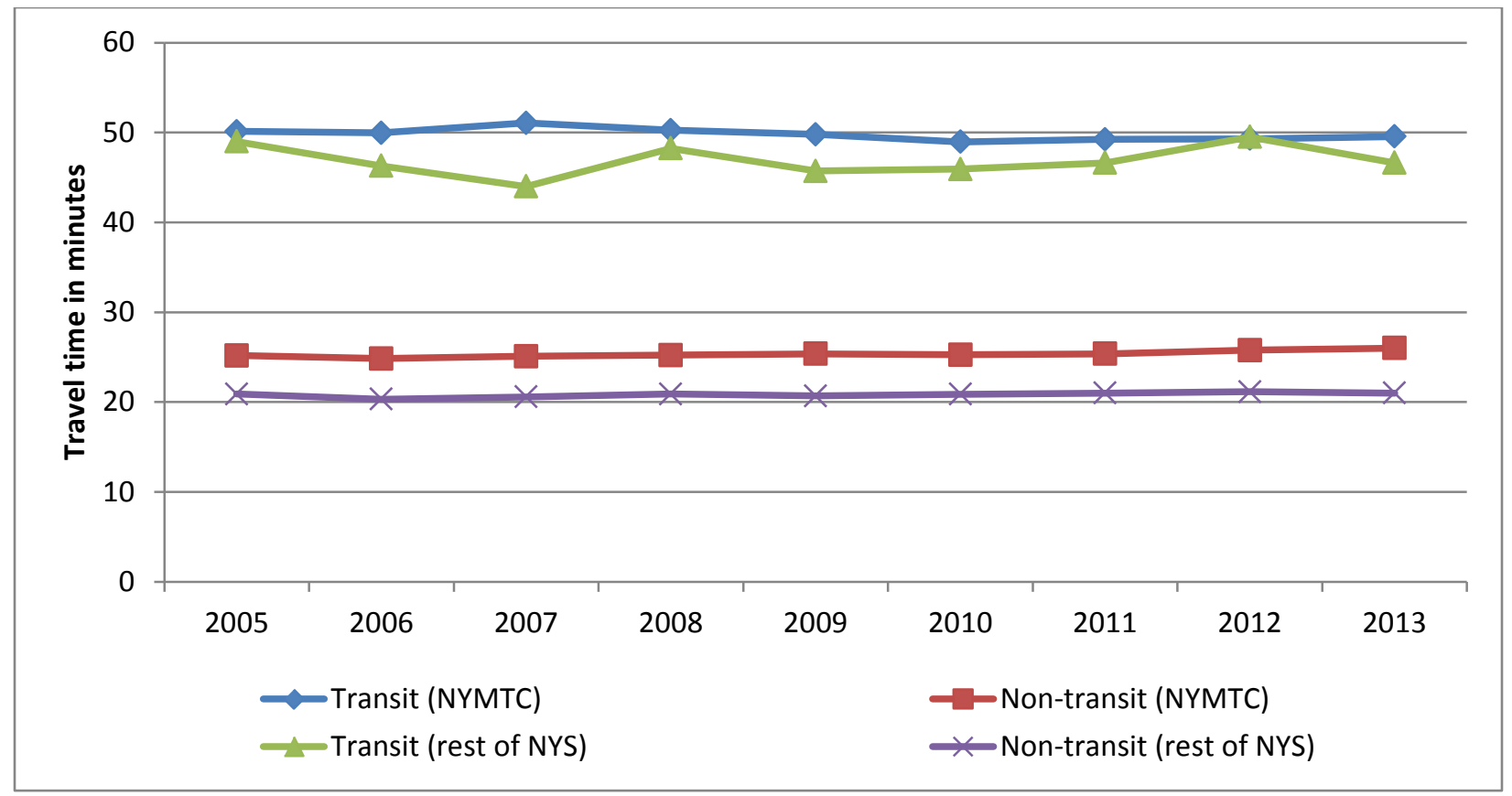

Figure 5-5. Average travel time (in minutes) by mode and geography of workers (ACS data).

\subsubsection{Relationship of Income to Transit Mode-Share for Commuting Trips}

The JTW data was also used to examine household income levels to transit use for commuting by NYS workers. Figure 5-6 shows that over the nine years from 2005 to 2013 the share of transit commuting by NYMTC workers who were from higher income households was consistently lower than those came from lower income households. While 40-44\% of workers from lower income households in NYMTC commuted by transit annually, only $35-39 \%$ of NYMTC workers from higher income households did so during the same years. Nonetheless, growth of transit shares for NYMTC commuters with household income over $\$ 50,000$, between 2005 and 2013, was slightly higher than from lower income households of the same region. 


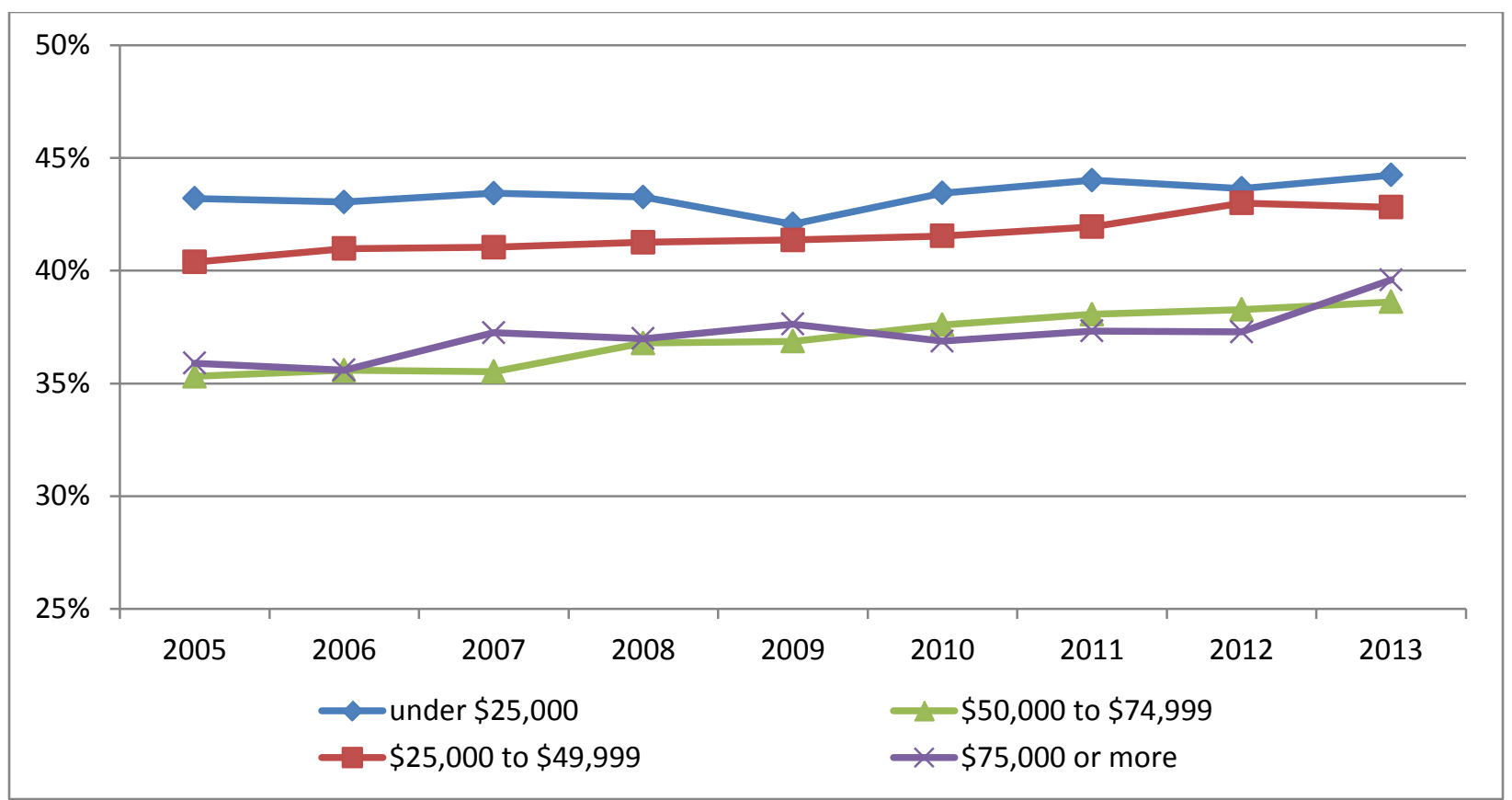

Figure 5-6. Transit mode shares for commuting by NYMTC workers and household income.

As presented in Figure 5-7, transit share as a mode for commuting was low, typically less than $4 \%$, in the Rest of NYS area. Specifically, workers from the lowest income group (under $\$ 25,000$ ) for the Rest of NYS were more likely to use transit for commuting than all others from the same region. In most cases, the level of transit commuting shares for workers from the Rest of NYS areas stayed relatively flat over the nine-year period from 2005 to 2013.

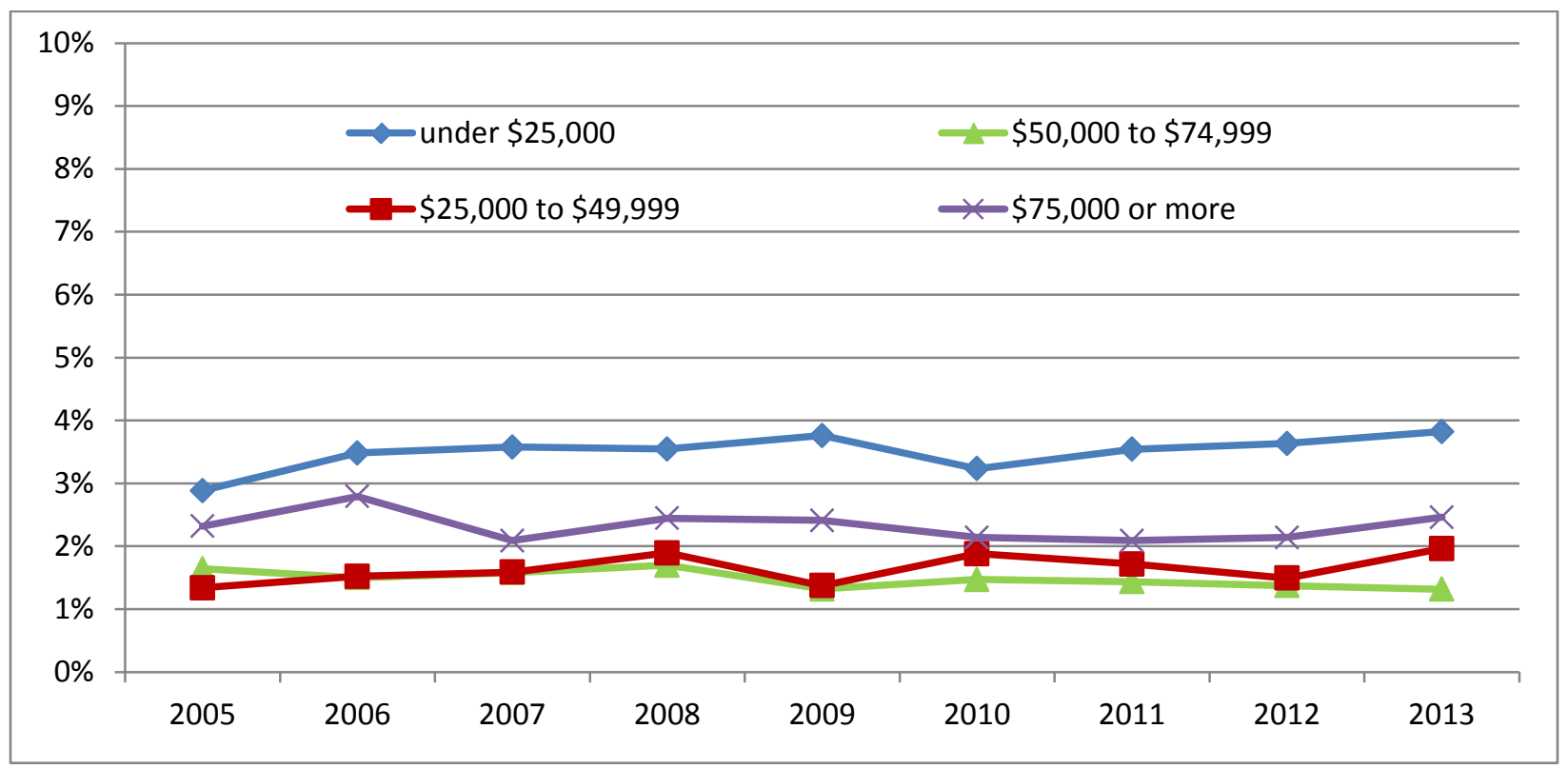

Figure 5-7. Transit shares for commuting for the Rest of NYS workers by household income. 


\subsection{TRANSIT AVAIABILITY AND BUSINESS LOCATIONS}

\subsubsection{Business Locations}

The NYSDOT provided the research team with a proprietary business database, namely InfoUSA (a product of Infogroup), which was used in a related study conducted for $\mathrm{NYS}^{8}$. This dataset contained business information (industry category, sales, employment size, etc.) and locations as of 2011 for businesses with 10 or more employees. Over 101 thousand business establishments were included in this dataset, representing more than 3.8 million employees and about $\$ 572$ million in sales. To illustrate the association between transit accessibility and businesses locations, this data was overlaid with the three transit sheds defined in this research and presented in Figure 5-8.

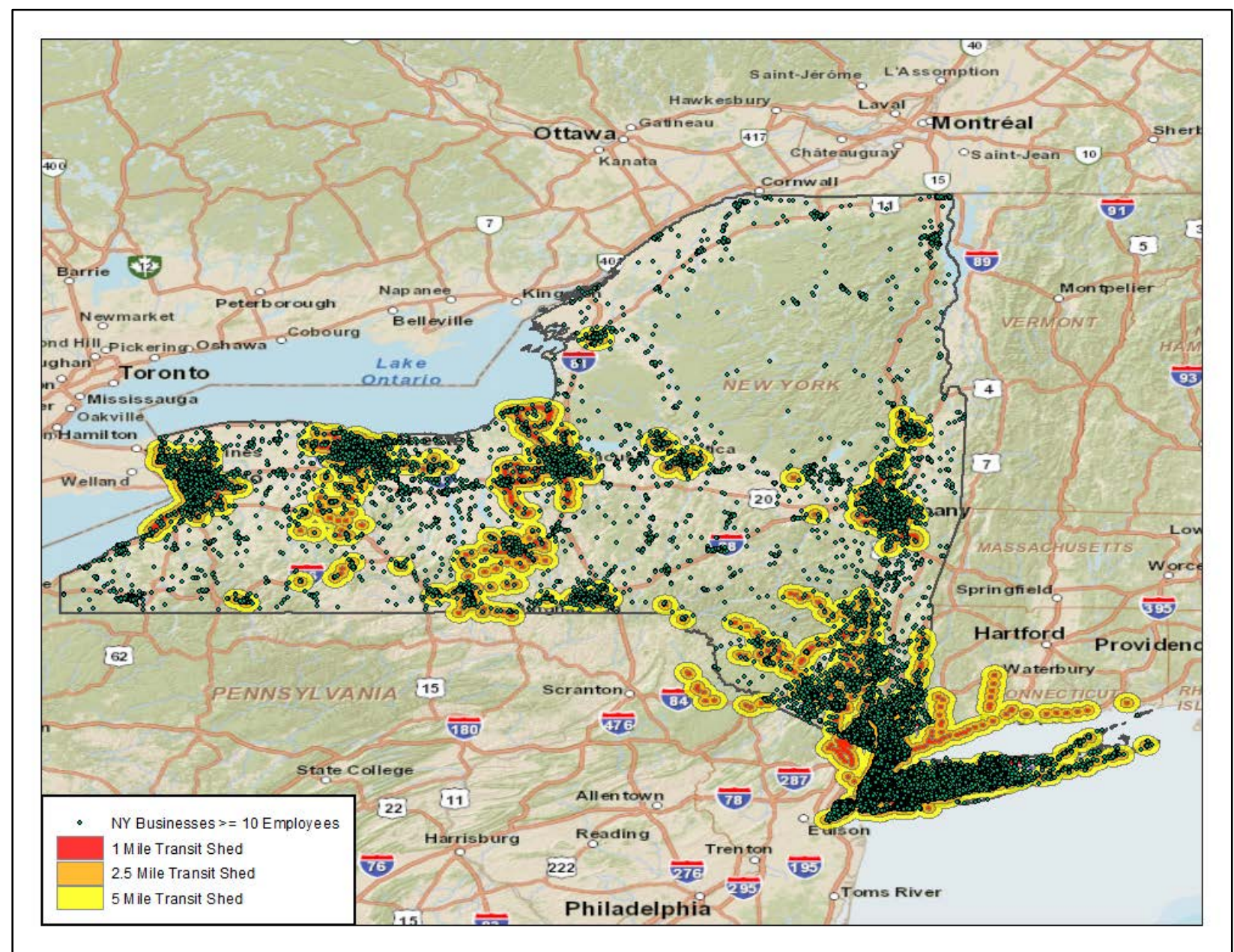

Figure 5-8. Locations of businesses (with 10 or more employees) overlaid on transit sheds in NYS.

\footnotetext{
${ }^{8}$ Hwang, H.L., D. Wilson, T. Reuscher, S.M. Chin, and R. Taylor, A Pilot Study to Explore Origin-Destination Passenger Travel Flow Patterns at Sub-County Level, ORNL/TM-2014/233, Oak Ridge Nation Laboratory, June 2014.
} 
As observed from the map, locations of business with 10 or more employees (shown in green points) are mainly concentrated in major urban areas, where transit services generally are available. Note that this dataset excluded small merchants or services that fell outside the " 10 or more employees" which is a limitation of this dataset. Because most businesses are likely to locate around population centers, the general pattern of business clusters as seen in Figure 5-8 would remain the same if all sizes of businesses were included.

\subsubsection{Transit Accessibility for Businesses}

By spatially analyzing business locations and transit sheds as presented above, the researchers also studied transit accessibility to business locations by distance to transit. Table 5-1 provides several business statistics for NYS regions covered under the transit sheds defined in this study. Three sets of statistics were considered here: number of business establishments, number of employees, and total volume of sales. More so than the population coverage (shown in Table $2-1$ ), about $90 \%$ of businesses with 10 or more employees are located within close proximity of transit stops (i.e., the 1-mile transit shed).

Table 5-1. Coverage of NYS Businesses with Ten or More Employees by Distance to Transit

\begin{tabular}{lccr}
\hline \multicolumn{1}{c}{ Distance to Transit } & $\begin{array}{c}\text { Percent of } \\
\text { Businesses }\end{array}$ & Percent of employees & $\begin{array}{c}\text { Percent of Total } \\
\text { sales }\end{array}$ \\
\hline 1 mile or less & $87.4 \%$ & $91.2 \%$ & $90.6 \%$ \\
$1-2.5$ miles & $6.3 \%$ & $5.2 \%$ & $5.9 \%$ \\
2.5 - 5 miles & $3.0 \%$ & $2.4 \%$ & $2.7 \%$ \\
Over 5 miles & $3.3 \%$ & $1.1 \%$ & $0.8 \%$ \\
All & $100.0 \%$ & $100.0 \%$ & $100.0 \%$ \\
\hline
\end{tabular}

In fact, about $82 \%$ of the over 101 thousand businesses in NYS were located in the NYMTC region. By employment, businesses in NYMTC accounted for over $93 \%$ of the 3.8 million employees in NYS, and nearly 95\% of the total sales in the state. As pointed out previously, transit coverage in the NYMTC region is rather intensive. Thus, Table 5-2 shows no surprises, in that about $91-93 \%$ of businesses by all measures in NYMTC were located within close proximity of transit.

Of the remaining businesses that are located outside NYMTC region, as shown in Table 5-3, over $70 \%$ of them are still in close proximity of transit stops (i.e., within 1-mile transit shed), most likely coinciding with transit availability around major city centers. Still, unlike in NYMTC, a significant percent of businesses located outside all three transit-sheds accounted for $18 \%$ of the businesses, $16 \%$ of the number of employees, and $15 \%$ of business sales. 
Table 5-2. Coverage of NYMTC Businesses with 10 or More Employees by Distance to Transit

\begin{tabular}{lccr}
\hline \multicolumn{1}{c}{ Distance to Transit } & $\begin{array}{c}\text { Percent of } \\
\text { Businesses }\end{array}$ & Percent of Employees & $\begin{array}{c}\text { Percent of Total } \\
\text { Sales }\end{array}$ \\
\hline 1 mile or less & $91.1 \%$ & $92.7 \%$ & $91.6 \%$ \\
$1-2.5$ miles & $6.0 \%$ & $4.9 \%$ & $5.8 \%$ \\
$2.5-5$ miles & $2.8 \%$ & $2.3 \%$ & $2.6 \%$ \\
Over 5 miles & $0.1 \%$ & $0.1 \%$ & $0.1 \%$ \\
All & $100.0 \%$ & $100.0 \%$ & $100.0 \%$ \\
\hline
\end{tabular}

Table 5-3. Coverage of Businesses (10 or More Employees) in Rest of NYS by Distance to Transit

\begin{tabular}{lccc}
\hline \multicolumn{1}{c}{ Distance to Transit } & $\begin{array}{c}\text { Percent of } \\
\text { Businesses }\end{array}$ & Percent of Employees & $\begin{array}{c}\text { Percent of Total } \\
\text { Sales }\end{array}$ \\
\hline 1 mile or less & $70.7 \%$ & $71.1 \%$ & $73.3 \%$ \\
$1-2.5$ miles & $7.6 \%$ & $8.9 \%$ & $7.7 \%$ \\
2.5 - 5 miles & $3.9 \%$ & $4.2 \%$ & $4.6 \%$ \\
Over 5 miles & $17.8 \%$ & $15.7 \%$ & $14.5 \%$ \\
All & $100.0 \%$ & $100.0 \%$ & $100.0 \%$ \\
\hline
\end{tabular}

\subsubsection{An Observation on Businesses with Less Than 10 Employees}

The 2011 Business Data used in the above analysis covered only businesses with 10 or more employees. Thus many small businesses, which are likely located around population centers, were not considered. To examine the scale of impact on employment coverage (i.e., job availability) due to "missing" small business establishments, NYS statistics obtained from the 2012 Economic Census ${ }^{9}$ and the 2011 County Business Patterns (CBP) from Census were examined. Table 5-4 shows several measures on the shares of NYS businesses that had less than 10 employees in 2012 and 2011, using Economic Census and CBP data, respectively.

Nearly 70\% of all business establishments qualified as small businesses (less than 10 employees) in NYS in 2012, while it was estimated at 77\% for 2011. However, these NYS small businesses accounted for only about $12-15 \%$ of employment offered by all businesses in the state. On financial impact, these small businesses attributed to roughly $10 \%$ of the total annual payroll. Note that information on total business receipts was only available from the 2012 Economic Census (i.e., not available for 2011). These statistics reassured that even though small businesses are very large in terms of the number of businesses, their combined economic impacts (on jobs, sales, etc.) is much smaller in scale. Again, most of these small businesses are expected to colocate with populations, thus no significant changes from those presented in Tables 5-2 and 5-3 above were anticipated.

\footnotetext{
${ }^{9}$ The Economic Census is conducted by the U.S. Census Bureau on a five-year interval during the years ending in 2 and 7. It is the U.S. Government's office measure of American business and the economy.
} 
Table 5-4. Percent of NYS Small Businesses by Select Economic Measures

\begin{tabular}{cccccc}
\hline Economic Factor & Year & Establishment & Employment & $\begin{array}{c}\text { Annual } \\
\text { Payroll }\end{array}$ & Receipts \\
\hline $\begin{array}{c}\text { Percent of businesses } \\
\text { with }<10 \text { employees }\end{array}$ & 2012 & $69 \%$ & $12 \%$ & $9 \%$ & $11 \%$ \\
\hline
\end{tabular}

\subsection{INFORMATION FROM THE SMART LOCATION DATABASE}

\subsubsection{Limited Data Availability}

The EPA SLD data associated with NYS was extracted for further reviews. Although this dataset includes many desirable variables listed in Section 1.3.5 (e.g., jobs within 45-minutes transit commute), its geographic coverage was rather spotty. Within the NYS, SLD transitrelated data is available only in three regions: New York City (NYMTC), Rochester (Genesee Transportation Council or GTC), and Buffalo (Greater Buffalo-Niagara Regional Transportation Council, or GBNRTC), and mainly driven by GTFS systems that were covered in the current release of SLD.

The SLD data is available at Census Block Group-level and distance measures such as distance to transit or jobs are typically estimated from the population-weighted centroid of a block group. The latest release of SLD covers 9,612 block groups in the NYMTC, 665 block groups in the GTC, and 954 block groups in the GBNRTC. Several variables from the SLD dataset were reviewed, particularly those associated with transit, i.e., "proportion of block group employment within half-mile of fixed-guideway transit stop," “jobs within 45-minute transit commute,” and "working-age population within 45-minute transit commute."

\subsubsection{Access to Fixed-Guideway Transit}

It is important to note that there is no fixed-guided transit in the GTC region, thus the distribution of block groups shown in Figure 5-9 includes only two regions, NYMTC and GBNRTC. As seen in Figure 5-9, about a third of the 9,612 block groups in NYMTC had no accesses to fixedguideway transit; while over $90 \%$ of the 954 GBNRTC block groups did have access. Nearly half of all NYMTC block groups have $80-100 \%$ of their employment within a half-mile of fixedguideway transit stops, but only $3 \%$ of block groups in the GBNRTC region. This characteristic is consistent with the intensity of transit coverage in the NYMTC region, and reflects the limited transit usage outside NYMTC. 


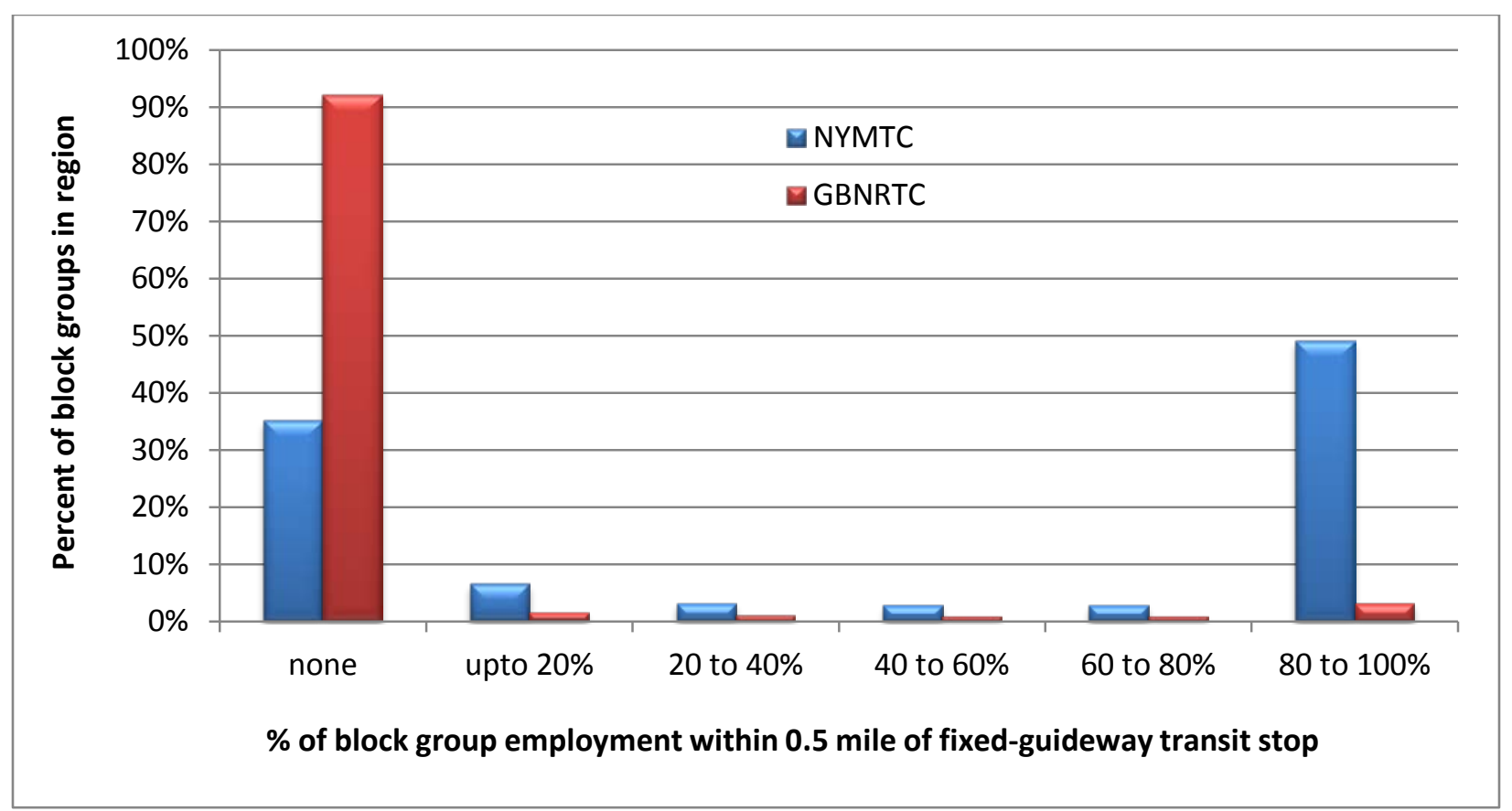

Figure 5-9. Distribution of block groups by the proportion of block-group employment within 0.5 mile of fixed-guideway transit stops in NYMTC and GBNRTC regions (EPA SLD data).

\subsubsection{Jobs and Worker Accessibility by Transit}

Figure 5-10 displays the distribution of NYMTC block groups by two select SLD variables. The blue bars show the number of jobs that were accessible within a 45-minute transit commute from a given block group in the region, and the other (in red) for the working-age population (i.e., availability of workers) within a 45-minute transit commute from the block group. Slightly over $20 \%$ of the total number of block groups in NYMTC could not access any jobs or workers within a 45-minute transit commute, likely due to lack of transit coverage in those block groups. This percent is smaller than the one shown in Figure 5-9, mainly because the prior one (about onethird of all block groups) considered fixed-guideway transit only.

Similar distributions for GBNRTC and GTC are provided in Figure 5-11 and Figure 5-12, respectively. Not surprisingly, transit coverage is not as good as in NYMTC for these areas, thus about 25\% of GBNRTC block groups and nearly 30\% of GTC block groups were not accessible to jobs or to workers within a 45-minute transit commute. Note that the distributions based on jobs accessibility seem to have a slightly wider range than their counterparts related to worker accessibility. Although block groups included in this analysis were drawn from NYS, jobs accessible within a 45-minute transit commute as well as working-age population within a 45minute transit commute could go beyond the NYS boundary (e.g., New Jersey or Connecticut). 


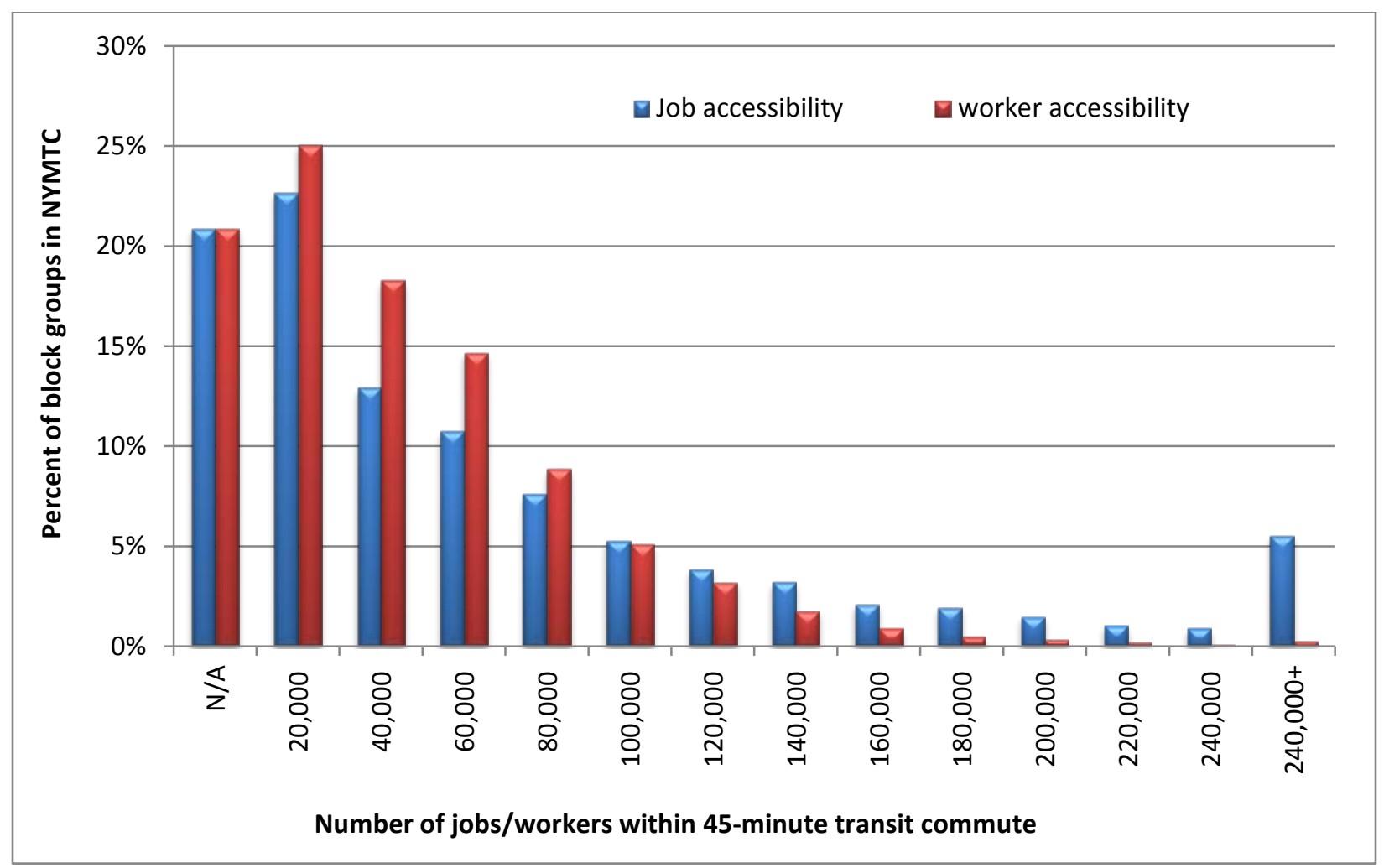

Figure 5-10. Distribution of block groups in NYMTC by the number of jobs/workers within a 45-minute transit commute (EPA SLD data).

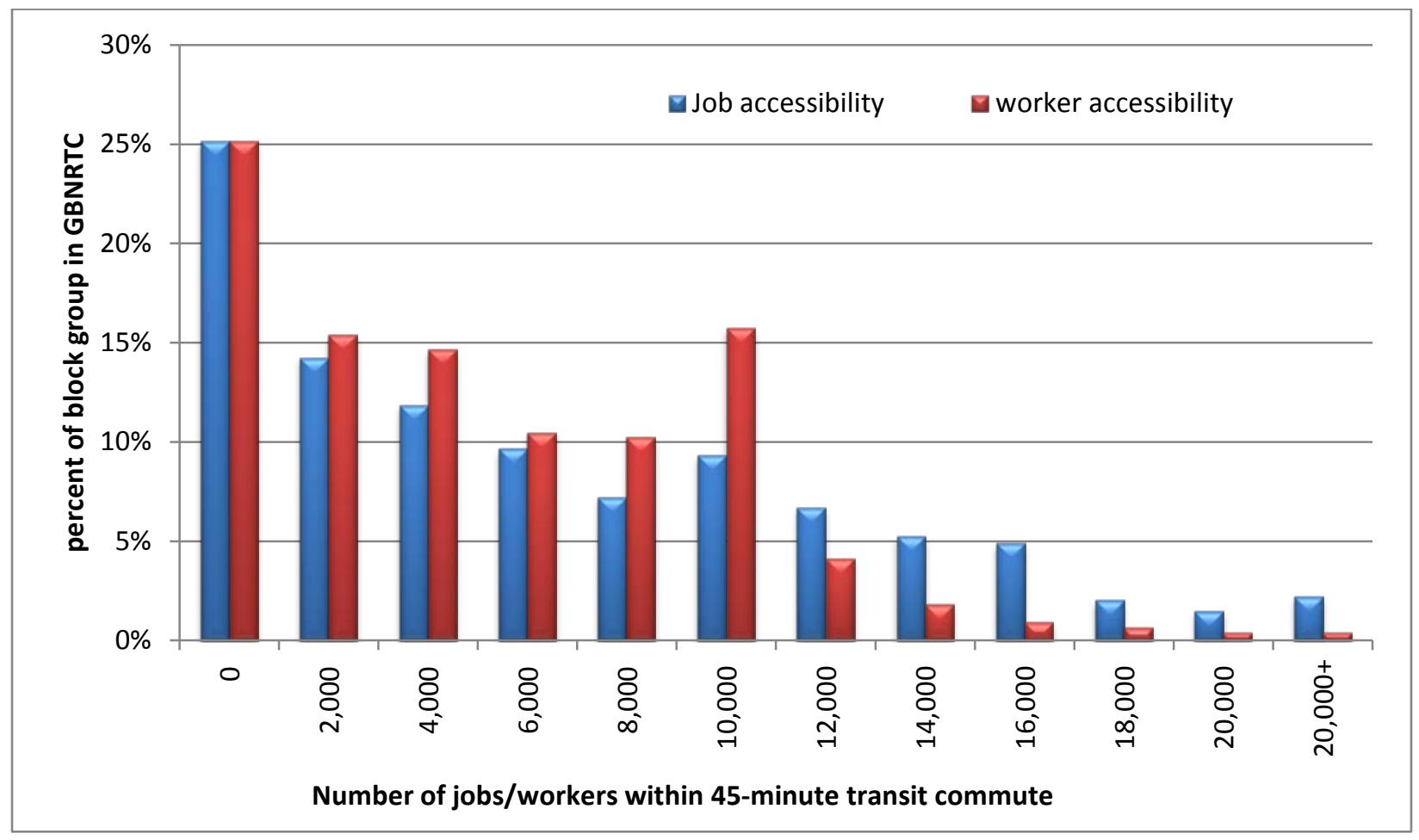

Figure 5-11. Distribution of block groups in GBNRTC by the number of jobs/workers within a 45-minute transit commute (EPA SLD data). 


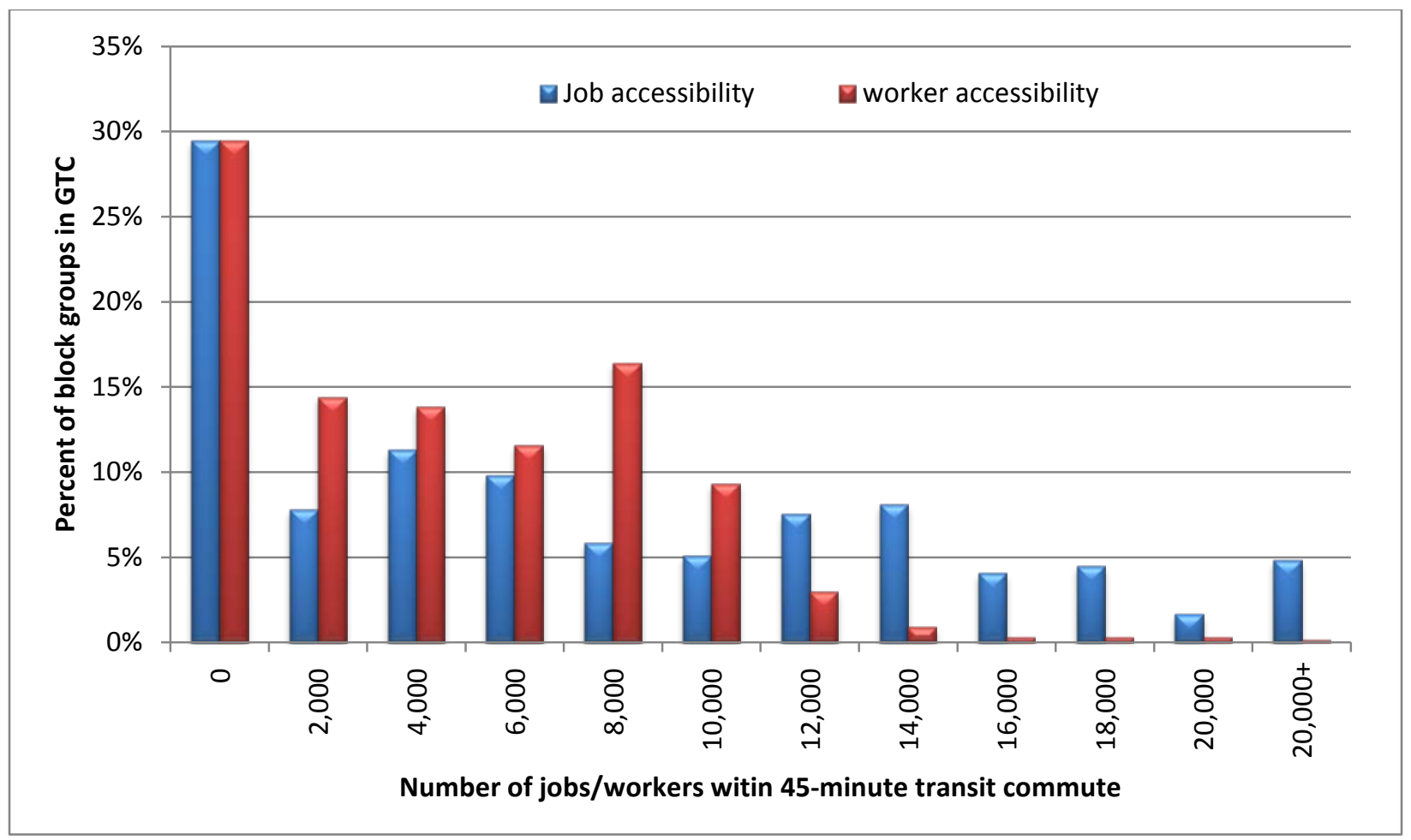

Figure 5-12. Distribution of block groups in GTC by the number of jobs/workers within a 45-minute transit commute (EPA SLD data). 


\section{SUMMARY}

This report describes research conducted using the 2009 NHTS data to examine and analyze travel characteristics of NYS transit users. Although NYMTC occupies only $4 \%$ of the land area in NYS, it is where approximately $60 \%$ of the entire NYS population lives. Thus, inclusion of NYMTC in analyses can likely produce misleading conclusions for the regions outside NYMTC. Because of this, two geographic regions (NYMTC and the Rest of NYS) were used throughout this study so that travel patterns for transit users who lived outside the New York City region could be properly examined.

The NYS transit network has significant coverage in terms of transit stop locations across the state's population. Out of the 19.3 million NYS population in 2011, about 15.3 million (or 79\%) resided within the 1-mile transit shed. This NYS population "transit coverage" increased to 16.9 million (or 88\%) when a 2.5-mile transit shed was considered and increased to 17.7 million (or 92\%) when the 5-mile transit shed was applied.

\subsection{KEY FINDINGS}

\subsubsection{Demographic Characteristics of Transit Users}

- Based on 2009 NHTS data, about 40\% of NYMTC households used transit as their means of transportation on any typical day, while only $4 \%$ of households lived elsewhere in NYS did the same.

- Single-occupant households in NYS were more likely to use transit as their main mode of transportation for daily activities than those from multiple-person households.

- A large portion of transit users came from zero-vehicle households, regardless of geographic region and accounted for 53\% of the transit users in NYMTC and $46 \%$ of transit users from the Rest of NYS.

- About $15 \%$ of elderly NYMTC residents used transit, versus around 30\% for their younger counterparts who lived in the same region. Although transit usage in the Rest of NYS was not common, the younger residents were about twice as likely to use transit as compared to their elderly neighbors.

- Regardless of geographic regions, $45 \%$ of their transit users came from households with income under $\$ 40,000$, while $20 \%$ of transit users were from the top income group of $\$ 100,000$ plus households.

\subsubsection{Travel Patterns and Trip Characteristics of Transit Users}

- Travel made by NYMTC transit users was nearly twice as likely to be for work trips, as compared to their counterpart non-transit users. No similar pattern was found in trips made by residents from the Rest of NYS. 
- For commuting person-trips by NYMTC residents, $45 \%$ of the total was taken by transit users; while less than $30 \%$ of trips were made for each of the other purposes by transit users.

- Trip rates for all NYS households and those who lived within the 1-mile transit shed were consistent for transit usage.

- Table 6-1 provides a summary of the average daily trip rates by transit use status for travel made by residents of NYMTC and the Rest of NYS. Transit users generally made more person-trips but with shorter distances (fewer PMT) than non-users. Transit users also drove less (smaller VT) and with fewer miles (smaller VMT).

Table 6-1. Average Daily Trip Rates by Transit Use Status and Geographic Location

\begin{tabular}{|l|r|r|r|r|r|r|r|r|}
\hline \multicolumn{10}{|c|}{ All NYS Households } \\
\hline $\begin{array}{l}\text { Geographic } \\
\text { Region }\end{array}$ & \multicolumn{7}{|c|}{ Transit Users } & \multicolumn{1}{|c|}{ Non-Users } \\
\cline { 2 - 9 } & PT & PMT & VT $^{\mathbf{1}}$ & VMT $^{\mathbf{1}}$ & \multicolumn{1}{c|}{ PT } & PMT & VT $^{\mathbf{1}}$ & VMT $^{\mathbf{1}}$ \\
\hline NYMTC & 4.2 & 18.8 & 0.4 & 3.7 & 3.4 & 22.0 & 2.7 & 20.1 \\
\hline Rest of NYS & 4.4 & 34.7 & 0.8 & 12.2 & 3.7 & 34.0 & 3.1 & 28.1 \\
\hline \multicolumn{8}{|c|}{ NYS households lived within 1-mile of transit } \\
\hline NYMTC & 4.2 & 18.0 & 0.3 & 3.2 & 3.3 & 19.8 & 2.5 & 17.4 \\
\hline Rest of NYS & 4.5 & 39.3 & 0.8 & 10.0 & 3.6 & 32.3 & 3.1 & 26.4 \\
\hline
\end{tabular}

1 - VT and VMT measured as per driver, instead of per person

- Although no significant differences on average PT lengths (in miles) were identified between transit users and non-users, a regional difference was observed.

- Transit users from NYMTC spent over 75\% more time per trip (measured in PT) than non-users from the same region in 2009, and averaged 35 minutes per trip for transit users versus a 20-minute per trip average for non-users. Furthermore, it took a transit user from the Rest of NYS an average of 31 minutes to finish a trip, while a non-user counterpart spent only about 18 minutes on a trip, or about $72 \%$ shorter time.

- Statistics based on past-month transit use status was generally consistent with those produced based on travel day information. About a quarter of past-month transit users from the NYMTC area could be considered as occasional transit riders while nearly $40 \%$ used transit more than 5 times per week (i.e., took transit more than 21 times in the past 30 days). One could expect that part of these might be attributed to transit commuters that NHTS failed to capture.

\subsubsection{Influence of Distance to Transit}

- Because of the intensity of transit network services within NYMTC, not surprisingly 88\% of the region's households reside within the 1-mile transit shed. Outside the NYMTC, however, only $54 \%$ of the region's households are located within the same distance. 
- In NYMTC, 93\% of the population from single-person households lived within the 1mile transit shed, while $61 \%$ of those from single-person households in the Rest of NYS lived within the same distance from transit stops.

- Impact from vehicle ownership was evident. Nearly all people from zero-vehicle households in NYMTC lived within a 1-mile radius of transit stops. Elsewhere in the NYS 74\% of persons from zero-vehicle households also resided within the 1-mile transit sheds.

- Close proximity to transit seems to have a significant impact on increasing transit use. As shown in Table 6-2, transit mode share (as a main mode) was 18\% for NYMTC residents that lived within the 1-mile transit shed, compared to the transit share of $16 \%$ when all NYMTC populations were combined.

Table 6-2. Share of Main Mode Used by Distance to Transit and by Region (Measured by PT)

\begin{tabular}{|c|c|c|c|c|c|c|c|c|}
\hline \multirow[b]{2}{*}{$\begin{array}{l}\text { Main } \\
\text { Mode }\end{array}$} & \multicolumn{4}{|c|}{ NYMTC } & \multicolumn{4}{|c|}{ Rest of NYS } \\
\hline & $\begin{array}{c}<=1 \\
\text { miles }\end{array}$ & $\begin{array}{l}1-2.5 \\
\text { miles }\end{array}$ & $\begin{array}{l}2.5-5 \\
\text { miles }\end{array}$ & $\begin{array}{c}>5 \\
\text { miles }\end{array}$ & $\begin{array}{c}<=1 \\
\text { miles }\end{array}$ & $\begin{array}{l}1-2.5 \\
\text { miles }\end{array}$ & $\begin{array}{l}2.5-5 \\
\text { miles }\end{array}$ & $\begin{array}{c}>5 \\
\text { miles }\end{array}$ \\
\hline POV & $44 \%$ & $81 \%$ & $84 \%$ & $90 \%$ & $81 \%$ & $88 \%$ & $88 \%$ & $86 \%$ \\
\hline Walk/bike & $33 \%$ & $12 \%$ & $8 \%$ & $9 \%$ & $12 \%$ & $8 \%$ & $7 \%$ & $9 \%$ \\
\hline Transit & $18 \%$ & $2 \%$ & $2 \%$ & 0\% & $2 \%$ & 0\% & $0 \%$ & $0 \%$ \\
\hline Others & $5 \%$ & $5 \%$ & $5 \%$ & $0 \%$ & $5 \%$ & $4 \%$ & $5 \%$ & $4 \%$ \\
\hline All mode & $100 \%$ & $100 \%$ & $100 \%$ & $100 \%$ & $100 \%$ & $100 \%$ & $100 \%$ & $100 \%$ \\
\hline
\end{tabular}

\subsubsection{Transit Commuting Trend}

- Based on ACS data, over the period from 2005 to 2013, the total number of NYMTC workers increased more than $9 \%$, while transit commuting grew at a higher rate of more than $15 \%$ during the same period.

- During this period, the total worker population in the Rest of NYS region changed slightly, about a 3\% increase from 2005 to 2013. Transit commuting for people that lived in this area, on the other hand, showed a $28 \%$ increase. Note that some of the increases in transit commuting could be due to additional transit services (i.e., outside the New York City region) in recent years.

\subsection{ADDITIONAL REVIEW NOTES}

\subsubsection{Distance to Transit From Trip Origins}

A limited examination considering the influence of distance-to-transit using the location where a trip began or ended (instead of household locations) was also carried out in this research. Since most NHTS-trips have a reverse order return trip, statistics based on trip origins or destinations were not expected to be significantly different from each other. Because of this reason, Table 6-3 presents the statistics on share of transit use as generated from review of trip origin locations. 
As illustrated in Table 6-3 summary, the influence of distance-to-transit from trip origins on share of transit usage is clearly visible by all measures.

Table 6-3. Shares of Transit Usage Measured in PT, PMT, VT, and VMT by Trip Origin Location

\begin{tabular}{|l|c|c|c|c|}
\hline \multicolumn{5}{|c|}{ Share of Transit Usage (\%) } \\
\hline $\begin{array}{c}\text { Trip-origin } \\
\text { geographic region }\end{array}$ & $\begin{array}{c}\text { Person-mile } \\
\text { traveled (PMT) }\end{array}$ & $\begin{array}{c}\text { Vehicle trip } \\
\text { (VT) }\end{array}$ & $\begin{array}{c}\text { Vehicle-mile } \\
\text { traveled (VMT) }\end{array}$ \\
\hline Origins within 1-mile transit shed \\
\hline NYMTC & 36.58 & 33.53 & 8.11 & 11.69 \\
\hline Rest of NYS & 3.55 & 3.46 & 0.81 & 1.46 \\
\hline Origins within 2.5-mile transit shed & 29.54 & 7.06 & 9.98 \\
\hline NYMTC & 33.80 & 3.18 & 0.77 & 1.37 \\
\hline Rest of NYS & 3.20 & 28.19 & 6.61 & 9.39 \\
\hline Origins within 5-mile transit shed & 32.53 & 2.95 & 0.74 & 1.26 \\
\hline NYMTC & 3.01 & 24.38 & 6.37 & 8.59 \\
\hline Rest of NYS & 31.41 & 2.56 & 0.61 & 0.99 \\
\hline All trips & 2.43 &
\end{tabular}

\subsubsection{Transit Time of Use as the Main Mode of Travel}

Interestingly, the distribution of transit use by time of the day differs mostly during morning peak hours (6:00 to 9:00 a.m.) and mid-day peak (11:00 a.m. to 2:00 p.m.) between weekday and weekend travel (see Figure 6-1). The higher share of transit use during the morning peak during the weekday is likely associated with commute trips occurring in both regions. Note that the “Other" timeframe includes a longer period, including hours prior to 6:00 a.m., between 9:00 to 11:00 a.m., and all hours between 7:00 p.m. to mid-night. Nearly all weekend trips made by transit in the Rest of NYS region occurred after 9:00 a.m. In NYMTC, however, transit usage during the morning peak hours still accounted for $12 \%$ share of weekend transit trips. 


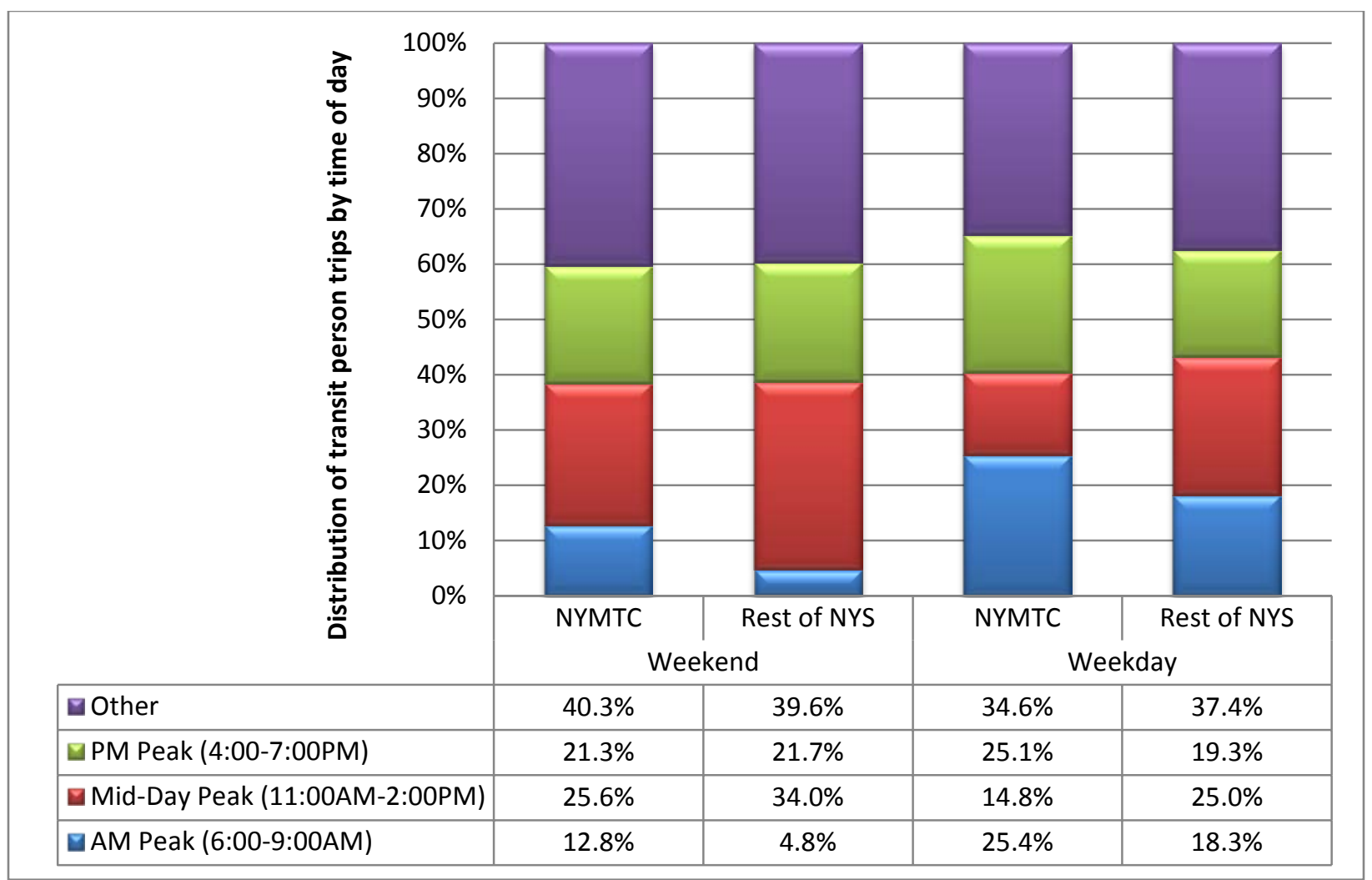

Figure 6-1. Distribution of transit use measured in person-trips by time of day and day of week. 